\title{
Diet and exercise in the treatment of obesity
}

Citation for published version (APA):

van Dale, D. (1989). Diet and exercise in the treatment of obesity. [Doctoral Thesis, Maastricht University]. Rijksuniversiteit Limburg. https://doi.org/10.26481/dis.19890512dd

Document status and date:

Published: 01/01/1989

DOI:

10.26481/dis.19890512dd

Document Version:

Publisher's PDF, also known as Version of record

\section{Please check the document version of this publication:}

- A submitted manuscript is the version of the article upon submission and before peer-review. There can be important differences between the submitted version and the official published version of record.

People interested in the research are advised to contact the author for the final version of the publication, or visit the DOI to the publisher's website.

- The final author version and the galley proof are versions of the publication after peer review.

- The final published version features the final layout of the paper including the volume, issue and page numbers.

Link to publication

\footnotetext{
General rights rights.

- You may freely distribute the URL identifying the publication in the public portal. please follow below link for the End User Agreement:

www.umlib.nl/taverne-license

Take down policy

If you believe that this document breaches copyright please contact us at:

repository@maastrichtuniversity.nl

providing details and we will investigate your claim.
}

Copyright and moral rights for the publications made accessible in the public portal are retained by the authors and/or other copyright owners and it is a condition of accessing publications that users recognise and abide by the legal requirements associated with these

- Users may download and print one copy of any publication from the public portal for the purpose of private study or research.

- You may not further distribute the material or use it for any profit-making activity or commercial gain

If the publication is distributed under the terms of Article $25 \mathrm{fa}$ of the Dutch Copyright Act, indicated by the "Taverne" license above, 


\section{DIET AND EXERCISE IN THE TREATMENT OF OBESITY}




\title{
DIET AND EXERCISE
}

\section{IN THE TREATMENT OF OBESITY}

\author{
PROEFSCHRIFT
}

ter verkrijging van de graad van doctor

aan de Rijksuniversiteit Limburg te Maastricht, op gezag van de Rector Magnificus Prof. Dr. F.I.M. Bonke, volgens het besluit van het College van Dekanen, in het openbaar te verdedigen op vrijdag 12 mei 1989 om 16.00 uur

door

\section{Djoeke van Dale}

geboren te Amsterdam op 12 mei 1961 
Promotores: $\quad$ Prof. Dr. Ir. W.H.M. Saris

Prof. Dr. F. ten Hoor

Beoordelingscommissie: Prof. Dr. P.B. Soeters, voorzitter

Dr. P. Deurenberg

Prof. Dr. Ir. R.J.J. Hermus

Prof. Dr. G.J. Kok

Prof. Dr. P. Webb

Dit proelschrilt werd mede mogelijk gemaakt door financiële bijdragen van : de Jan Dekkerstichting \& Dr. Ludgardine Bouwmanstichting de Nederlandse Hartstichting
Vormgeving:
Hein Zoete
Omslag:
Fotografie:
André Kok
Druk:
Wim Venhuis
Krips Repro, Meppel 


\section{PUBLICATIONS}

This thesis is mainly based on the following papers:

" Dale D van, Saris WHM, Schoffelen PFM, Hoor F ten.

Does exercise give an additional effect in weight reduction regimens?

Int J Obes 1987;11:367-375. (CHAPTER 2).

- Dale D van, Schoffelen PFM, Saris WHM.

The effects of the addition of exercise to energy restriction on 24-hour

Energy Expenditure (24-h EE), Resting Metabolic Rate (RMR) and daily physical activity.

Eur J Clin Nutr: accepted. (CHAPTER 3).

- Dale D van, Beckers E, Schoffelen PFM, Hoor F ten, Saris WHM.

Changes in Resting Metabolic Rate (RMR) and Glucose Induced Thermogenesis (GIT) during an exercise and/or diet treatment.

Eur J Clin Nutr: submitted. (CHAPTER 4).

- Dale D van, Schrijuer J, Saris WHM.

Changes in vitamin status in plasma during dieting and exercise.

Am J Clin Nutr: submitted. (CHAPTER 5).

- Dale D van, WHM Saris WHM.

Repetitive weight loss and weight gain: effects on weight reduction, Resting Metabolic Rate (RMR) and lipolytic activity before and after an exercise and/or diet treatment.

Am J Clin Nutr 1989;49:409-416. (CHAPTER 6).

" Dale D van, Hoor F ten, Saris WHM.

Weight maintenance and Resting Metabolic Rate (RMR) 18-42 months after a diet or a diet-exercise treatment.

Int J Obes: submitted. (CHAPTER 7). 


\section{CONTENTS}

1. Introduction

$1.1 \quad$ Obesity and health

1.2 Regulation of energy balance: are there differences between lean and obese subjects?

1.3 Changing the energy balance: reduction in energy intake

$1.4 \quad$ Increasing energy expenditure

1.5 Reducing energy intake and increasing entergy expenditure: the ideal combination?

1.6 Conclusion and aims of the study

2. Does exercise give an additional effect in weight reduction regimens?

3. Effects of adding exercise to energy restriction on 24-hour energy expenditure, resting metabolic rate and daily physical activity

4. Changes in resting metabolic rate and glucoseinduced thermogenesis during a diet or diet/exercise treatment

5. Vitamin status in plasma during dieting and exercise

6. Metabolic effects of repetitive weight loss during an exercise and/or diet treatment

7. Weight maintenance and resting metabolic rate 18-42 months after diet or diet/exercise treatment

8. Discussion and general conclusions

References

103

Summary

115

Samenvatting

Abbreviations

Nawoord 


\section{INTRODUCTION}

\subsection{Obesity and health}

Human beings have a high capacity to store excess energy intake as fat tissue. From an evolutionary point of view, the accumulation of fat during periods of excess food availabity was necessary to survive the following periods of food scarcity. Nowadlays, in all affluent societies there are no longer periods of food scarcity. On the contrary, there is a persistent unlimited food supply. This large availability of food, particularly of high fat containing food, together with a decreased energy demand due to mechanization, seems to be the cause of an accumulation of fat tissue. This has resulted in a high prevalence of obese subjects (Kluthe \& Schubert, 1985; Van Itallie, 1985). Obesity is reported to be associated with the incidence of hypertension, diabetes and hypercholesterolemia (Burton et all., 1985; Royal College of Physicians, 1983). Independent of these risk factors, obesity is also associated with cardiovascular diseases and certain malignancies (Burton et al., 1985; Royal College of Physicians, 1983). The psychological consequences of obesity are less clear. It has been suggested that obesity affects one's self-concept and emotional well-being (Stunkard, 1980). However, other studies could not establish a relationship between emotional disturbance and obesity and it was concluded that there is no

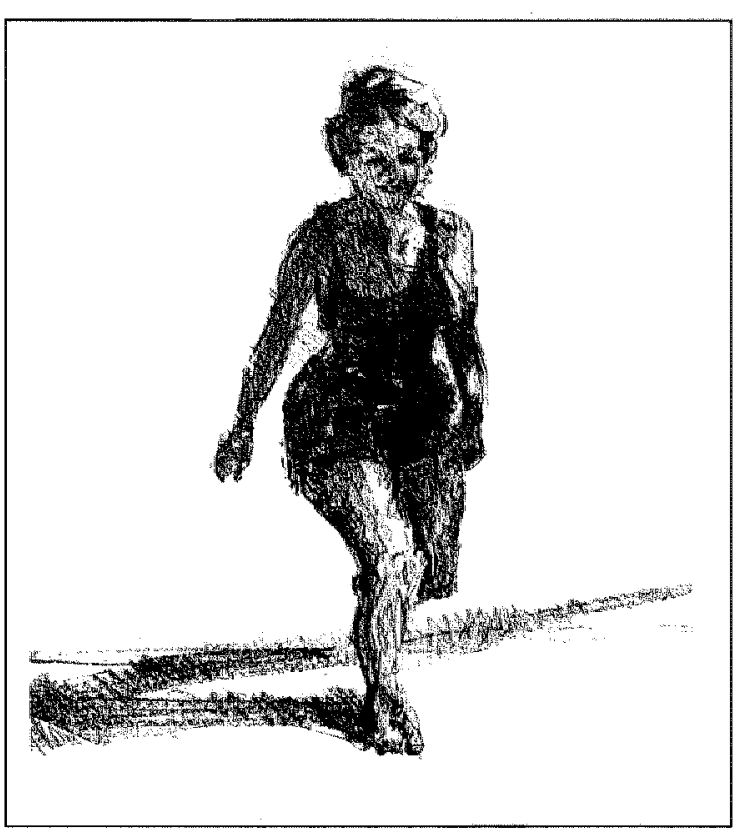

consistent evidence supporting the relationship between psychological disorders and obesity (Rodin, 1984; Wadden \& Stunkard, 1985).

Obesity is defined as a condition in which there is an excess of body fat (Garrow, 1981). The prevallence of obesity is usually assessed by means of the body mass index (BMI; weight $(\mathrm{kg}) /$ height $\left.^{2}(\mathrm{~m})\right)$, which has proven to be a reliable indicator of obesity in large populations (Garrow, 1987a). In studies dealing with only a small number of subjects more sophisticated methods such as body density measurement, computed tomography etc. are preferred for determining the amount of body fat. Classification of the Dutch 
population on the basis of BMI revealed that $34 \%$ of women and $24 \%$ of men were moderately obese $(25<\mathrm{BMI}<30)$ while $4 \%$ of women and $6 \%$ of men were severely obese (BMI > 30) (Seidell et al, 1986).

It has recently been demonstrated that not only the degree of obesity is important in relation to health consequences but also the distribution of fat tissue over the different parts of the body (Bjorntorp, 1987). The android type, with more internal fat in relatively large fat cells distributed around the waist, correlates with disturbances in carbohydrate and lipid metabolism; this correlation is independent of the degree of obesity. Upper body obesity has also been shown to be associated with an increased frequency of cardiovascular risk factors such as hypercholesterolemia and hypertension (Seidell, 1985). By contrast the gynoid type of obesity, where fat is mainly stored in an increased number of subcutaneous fat cells around the hip and thigh, seems to have less. serious health consequences (Krotkiewski et al., 1983).

Although from the foregoing it is quite clear that obesity has harmful health consequences, the risks of being obese must not be exaggerated. The health hazards associated with smoking are much larger as is shown in Fig. 1, where the mortality risks of smoking are compared with those of being overweight (Royal College of Physicians, 1983). Howewer, in view of the better life expectancy and lower morbidity of normal weight individuals, reduction to normal proportions will have promotive effects on overall health (Royal College of Physicians, 1983 ; Kirschner et al., 1988).

As a consequence of the slenderness cult a large number of people nowadays try to loose weight using a variety of slimming methods. In Britain it has been demonstrated that at any time $65 \%$ of the females and $35 \%$ of the males are dieting (Anomyneus, 1980). In view of the constant number of dieters one may conclude that the success rate is
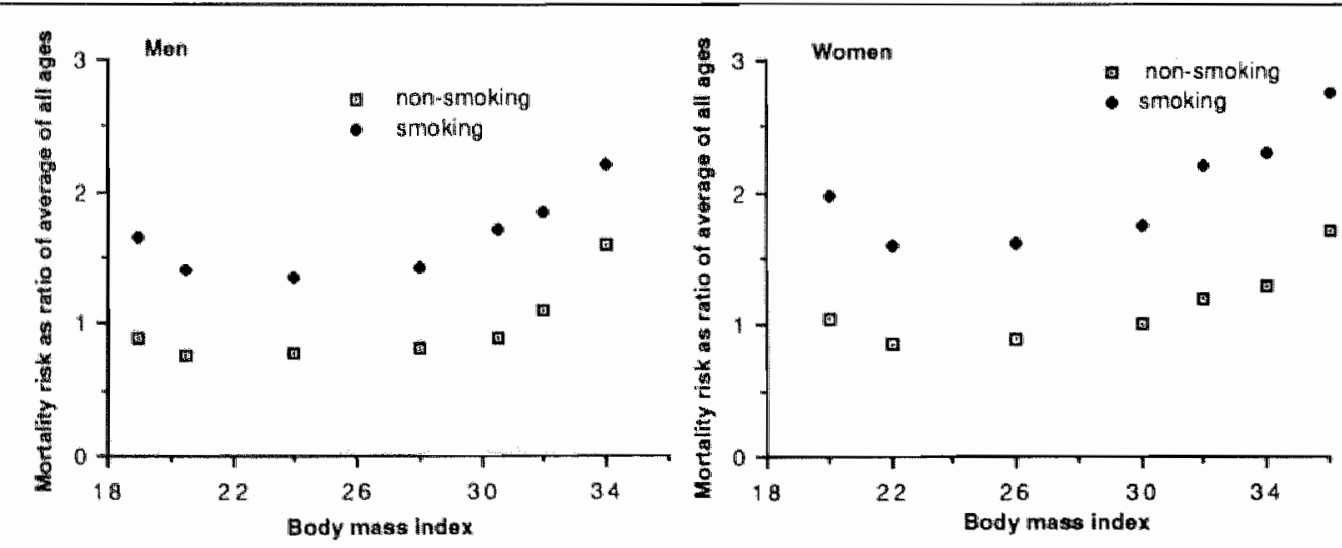

Fig. I Body weight, smoking and death rates for men and women (data from Royal College of Physicians, 1983). non-smoking - smoking > 20 cigareties per day. 
poor and results do not last very long. Indeed, only a small percentage $(10-30 \%)$ is able to maintain a lower weight in the long term (Wing \& Jeffery, 1979; Saris, 1983).

Management of obesity requires knowledge of body weight regulation, which is in principle based on energy balance:

$$
\mathbf{E}_{\text {in }}=\mathbf{E}_{\exp }+\mathbf{S}
$$

where $E_{\mathrm{in}}$ is energy intake, $E_{\exp }$ is energy expenditure and $S$ represents storage, which is mainly adipose tissue. As $E_{\text {in }}$ and $E_{\text {exp }}$ are, on average, in the order of magnitude of $10 \mathrm{MJ}$, in cases of obesity $E_{\text {in }}$ must have exceeded Eexp over a considerable period of time, as $1 \mathrm{~kg}$ fat contains about $38 \mathrm{MJ}$ and it is difficult to overeat (i.e. increase $\mathrm{E}_{\mathrm{in}}$ ) by more than $50 \%$ for longer periods of time with $E_{\text {exp }}$ in the "normal" range.

There are indications, however, that obese people gain weight more easily than lean people. Therefore section 1.2 of this chapter discusses whether there are physiological differences between lean and obese people which might contribute to an easy weight gain in the obese.

Once obesity has occurred, loss of weight can be achieved by decreasing $\mathbb{E}_{\mathrm{in}}$, increasing $\mathrm{E}_{\text {exp }}$ or both. All approaches have their advantages and disadvantages. In sections 1.3. and 1.4 literature on the manipulation of $E_{\text {in }}$ and $E_{\text {exp }}$ will be discussed, while 1.5 deals with the combination of the two. The aim of this study, which is presented in detail in section 1.6 , was to investigate the role of diet and exercise in the treatment of obesity and whether a combination of diet and exercise yields better results than either alone.

\subsection{Regulation of energy balance: are there differences between lean and obese subjects?}

Energy balance is defined as a situation in which the average difference between measured energy intake and expenditure does not differ more than 0.6 MJ per day (Garrow, 1974). With respect to this energy balance two factors have to be considered: energy intake and energy expenditure. The third factor, energy stores, will be not reviewed, because it is the result of energy intake and energy expenditure.

\section{Energy intake}

The amount of food ingested is the only factor determining energy intake. Of the total energy ingested most can be digested and absorbed to meet the body's needs; this is called metabolizablle energy. A small amount of the ingested energy is excreted in feces and urine. Individual differences in the metabolizability of energy could be a cause of easy weight gain, but studies comparing obese and lean subjects revealed no significant differences between these groups with respect to the excretion of energy in stool (Webb \& Abrams, 1983; Webb \& Annis, 1983; de Boer et all, 1987).

One of the most obvious explanations of the development of obesity is overeating. Several studies have tried to find out whether overeating is the main cause of obesity, but failed to provide consistent results (Stunkard \& Kaplan, 1977; Bray et al., 1978). It is very difficult to get reliable data with respect to the actual food intake of obese subjects. 
Obese people appear to underreport their food intake and the accuracy of reporting is related to the degree of excess weight (Bray et al., 1978).

However, al least part of the development of obesity can be attributed to overeating. It has frequently been suggested that the reasons why obese people are eating too much is related to psychological factors (Rodin, 1984; Wadden \& Stunkard, 1985). There are several factors which might explain obesity (Rodin, 1984). However, psychological factors which are used to explain deviant eating behaviour in obese subjects, have also been demonstrated in lean subjects (Rodin, 1984). This, and the observation that there are lean subjects eating similar amounts of food as

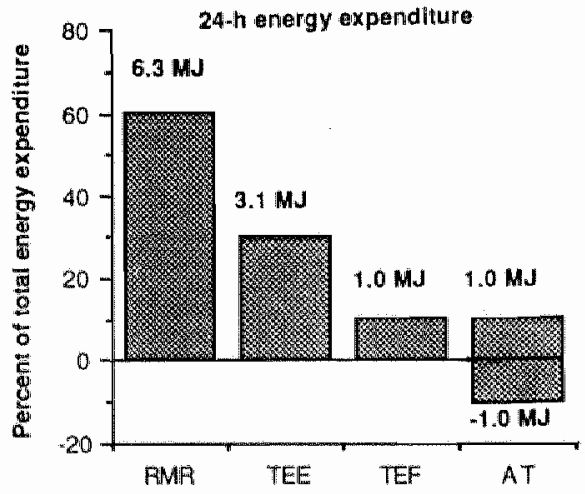

Fig. 2 Compartments of energy expenditure during weight maintemance and the potential modifying effect of adaptive thermogenesis. Approximate percentage of tolal calories expended by a $70 . \mathrm{kg}$ man consuming $10.4 \mathrm{MJ}$ per day (redrown from florton, 1983). obese subjects without developing obesity (Widdowson, 1936) has led to the question whether there are individual differences in the regulation of energy expenditure, which favour weight gain in obese individuals but not in the lean.

\section{Energy expenditure}

The counterpart of the energy intake in energy balance is energy expenditure, which can be accurately determined by indirect and direct calorimetry. Using direct or indirect calorimetry it has been possible to compare energy expenditure of, e.g. lean and obese individuals. Recently, several studies have been published giving information about the 24-h energy expenditure (24-EE) in whole-body calorimeters, showing that total energy expenditure was similar or higher in obese subjects compared to lean controls (Ravussin et al., 1982; Prentice et al., 1986; de Boer et al, 1987). Twenty-four hour energy expenditure can be divided into 4 components (Horton, 1983) and in the study of the normal or possibly defective regulation of energy balance, these components are dealt with separately. These components are (Fig. 2): Basal, Resting or Sleeping Metabolic Rate (BMR, RMR or SMR), Thermic Elfect of Exercise (TEE), Thermic Elfect of Feeding (TEF), and Adaptive Thermogenesis (AT).

\section{Basal, resting or sleeping metabolic rate}

The terms basal, resting and sleeping metabolic rate all refer to energy exchange, measured under similar, but nevertheless somewhat different conditions. Basal Metabolic Rate (BMR) is defined as the energy expenditure measured in the postab- 
sorptive state under highly standardized conditions (Passmore \& Eastwood, 1986). Resting Metabolic Rate (RMR) is defined as the energy expenditure required by the body in a resting state. Sleeping Metabolic Rate (SMR) is defined as the energy expenditure measured during a period of sleep. The differences measured between SMR, BMR and RMR are small. SMR has been demonstrated to be almost $5 \%$ lower than BMR (Goldberg et al., 1988a). For reasons of convenience we shall always use RMR in this thesis ${ }_{y}$ even when we actually measured SMR. As fat itself does not use energy, the amount of Fal Free Mass (FFM) determines energy exchange and the RMR (Webb, 1981). Resting metabolic rate varies greatly between individuals due to differences in age, sex and body size. Most of the variation disappears when RMR is corrected for the amount of fat free mass, leaving a variation of about $11 \%$ (Bogardus et al., 1986). Several studies have tried to find differences in resting metabolic rate between lean and obese subjects, but failed to find a consistently lower metabolic rate in obese subjects (Ravussin et al., 1982; de Boer et al., 1987). On the contrary, obese subjects have demonstrated higher absolute values of RMR (Prentice et al., 1986), but standardization for fat free mass yiclded similar values in obese and lean subjects. Bogardus et al. (1986) reported that $82 \%$ of the observed variance could be explained by differences in FFM. However, they also reported that $11 \%$ of the variance was accounted for by a familial trait, independent of fat free mass, age or sex. Recently, Ravussin and coworkers (1988) demonstrated that this genetic factor was responsible for a weight gain over a two year period. RMR values, which turned out to be low, were associated with a considerable weight gain 2 years later. However, they also found that the observed weight gain could not be attributed solely to the lower RMR.

Even after correction for FFM, RMR still shows variations.. The metabolism of Cat free mass is regulated by the concentration of thyroid hormones and the sympathetic nervous system. There are indeed people who show a very low concentration of the thyroid hormones and their obesity can be attributed to deficiencies of the thyroid gland. However, this is the case in only a small part of the obese population and can be normalized by the administration of thyroid hormones.

\section{Thermic effect of exercise}

Physical activity induces additional energy costs above resting values and contributes about $20 \%$ to the total energy expenditure. It is the only factor which can be increased voluntarily, providing a considerable increase in total energy expenditure. It is also this factor which has been the subject of many studies. Are the obese less active than the lean? As reported in some studies obese subjects have a tendency to be less active (Chirico \& Stunkard, 1970; Brownel\| et al, 1980). Correcting for the larger body mass, other reseachers found no differences in activity between lean and obese children (Waxman \& Stunkard, 1980; Saris et al, 1984). Similarly, spontameous activity in obese subjects, used as an indicator of physical activity, was shown to be similar to that of lean subjects (Schutz et al., 1982). However, Ravussin et al. 
(1986) observed a wide variation in the minor movements of the body which are called "fidgeting'activities. These fidgeting activities -also called spontaneous activity - varied from 0.42 to as much as $3.8 \mathrm{MJ}$ per day. There was evidence that variation in such activities was a familial characteristic. Differences in these fidgeting activities may thus contribute to the development of obesity. Another possibility is a higher efficiency of movement, leading to a reduced energy cost in obese subjects as was shown by $\AA$ strand et al. (1960). However, Bray et al. (1974) did not find any differences in efficiency of the energy costs of different activities between lean and obese subjects.

\section{Thermic effect of feeding (TEF) or diet-induced thermogenesis (DIT)}

The ingestion of food is associated with an increase in energy expenditure for several hours after a meal, which can be attributed in part to the energy costs of absorption, digestion, intermediary metabolism and storage of food. The energy costs of processing food vary with its caloric value, being lowest for fat and highest for protein and de novo lipogenesis from carbohydrate. On average, TEF or DIT accounts for a daily energy expenditure of approximately $10 \%$ of the total energy intake (range 7\%-14\%). The rise in cnergy expenditure starts even before the meal, induced by the smell and sight of the meal, and a tasty meal induces a larger increase than a distastcful meal (Leblanc \& Blondel, 1984; Blondheim et al., 1988).

Studies comparing obese and lean subjects have not yielded consistent evidence for a lower thermic effect of feeding for obese subjects since both lower and equal values in obese compared to lean subjects have been observed (Blondheim, 1986) These conflicting results are probably caused by differences in time over which measurements were made after a meal, since TEF may not be blunted but delayed (Schutz et al., 1984; Sims \& Danforth, 1987).

However, a consistently lower thermic response has been demonstrated in insulin resistant subjects, which indicates the importance of insulin in the thermic effect of feeding (Golay et al., 1982; Ravussin et al., 1985a; Ravussin et al., 1985b). Comparing obese subjects with normal and impaired glucose tolerance it was found that those with the impaired glucose tolerance had a significantly lower thermic response to a meal or glucose load. A negative correlation was found between the degree of thermic response and the level of circulating insulin. This suggests that an impairment in the thermic response to a meal may be based on a change in the secretory response of the pancreas in releasing insulin (Bray, 1983).

\section{Adaptive thermogenesis}

Adaptive thermogenesis or facultative thermogenesis refers to the body's response to changes in the environment such as cold, overeating, caffeine, etc., in which heat production varies independently of the obligatory demands, and provides no net synthesis or mechanical work (Sims \& Danforth, 1987). Facultative or adaptive thermogenesis is a way of reducing the efficiency of metabolic processes, providing energy for e.g. body temperature regulation. Individual differences in the 
capacity of activating" inefficient" metabolic pathways might explain the maintenance of weight in lean individuals and the weight gain in obese individuals in period of overfeeding. In small animals this phenomenon of heat production, independent of synthesis or mechanicall work, has been clearly described with respect to cold and overfeeding. In man the reactions to these changes in the environment are less well documented.

A number of possible mechanisms for facultative thermogenesis have been proposed. In theory, the most potent mechanism is a change in the activity of $\mathrm{Na}^{+}-\mathrm{K}^{+}$-ATPase, providing the maintenance of $\mathrm{Na}^{+}$and $\mathrm{K}^{+}$ gradients in the cell membranes. This $\mathrm{Na}^{+}-\mathrm{K}^{+}$-ATPase activity is dependent, among other things, on thyroid hormones and the supply of phosphatidyl-inositol (Simmons et al., 1986). Comparison of this activity in red blood cells for lean and obese subjects has yielded inconsistent results. There is no consistent evidence towards a lower activity of $\mathrm{Na}^{+}-\mathrm{K}^{+}$-ATPase between lean and obese subjects (Newsholme, 1978).

A second possible mechanism of facultative thermogenesis is situated in brown adipose tissue, which has been demonstrated clearly in rats (Rothwell \& Stock, 1979). In humans, however, the amount of brown adipose tissue is wery small and in adult man it is negligible. However, some studies have found differences in heat production in response to infusion of norepinephrine and have attributed this response to differences in the amount of brown adipose tissue or partly to differences in white adipose tissue (Astrup, 1986). Recently, skeletal muscle has been proposed as a major site of facultative thermogenesis (Astrup et al, 1987). Fagher et al. (1986) found at stimulated thermogenesis in muscle cells induced by activation of the sympathetic nervous system. Astrup et al. (1987) observed that the inges tion of oral glucose raised oxygen consumption in muscle tissue of the forearm, concurrent with a rise in arterial epinephrine concentration. This facultative thermogenesis of glucose has been suggested to be mediated by catecholamines through adrenoreceptor stimulation. The proposed mechanism responsible for this increase in energy expenditure is 'futile cycling' of substrates, as defined by Newsholme (1980). A futile cycle is defined as a cycle in which ATP is used to form a phosphorylated product, which is then dephosphorylated with loss of nonutilizable energy. Newsholme (1980) suggested that before, durimg, but also after exercise the rate of cycling is increased. The glycerol phosphate cycle has attracted particular attention because of its dependence on thyroid hormones. In obese subjects the activity of this cycle has been showed to be reduced compared to their lean counterparts (Bray, 1969). The activity of this cycle is increased by thyroid hormone in both obese and lean subjects (Bray, 1976).

In view of the considerations discussed above, it is difficult to con clude that the obese state can be attributed to metabolic defects. It seems that obesity can be attributed for the most part to chronic overeating. However, there are probably individual exceptions to this rule, such as the insulin resistant individual with a defective thermic effect of feeding. 
ANA

1.3 Changing the energy balance: reduction in energy intake

As stated in the introduction most approaches in the treatment of obesity, such as energy restriction, surgical, behavioral or pharmacological treatment, focus directly or indirectly on a reduction of energy intake. Since the body will try to reach homeostasis, energy restriction leads to the appearance of several adaplive mechanisms, providing a partial restoration of the energy balance.

\section{Diet-induced fall of RMR}

One of the most important and welldocumented adaptations to diet-induced weight loss is a significant drop in resting metabolic rate. Depending on the degree of energy restriction resting metabolic rate can decrease by 15 to $30 \%$ in obese and normal weight persons (Keys et al., 1950; Drenick and Dennin, 1973; Bessard et al., 1983; Webb, 1985; de Boer et al., 1986; de Groot, 1988). The decline in resting metabolic rate can already be measured $48 \mathrm{~h}$ after the start of dieting and may decrease up to $25 \%$ after 4 weeks. However, it also has been argued that it takes a longer time before energy restriction is measurable (de Groot, 1988). The initial decrease of metabolic rate during dieting is caused by a decrease in thyroid hormones. The largest contribution to this metabolic decline is due the loss of fat free mass which is associated with weight loss. Ravussin at al. (1985c) demonstrated that the reduction in resting metabolic rate can be explained entirely by the loss of fat Iree mass. When RMR was ex- pressed per $\mathrm{kg}$ fat free mass, no change was found. Other studies, however, showed a larger decline than could be explained on the basis of the loss of fat free mass (Hill et $\mathrm{al}_{\text {. }}$ 1987b). Reductions in hormonal activity and the activity of the sympathetic system (Jung et al., 1980), resulting in the above mentioned reduction of metabolic processes, are probably the cause. During dieting thyroid hormones triiodothyronine (T3) and thyroxine (T4), as well as sympathoadrenomedullary activity, have been found to be decreased (Krotkiewski et al., 1981; Koppenschaar et al., 1985). Recently, red blood cell Na ${ }^{+}$. $\mathrm{K}^{+}$-ATPase activity was shown to be reduced during dieting in obese subjects, whereas there were no differences between lean and obese subjects during normal energy intake (Pasquali et al, 1988).

It has been postulated by some authors (Andersen et al., 1988) that RMR decreases only to normal values comparable that of non-obese subjects. In addition, the decline is said to be limited to the energy restriction period (Wadden et al., 1988) However, contrasting evidence is claimed with respect to the results in post-obese subjects. It has been shown that post-obese subjects had lower RMR values than predicted. Compared to lean subjects postobese subjects had a significantly lower RMR, which hampers their weight maintenance (Leibel \& Hirsch, 1984; Geissler et al., 1987). Similarly, it was shown that one week of refeeding did not increase T3 and RMR to baseline values (Barrows \& Snook, 1987). In view of these inconsistent results the evidence for a persistently lower value of $R M R$ after a period of 
weight loss still remains to be established.

\section{Physical activity}

A considerable part of daily physical activity is accounted for by the "fidgeting activities'. As mentioned above these activities vary between individuals from $0.4-3.8 \mathrm{MJ}$, and may decrease during dieting. Warwick \& Garrow (1981), who called them spontaneous activities, reported a significant reduction in these activities during dieting. Other investigators did not find any change during dieting (Bessard et all, 1983). Another suggested adaptation with regard to physical activity is increased energetic efficiency of activities. This increase in efficiency might also be caused by a reduction of metabolic processes, such as futile cycles. An increased efficiency in terms of lower energy costs was reported by Apfelbaum et al. (1971). However, the performance of external work is requisite to the determination of work efficiency. Therefore the reduced oxygen costs of unloaded cycling reported by Apfelbaum et al. (1971) cannot be used to rigorously establish increased work efficiency (Gaesser \& Brooks, 1975). A recent publication reported no effect of dieting on work efficiency (Poole \& Henson, 1988).

\section{Thermic effect of feeding}

A small contribution to the decrease in total energy expenditure can be made by a decrease in the thermic effect of feeding. As a consequence of the lower energy intake the thermogenic response after a meal (TEF or diet-induced thermogenesis; DIT) is lower during dieting. Therefore for an accurate comparison of the response to a meal, the increase in energy expenditure has to be expressed as a percentage of baseline $R M R$. In that case the response in energy expenditure has sometimes been found to be lower (Schutz et al., 1984), by others to remain the same (Belko et al., 1987a) and still by others to increase (Golay et al., 1982; Ravussin et al., 1985a). Both decrease and increase were probably associated with the response to insulin concentration, as insulin resistance resulted in a lower DIT (Golay et al., 1982) and an improved insulin sensitivity after dieting resulted in an increased DIT (Ravussin et al., $1985 \mathrm{a} / \mathrm{b}$ ). Insulin thus appears to play an indirect rolle in the regulation of the thermic effect of feeding.

\section{Long term effects}

It has been shown to be extremely difficult for some people to maintain a steady weight, and after several periods of weight loss and weight gain it seems to be even more difficult (Wing \& Jeffery, 1979; Saris, 1983; Hoiberg et al., 1984). Although this difficulty in maintaining weight (especially after several periods of weight loss and regain) may be partly attributed to psychological factors (Brownell et al., 1986a); a long term physiological adaptation has also been proposed. Several studies dealing this problem have been performed in rats. It was found that during a second period of energy restriction, which took place immediately after the first period of dieting and regaining weight, the rate of weight loss in rats was $50 \%$ of that of the first period, even though food intake was identical during both restrictions. During the second period of regain, weight gain occurred 3 times more rapidly than in 
the first period (Boyle et al, 1981; Brownell et al., 1986b). Other athors, did not confirm these results about a decreased weight loss during a second period of dieting (Gray et al., 1988). Howewer, an increased lipoprotein lipase (LPL) activity was found during a second regaining phase (Hill et al.,1987a). Since LPL regulates the storage of free fatty acids in adipose tissue, an increased activity of LPL may lead to increased fat storage.

In conclusion dieting results in a reduction of RMR, which is proportional to the level of energy restriction. It is not clear whether the reduction remains after dieting or is normalized compared to lean controls. For the other components of energy expenditure (DIT, physical activity and adaptive thermogenesis), no consistent evidence has been found to explain differences between obese and lean subjects.

स\%

\subsection{Increasing energy expenditure}

\section{Exercise and energy intake}

The only woluntary way to increase energy expenditure is to increase dailly physical activities by e.g. exercise. There are also thermogenic agents like calleine, which can increase energy expenditure, but they will not be considered in this thesis. It is quite obvious that exercise results in a rise in energy expenditure, creating a negative energy balance, if energy intake is not increased proportionally. However, it has been suggested that exercise also increases energy intake, preventing a negative energy balance. This com- pensatory mechanism has indeed been found in normal weight subjects (Tremblay et al.,1987a; Krotkiewski \& Björntorp, 1986). Recently, it has been shown that exercise did not increase food intake in obese subjects (Woo et al., 1982; Reger et al., 1986). In addition, the energy intake appeared to depend on the intensity of exercise. Reger et al. (1986) observed that energy intake only increased with short term intensive exercise, whereas physical training of a low intensity and long duration did not result in an increased energy intake.

\section{Extra energy costs}

However, very long and intensive exercise is necessary before an energy deficit is obtained which is similar to that achieved by dieting. For example a man who goes jogging for 2 hours at a rate of $21 \mathrm{~kJ}$ per min has used $2.5 \mathrm{MJ}$ by the time he returns home, However, if he had watched T.V. at home for these two hours, his energy expenditure would have been about $0.8 \mathrm{MJ}$; so the extra energy expenditure attributable to the jogging is only 1.7 MJ (Garrow, 1981). Two hours of jogging per day is very difficult to keep up, especially for obese people, and weight will decrease very slowly. In contrast to exercise, reducing the diet by 4-6 MJ to about $4.2 \mathrm{MJ}$ is less difficult and results in more rapid weight loss.

\section{Fat loss and maintenance of fat free mass.}

In contrast to dieting exercise is found to have favourable effects on the composition of the weight loss, as a greater part of the weight loss can be attributed to fat loss (Epstein \& Wing, 1980; Thompson et al., 1982). Reducing body weight by 
means of exercise results in the maintenance of FFM (Ballor et al,, 1988). It has been found that with low intensity, long duration exercise, fat mass decreased more than with short term, high intensity exercise (Epstein \& Wing, 1980). In par ticular, aerobic exercise training such as cycling and jogging resulted in weight loss and fat loss (Gwinup, 1987). This decreasing effect of exercise on fat mass and the preserving effect on lean body mass reflects a lipid mobilization. Higher levels of basal and stimulated lipolysis in suprailiac fat cells have been observed, all denoting an increased fat oxidation capacity during exercise (Després \& Bouchard, 1984).

\section{Sustained elevation of resting metabolic rate}

Recently, however, it has been claimed that exercise causes a prolonged elevation of energy expenditure. Several studies have found an elevated oxygen uptake lasting for many hours after the exercise session (Bielinski et al., 1985; Freedman-Akabas et al., 1985; Tremblay et al., 1986). In other studies (Shah et $a l, 1.988$ ) the increased metabolic rate was found to return to normal levels within one hour after exercise. The sustained elevation after exercise can probably be explained by a recovery from the oxygen debt, and persistently increased levels of circulating catecholamines, which in turn influence the rate of metabolism.

\section{Sex differences in weight and fat loss}

Not all studies have demonstrated fat loss after exercise, and a careful examination of the studies reveals that exercise fails to produce fat loss especially in women. A suggested explanation for this sex-linked difference is a dimorphism in fat distribution; as fat tissue in the lower part of the body has been shown to be more resistant to lipolysis during starvation and/or exercise than fat in the abdominal region (Tremblay et al.,1984a; Krotkiewski \& Björntorp. 1986).

The effect of exercise on diet-induced thermogenesis (DIT) is not clear, since both positive and negative effects of exercise on DIT have been found. Diet-induced thermogenesis appeared to be decreased in athletes (Tremblay et al., 1983; Leblanc, 1985; Poehlman et al., 1988) which was explained by a glycogen sparing capacity. In sedentary normal subjects, however, exercise increased diet-induced thermogenesis, an increase which was associated with the increase in maximal aerobic power (Tagliaferro et al., 1986; Hill et al., 1984). Moreover, in a recent study Tremblay et al. (1988) contradicted their own observation of a lower thermic effect of feeding in athletes and concluded that the lower DIT was caused by glycogen sparing due to acute effects of exercise. When DIT was measured three days later, higher values were shown com. parable to sedentary subjects. Athletes are seldom obese and in general maintain a stable weight over the years, which contrasts with the obese individual. Obese people often show a pattern of losing and gaining weight. Only 10-30\% maintain their achieved weight (Saris, 1983), others regain weight and start. dieting again. In view of the stability of body weight shown by athletes, exercise may be the key factor in weight maintenance. Indeed, ex- 
obese subjects, who had achieved their weight loss by training for a marathon, kept their body weight stable by running 90 miles per week (Tremblay et al., 19846). Similarly, long term studies have revealed that successful weight maintenance was associated with a dally exercise routine (Dahlkoetter et al., 1979; Holden et al., 1988). Most of the successful maintainers reported daily or frequent exercise activities, in contrast with regainers, who did not report any exercise activities (Kayman, 1986).

In summary, exercise has many advantages with respect to short term and long term effects on weight loss, and body composition changes in fawour of fat loss and preservation of fat free mass. For meaningful weight loss (more than $10 \mathrm{~kg}$ ), however, exercise should be combined with a reduction in energy intake.

\subsection{Reducing energy intake and increasing energy expenditure: the ideal combination?}

In view of the favourablle metabolic consequences of exercise and the rapid weight loss due to energy restriction, the combination of these treatments has been suggested to lead to improved weight and fat loss, lower decrease in fat free mass and $\mathrm{RMR}$ and to long term success.

\section{Resting metabolic rate}

As a consequence of the suggested favourable effects of exercise on RMR the combination of diet and exercise has received a good deal of attention. Several studies (long term and short term) have found no dif- ferences in adaptation of resting metabolic rate during dieting (Garrow et al., 1978; Krotkiewski et al , 1981; Warwick \& Garrow, 1981; Bogardus et al. 1984; Belko et al., 1987a; Hill et al., 1987b; Donnelly \& J acobsen, 1988). Two short term studies even demonstrated a tendency towards a greater decrease for the combination (Krotkiewski et al., 1981; Phinney et al., 1980). However, in 4 studies a significantly smaller decline in $R M R$ or even a restoration to baseline values in the diet-exercise group was observed (Schultz et al., 1980; Donahoe et al., 1984; Lennon et al., 1985; Nieman et al., 1988). Differences in methodology may have attributed to these equivocal results (Thompson \& Blanton, 1987). However, a detailed comparison failed to indicate one factor as being responsible for the appearance or non-appearance of the suppression of the diet-induced RMR in the combination treatment. Each differentiation in methodology (intensive and frequent exercise, moderate exercise, severe energy restriction and moderate energy restriction) showed equivocal results (Garrow et al., 1978; Schultz et al., 1980; Krotkiewski et al., 1981; Warwick \& Garrow, 1981; Bogardus et al. 1984; Donahoe et al., 1984; Lennon et al., 1985; Belko et al., 1987a; Hill et al.,1987b; Donnelly \& Jacobsen, 1988; Nieman et al., 1988). Similar results were shown with differences in the length of the study period (Schultz et al., 1980; Warwick \& Gar* row, 1981; Donahoe et al, 1984; Belko et all., 1987a). Despite a conformity in some aspects of study design, these equivocal results make it difficult to attribute the inconsistencies only to variation in methodology. 


\section{Compensation for exercise}

Most studies have dealt with female subjects and it has recently been suggested that females, as a consequence of their reproductive function have a special energy saving adaptation to an energy deficit (Uvnäs-Moberg, 1988). In animal studies it has been shown that females compensate an exercise in duced energy deficit by increasing their food intake (Tremblay et al., 1987a). As was mentioned above (section 1.4) such compensatory reactions are not conclusively evident during exercise in humans (Woo et al., 1982; Reger et al. 1986). Since studies using energy restriction exclude compensation for exercise by extra food intake during the combination treatment, another compensation mechanism might play a role.

De Boer and co-workers (1987) suggested that adaptation to energy restriction occurred during the day, indicating that either thermic effect of feeding or physical activity may be the compensatory factors. The thermic effect of feedling, however, has not often been studied in combination studies. DIT was shown to remain the same (Belko et al., 1987a) or to increase (Ravussin et al., 1985a). The increase was associated with an improved insulin sensitivity.

The response by means of an adaptive mechanism is more pronounced for a larger energy deficit. Since the energy deficit is larger in a combination treatment than in a treatment. with energy restriction alone, adaptation might be more pronounced. In a combined treatment adaptation in food intake is not allowed, and the only possible compensation left is a reduction in daily habitual activities outside the prescribed exercise periods. If this compensation in daily habitual activities leads to a similar energy expenditure as when dieting alone this could result in a similar weight and fat loss for a diet and a diet-exercise group (Belko et al., 1987a; Epstein \& Wing, 1980).

This hypothesis is supported by the fact that several studies failed to demonstrate significant differences in weight loss and fat loss (Garrow et al., 1978; Krotkiewski et al., 1981; Henson et al., 1987; Hill et al., 1987b), despite $3-5$ h physical training per week. Compensation in daily habital physical activities might be the explanation, since Belko et al. (1987a) found that in the diet-exercise group the recorded $24-$ h activity did not meet the prescribed physical activity in terms of energy expenditure. It was suggested that the dietexercise group decreased their nonexercise activities.

Only a few studies have observed significant diflerences in weight loss (Hagan et al., 1986), but the promotive effect of exercise on fat loss was more evident (Pavlou et all, 1985; Hagan et al., 1986; Belko et al., $1987 \mathrm{a} ;$ Hill ct al, 1987b). But although more fat was lost, exercise could not prevent the breakdown of fat free mass due to energy restriction (Krotkiewski et al., 1981; Bogar dus et al. 1984, Belko et al., 1987a, Hill et al.,1987b). However, the dietexercise combination does seem to show consistently better effects in terms of weight and fat loss in male subjects compared to diet alone (Pavlou et al., 1985; Hagan et al., 1986). This may be explained by the differences in fat distribution between male and females. 


\section{Weight maintenance}

It is only in the past 10 years that research has been focussed on the maintenance of reduced weight, and in this respect little is known about the effects of the combination of diet and exercise. Studies in which behavioral and exercise treatment were combined have shown that exercise significantly enhances the effects of changes in eating habits on the extent of weight reduction and maintenance of that reduction (Dahlkoetter et al., 1979; Holden et al., 1988). Another study comparing the effects of a very low-calorie diet with the combination of the very-low-calorie and exercise reported also lower body weights after a two-year followup for the combination treatment than for the diet alone (Sikand et al., 1988).

(3.)

\subsection{Conclusions and aims of the study}

Reviewing the literature about diet and exercise in the treatment of obesity it may be concluded that the combination of diet and exercise should have the best short and long term results in terms of weight loss, fat loss and the prevention of the diet-induced fall of RMR. Despite a number of diet and diet-exercise st udies no consistent evidence can be found for the favourable effects of a diet-exercise treatment compared to diet alone. Some of the explanations proposed for the inconsistent results, have been investigated in the present study. Therefore the main subject of this thesis can be formulated as follows:
What are the short term and long term effects of a diet and a diet-exercise treatment on the different components (RMR, DIT, daily physical activity) of energy expenditure in male and female subjects.

Chapter 2 questions whether the combination of diet and moderate exercise has any favourable effects on weight and fat loss and on the prevention of the decrease in RMR in women during dieting. In Chapter 3 results of studies on 24-h energy expenditure, RMR and daily physical activity are presented, since a decline in daily physical activity during the non-exercise hours in the diet-exercise combination has been hypothesized as a possible cause for the lack of significant differences between diet and diet-exercise treatment.

The effects of diet and diet-exercise treatments on DIT have not been studied extensively. In chapter 4 such a study is reported on, and the effects of this combination and diet alone on DIT are described. Also one of the suggested causes of inconsistency in study results with respect to the prevention or restoration of the diet-induced fall of RMR, viz. the timing of the RMR measurement after exercise, is investigated. Chapter 5 presents the response of male subjects to a diet and a diet-exercise treatment together with the changes in their plasma vitamin status during the different treatments.

Reported differences in study results might also be attributed to the fact that some people have had several periods of weight loss and regain, whereas others have remained at a stable weight level. It is hypothesized that several periods of weight loss 
might lead to a sustained lower RMR, and hence to more difficulties with weight loss (Chapter 6).

Finally the long term effects of the different treatments on weight loss are compared in Chapter 7 . It has been shown to be extremely difficult for the successfully reduced-obese to maintain their weight; most of them regain weight. Since exercise has a favourable effect on weight maintenance, it was investigated whether the diet-exercise groups kept on exercising and whether this resulted in the maintenance of lower weight and in a decreased or increased RMR. 



\section{DOES EXERCISE GIVE AN}

\section{ADDITIONAL EFFECT IN WEIGHT REDUCTION REGIMENS?}

\section{Introduction}

Recently there is an increasing interest in the potential benefits of the addition of exercise in weight reduction regimens. With exercise an incteasing energy expenditure is produced and with equal energy intake, it may result in a greater negative energy balance, followed by a greater weight loss (Buskirk et al., 1963; Dahlkoetter et al., 1979;

Reeves et al., 1985), an enhanced fat loss or preservation of fat free mass (FFM) (Kenrick et al., 1972; Wolf et al., 1975; Zuti \& Golding, 1976; Pavlou et al, 1985). However, contradictory results are also found (Garrow et al., 1978; Krotkiewski et al., 1981; Warwick \& Garrow, 1981; Bogardus et al., 1984). In these studies an improvement of maximal aerobic power was observed but no greater weight or fat loss. Another potential benefit of exercise, which can produce an accelerated weight loss, is the increasing oxygen consumplion after exercise (Hermansen et al., 1984; Maehlum et al., 1986). During dieting this effect of exercise can result in counteracting the dietary-induced fall in RMR. With moderate exercise this effect is shown in different studies (Schultz et al., 1980; Donahoe et al., 1984; Lennon et al., 1985), although others with the same protocol could not show preventive effects of exercise

\section{D. van Dale, W.H.M. Saris, P.F.M. Schoffelen, F. Ten Hoor}

Published in: International Journal of Obesity $1987 ; 11: 367-75$

\section{ABSTRACT}

The effects of dieting and exercise on resting metabolic rate (RMR), body composition and maximal ae robic power were stwied in twelve obese women. The subjects were patired om basis of their body mass index and divided in to a diet (D) and a diet + exercise group (DE). The treatment consisted of a 5 week period with a low energy form th la diet of $2.9 \mathrm{MJ} / \mathrm{day}$ and a 8 week period with a mixed diet of 1.7 $\mathrm{MJ} /$ day supplenented with $1.8 \mathrm{MJ}$ /day normal foodstuffs. The DE group trained 4 h per week at 50-60\% of their maximal aerobic power with aerobics and fitness. Body composition was determined by hydrositatic weighing and RMR was neasured from $3.00 \% 6.00$ h in a respiration chamber. Maximal aerobic power was measured on a continuousty traked ergometer. The measurements were dome in week 0 , after 4 weeks (week 5), and affer 12 weeks (week 13). Weight loss ( $\mathrm{kg}$ ) after 4 weeks was 7.9 (D) and 8.2 (DE), after 12 weeks $12.2(\mathrm{D})$ and $13.2(\mathrm{DE})$. There were no significant differences between the groups. Fat loss was also not statistically different between $\mathrm{D}(6.0$ and $9.4 \mathrm{~kg})$ and $\mathrm{DE}(6.7$ and 10.9 $\mathrm{kg})$. Both groups showed a signifficant dectease in RMR per $\mathrm{kg} \mathrm{FTM} \mathrm{after} 12$ weeks (D: $26.5 \%$ and DE: $18.2 \%$ ). "There was also a significant decrease in RMR for $\mathbb{D}(19.9 \%)$ after 4 weeks but not for $\mathrm{DE}(12.3 \%)$. Maximal aerobic power per $\mathrm{kg}$ fat free mass (FFM) was decreased in $\mathrm{D}(6.3 \%$ and $3.1 \%)$ and increased in DE ( $3.2 \%$ and $6.2 \%)$ after 4 and 12 weeks respectively. From the results in this study we con clade that in women the combination of diet and exercisie gives no significant extra weight or fat loss. 
on RMR (Garrow et al., 1978; Warwick \& Garrow, 1981).

It is not clear why there are discrepancies between the results. A possible explanation is the great variability between all the studies. There are differences in the level of energy restriction, intensity and frequency of the exercise ( 3 to $7 \mathrm{~h}$ per week), and the study period (2 to 26 weeks). A study period of four weeks is probably too short for measuring signilficant effects of exercise. For example, Krotkiewsky et al. (1981) observed in four weeks a posilive trend towards better results for the combination group (DE), but there were no significant effects. Maybe with a longer study period or a more intensive training program, the results would have shown statistical differences. However, Garrow et al. (1978) and Warwick \& Garrow (1981) could not find a positive trend with a more intensive training program. Warwick \& Garrow (1981) suggested that the lack of differences in weight loss between a diet and diet-exercise group was due to the increasing glycogen stores through intensive exercise. The present study was designed to compare the effects of the combination of a low energy intake with moderate exercise and a low energy intake alone in 12 weeks.

\section{Methods}

\section{Subjects}

Sixteen women aged 19 to 48 (mean age 29) were recruited from respondents to an advertisement in a local newspaper. The subjects were paired on the basis of their body mass index $\left(B M I>28 \mathrm{~kg} / \mathrm{m}^{2}\right)$ and randomly assigned to a diet (D) and a diet-exercise group (DE). They were medically screened to exclude abnormalities which might affect their RMR or their ability to sustain a very-low-caloric diet. Each individual was informed about the nature of the investigation and gave her informed consent. The study was reviewed and approved by the ethics committee of the university.

\section{Diet}

The study took place over a 12 -week period which was divided into two parts. The first period consisted of a low energy formula diet

(Meriteneß, Wander) of $2.9 \mathrm{MJ} / \mathrm{day}$ for four weeks. It provided $76 \mathrm{~g}$ carbohydrate, $55 \mathrm{~g}$ protein and $18 \mathrm{~g}$ fat. In the second part of the study, week 6 until week 13, a mixed diet of 3.5 $\mathrm{MI} / \mathrm{day}$ was followed. This diet contained $1.7 \mathrm{MJ} / \mathrm{day}$ from the formula diet and was supplemented to 3.5 $\mathrm{MJ} /$ day by a free choice of foodstuffs. During the whole period the subjects kept a record of food intake and activities. The subjects were instructed and motivated to record all foods and beverages consumed precisely. Ewery week the food records were checked and discussed with the subjects. From the food record it turned out that during the second part of the study the diet contained $91 \mathrm{~g}$ carbohycrate, $67 \mathrm{~g}$ protein, $20 \mathrm{~g}$ fat and a micronutrient intake which meets the Dutch RDA (Nederlandse Voedingsmiddelen Tabel, 1983).

\section{Procedure}

Before the start of the study the subjects were introduced to the equipment and tested for selection. The actual measurements of body composition, RMR and maximal aerobic 
power were done two weeks before the start of the treatment, after 4 weeks (in week 5) and after 12 weeks (in week 13).

\section{Exercise}

The diet-exercise group participatted four times per week in a training program during the entire period. Each training lasted one hour. This weekly program consisted of two aerobic dancing trainings and two fitness trainings. The atrobic training consisted of 10 minutes stretching, 30 minutes aerobic dancing, 15-20 min stretching, and light exercises. The fitness training consisted of 40 min weight resistance training and 20 min aerobic dancing. Training sessions were done at $50-60 \%$ of $\mathrm{VO}_{2}$ max, calculated from the maximal exercise test, and heart rate recordings during the training sessions. Heart rate was recorded with a heart rate memory system (Depex, Holland) before the start of the study in week 5 and week 13. The attendance of the subjects was monitored and the training was supervised by professional trainers.

\section{Measurements}

During the study body weight was measured weekly using a balance beam scale. At the start of the treatment, after lour weeks and at the end of the 12-week period body fat was determined by hydrostatic weighing. Residual lung volume was measured with a spirometer (Volugraph 2000, Mijnhardt, The Netherlands) at the moment of weighing under water. The average of six trials was used for true body weight under water. The percentage of body fat was calculated from body density by the method of Siri (1956). For the measurement of RMR each

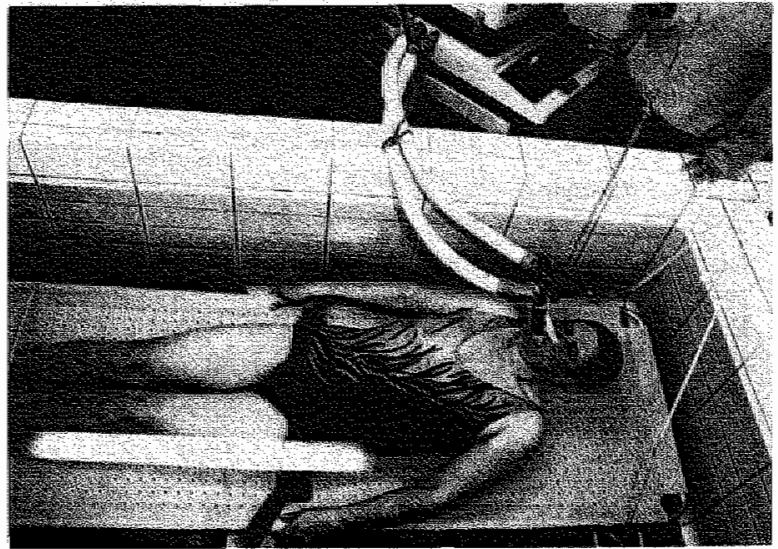

Body fat was determined by hydrostatic weighing.

subject stayed $12 \mathrm{~h}$ in one of two similar respiration chambers. These are open-circuit chambers with a volume $14 \mathrm{~m}^{3}$, equipped with bed, toilet, tv, telephone, etc. The volume of air drawn from the chambers was measured by a dry gasmeter.

Samples of in-and outgoing air were collected in glass tubes (the composite sample) as well as continuously analysed by a paramagnetic $\mathrm{O}_{2-}$ analyser (Servomex Taylor, England) and an infrared $\mathrm{CO}_{2}$-analyser (Hartmann and Braun, West Germany). The composite samples were analysed chemically with a Sonden apparatus (van $\mathbb{E s}$ et a $\mathbb{1}_{\text {, }}$ 1984). The air flow rate, $\mathrm{O}_{2}$ - and $\mathrm{CO}_{2}$-concentration of the outflowing air were computed on line through an automatic acquisition system interfaced with an Apple $2 \mathbb{E}$ computer (Schoffelen et al., 1985). $\mathrm{VO}_{2}$, $\mathrm{VCO}_{2}, \mathrm{R}$, and consequently energy expenditure were calculated using the equation of Browwer, (1965). RMR was calculated from measurements taken during the sleeping period from 03.00 to 06.00 h a.m. From earlier experiments in our 


\section{Exercise, RMR and Fat Loss}

Table I Descriptive data of the experimental subjects

\begin{tabular}{lcccc}
\hline \multirow{2}{*}{ Variables } & \multicolumn{3}{c}{ Diet group (N=6) } & \multicolumn{2}{c}{ Diet-exercise group (N=6) } \\
& mean & SEM & mean & SEM \\
\hline Weight (kg) & 87.3 & 2.0 & 81.2 & 4.0 \\
Height (cm) & $170.0^{\circ}$ & 2.1 & $163.0^{\circ}$ & 2.4 \\
Body Mass Index $\left(\mathrm{kg} / \mathrm{m}^{2}\right)$ & 30.3 & 1.1 & 30.3 & 0.8 \\
Body fat (\%) & 37.4 & 1.5 & 39.0 & 0.6 \\
Body fat (kg) & 32.9 & 1.8 & 31.7 & 1.7 \\
\hline
\end{tabular}

- $P<0.05 D$ vs DE

Table 2 Weight loss, fat loss and loss of fat free mass after 4 and 12 weeks of treatment (meantSEM)

\begin{tabular}{|c|c|c|c|c|c|c|c|c|}
\hline & & & & 4 weeks & & & 12 wee & eaks \\
\hline & No. & $\begin{array}{l}\text { Initial } \\
\text { weight }\end{array}$ & $\begin{array}{l}\text { weight } \\
\text { loss }\end{array}$ & $\begin{array}{l}\text { fat } \\
\text { loss }\end{array}$ & $\begin{array}{l}\text { loss of } \\
\text { fat free } \\
\text { mass }\end{array}$ & $\begin{array}{l}\text { weight } \\
\text { loss }\end{array}$ & $\begin{array}{l}\text { fat } \\
\text { loss }\end{array}$ & $\begin{array}{l}\text { loss } \\
\text { fat free } \\
\text { mass }\end{array}$ \\
\hline $\bar{D}$ & 3 & 86.4 & 7.3 & 5.4 & 1.9 & 10.2 & 7.4 & 2.8 \\
\hline & 7 & 89.5 & 7.3 & 5.7 & 1.6 & 9.2 & 7.2 & 2.0 \\
\hline & 9 & 90.7 & 8.3 & 6.8 & 1.5 & 9.2 & 7.5 & 1.7 \\
\hline & 12 & 90.5 & 4.2 & 2.8 & 1.4 & 8.7 & 6.7 & 2.0 \\
\hline & 13 & 78.8 & 10.1 & 8.1 & 2.0 & 158 & 12.4 & 3.4 \\
\hline & 14 & 88.1 & 10.1 & 7.2 & 2.9 & 200 & 15.1 & 4.9 \\
\hline mean & & 87.3 & $7.9^{* *}$ & $6.0^{* *}$ & $1.9^{* *}$ & $12.2^{* *}$ & $9.4^{* *}$ & $2.8^{* *}$ \\
\hline SEM & & 2.0 & 0.9 & 0.8 & 0.2 & 1.9 & 1.4 & 0.5 \\
\hline & 1 & 69.5 & 5.8 & 4.7 & 1.1 & 11.5 & 9.5 & 2.0 \\
\hline & 2 & 75.7 & 6.8 & 5.5 & 1.3 & 12.5 & 10.3 & 2.2 \\
\hline & 4 & 98.5 & 7.4 & 6.5 & 0.9 & 12.2 & 10.4 & 18 \\
\hline & 5 & 80.1 & 9.1 & 7.5 & 1.6 & 11.5 & 9.6 & 1.9 \\
\hline & 6 & 81.0 & 10.9 & 8.2 & 2.7 & 17.0 & 13.2 & 3.8 \\
\hline & 15 & 82.4 & 8.9 & 7.6 & 1.3 & 14.6 & 12.3 & 2.3 \\
\hline mean & & 81.2 & $8.2^{* *}$ & $6.7^{* *}$ & $1.5^{\circ *}$ & $13.2^{* *}$ & $10.9^{* *}$ & $2.3^{* *}$ \\
\hline SEM & & 4.0 & 0.7 & 0.6 & 0.2 & 0.6 & 0.6 & 0.3 \\
\hline
\end{tabular}

"P<0,01 paired l-test, results after 4 and 12 weeks vs those of week 0 
laboratory it was shown that the variability of the metabolic rate was lower during the sleeping period compared to the measurements after waking up. Metabolic rate determined during sleeping is demonstrated to be about $5 \%$ lower as RMR and is usually called sleeping metabolic rate (Goldberg et al., 1988a). Although actually sleeping. metabolic rate is determined, for reasons of convenience, in the present study the term RMR is used. Maximal aerobic power was measured on a bicycle ergometer with an automatic ergo-analyser (Ergosereen, Fenyvus and Gut, Basel, Switserland). $\mathrm{VO}_{2}$ max and heart rate were simultaneously measured. The workload was increased 20 W/min until exhaustion. Criteria for maximal exercise were: levelling off of oxygen uptake, forced ventilation and a R-value higher than 1.1. Because a plateau in oxygen consump- tion was not always attained, we considered the highest value of oxygen consumption, measured during one minute, which is actually the peak $\mathrm{VO}_{2}$, as the $\mathrm{VO}_{2} \max$. However, in the text we use the term $\mathrm{VO}_{2} \max$.

\section{Statistics}

Results are expressed as mean \pm SEM. Comparisons between data were made using the Student's t-test.

\section{Results}

Physical characteristics of the subjects are summarized in Table 1. There were no significant differences between the variables of the two groups at the start of the study.

Both the D and DE group had a drop-out of $25 \%$ (2 subjects out of 8 subjects), which is usual for this type of study (Wing \& Jeffery, 1979). The

Table 3 Resting metabolic rate during a period of sleep from 03.00 to 06.00 a.m. $(\mathrm{kJ} / \mathrm{kg} F F M / \mathrm{h}$; mean \pm SEM)

\begin{tabular}{|c|c|c|c|c|c|c|c|}
\hline \multirow[b]{2}{*}{$\begin{array}{l}\text { Woeks } \\
\text { subject }\end{array}$} & \multicolumn{3}{|c|}{$\bar{D}$} & & \multicolumn{3}{|c|}{$\mathrm{DE}$} \\
\hline & 0 & 5 & 13 & & 0 & 5 & 13 \\
\hline 3 & 5.7 & 4.0 & 3.3 & 1 & 5.3 & 5.7 & 5.7 \\
\hline 7 & 6.0 & 5.8 & 6.2 & 2 & 5.6 & 5.2 & 4.3 \\
\hline 9 & 5.9 & 4.9 & 4.1 & 4 & 5.8 & 5.4 & 4.8 \\
\hline 12 & 5.2 & 4.4 & 3.9 & 5 & 6.0 & 4.8 & 5.0 \\
\hline 13 & 5.3 & 3.3 & 3.2 & 6 & 5.7 & 3.4 & 3.6 \\
\hline 14 & 5.5 & 4.0 & 4.1 & 15 & 5.2 & 4.9 & 4.2 \\
\hline mean & 5.6 & 4.4 & 4.1 & mean & 5.6 & 4.9 & 4.6 \\
\hline SEM. & 0.2 & 0.4 & 0.4 & SEM & 0.1 & 0.3 & 0.3 \\
\hline$\%$ change & & $19.9^{1}$ & $26.5^{2}$ & $\%$ cha & ge & 12.3 & $18.2^{2}$ \\
\hline
\end{tabular}

$\mathrm{D}=$ Diet group; $\mathrm{DE}=$ Diet-exercise group

1 week 5 ws week $D \quad P<0.01$

2 week 13 ws week $0 \quad P<0.01$ 
Table $4 \mathrm{VO}_{2} \max (\mathrm{mllkg} B \mathrm{~W} / \mathrm{min}$ ) of the subjects after 4 and 12 weeks (meantSEM)

\begin{tabular}{|c|c|c|c|c|c|}
\hline & \multicolumn{2}{|c|}{$\mathrm{D}$} & \multicolumn{2}{|c|}{$\mathrm{DE}$} & \multirow{2}{*}{$\begin{array}{c}P \\
D E v s D\end{array}$} \\
\hline & $\mathrm{VO}_{2} \max$ & SEM & $\mathrm{VO}_{2} \max$ & SEM & \\
\hline Start & 28.3 & 3.6 & 31.3 & 1.9 & n.s \\
\hline 4 wreks & 24.6 & $2 . \pi$ & $34.2^{*}$ & 2.2 & 0.05 \\
\hline 12 weeks & 28.5 & 2.0 & $36,0^{*}$ & 2.7 & 0.01 \\
\hline
\end{tabular}

$D=$ Diel group : $D E$ es Diet-exercise group

" $P<0.05$ with respect to start: " $P<0.01$ with respect to start

Table $5 \quad$ Differences in weight and far loss found in studies with a low energy diet (D) and with a low energy dies plus exercise (DE)

\begin{tabular}{|c|c|c|c|c|c|c|c|c|}
\hline Study & $\begin{array}{l}\text { Study } \\
\text { period } \\
\text { (weeks) }\end{array}$ & $S e x$ & $N$ & $\begin{array}{l}\text { Diet } \\
(\mathrm{MJ} / \mathrm{day})\end{array}$ & $\begin{array}{l}\text { Training } \\
\text { (h/weok) }\end{array}$ & Intensity ${ }^{1}$ & $\begin{array}{l}\text { AWoight } \\
\text { loss } \\
\text { DE-D }\end{array}$ & $\begin{array}{l}\triangle \text { Fat } \\
\text { loss } \\
D E-D\end{array}$ \\
\hline
\end{tabular}

(kg/week)

\begin{tabular}{lllllllll}
\hline$(22)$ & 8 & $\mathrm{~F}$ & 39 & 4.3 & 1.5 & ++ & -0.10 & \\
$(4)$ & 26 & $\mathrm{M} / \mathrm{F}$ & 12 & $4.3 / 6.4$ & 3.5 & ++ & 0.25 & $0.24^{*}$ \\
$(9)$ & 3 & $\mathrm{~F}$ & 37 & 3.4 & 7.14 & ++ & -0.14 & \\
$(11)$ & $3-4$ & $\mathrm{~F}$ & 3 & 3.4 & 1.4 & ++ & -0.28 & \\
$(10)$ & 3 & $\mathrm{~F}$ & 18 & 2.12 & 3.0 & +++ & 0.20 & -0.24 \\
$(8)$ & 12 & $\mathrm{M} / \mathrm{F}$ & 18 & $3.6 / 3.8$ & 3.0 & +++ & 0.1 & 0.12 \\
$(5)$ & 8 & $\mathrm{M}$ & 72 & 3.4 & 3.0 & +++ & 0.33 & $0.66^{* * *}$ \\
$(14)$ & $6-8$ & $\mathrm{~F}$ & 12 & $3.4 / 4.3$ & 4.3 & +++ & 0.02 & \\
This study & 12 & $\mathrm{~F}$ & 12 & 3.5 & 4.0 & ++ & 0.09 & 0.12 \\
\end{tabular}

P<0.05, $P<0.001$

1 intensity of the physical training: moderate, ++ intensive

Dediet group, DE $=$ diet-exercise group 
mean weight loss of these drop-outs after 5 weeks was $8.2 \mathrm{~kg}$ (D) and 6.5 $\mathrm{kg}(\mathrm{DE})$. The diet was acceptable for all the subjects and was with and without the exercise successful in promoting weight loss. Body composition cluanges for both groups are shown in Table 2 . There were significant changes in body weight and body fat in both groups after 4 weeks and after 12 weeks $(P<0.01)$.

However, between the two groups the body composition changes were not significant.

The mean daily energy intake during the first 5 weeks with the formula diet was $2.8 \mathrm{MJ} /$ day for the $\mathrm{D}$ group and $2.9 \mathrm{MJ} / \mathrm{day}$ for the DE group. In the second part of the study (week 5 to week 13 ) the actual daily intake was $3.3 \mathrm{MJ} / \mathrm{day}$ for the D group and 3.6 MJ/day for the DE group. The DE group tended to have a systematically higher energy intake.

However, there was no significant difference between the $\mathrm{D}$ and $\mathrm{DE}$ group in energy intake.
Results of the RMR measurement, expressed on the basis of fat free mass, are shown in Table 3 .

After 4 weeks the D group had a significant decrease in RMR of $19.9 \%$ $(\mathrm{P}<0.01)$ and after 12 weeks $26.5 \%$ $(\mathrm{P}<0.01)$. For the DE group there was allso a decline, although not significant in the first period. After 4 weeks the decrease for the DE group was $12.3 \%$ and after 12 weeks $18.2 \%(\mathrm{P}<0.01)$. Between the groups there were no significant differences in $R M R$ in response to energy restriction.

The changes in percent of maximal oxygen uptake, expressed on the basis of fat frew mass, are shown in Fig. 1. For the D group maximal oxygen uptake was affected by the energy restriction. After 4 weeks a decrease was shown of $6.3 \%$ and after 12 weeks $\mathrm{VO}_{2}$ max remained still decreased by $3,1 \%$. The DE group showed a small increase of $3.3 \%$ after 4 weeks and of $6.2 \%$ after 12 weeks (N.S.). Expressed on the

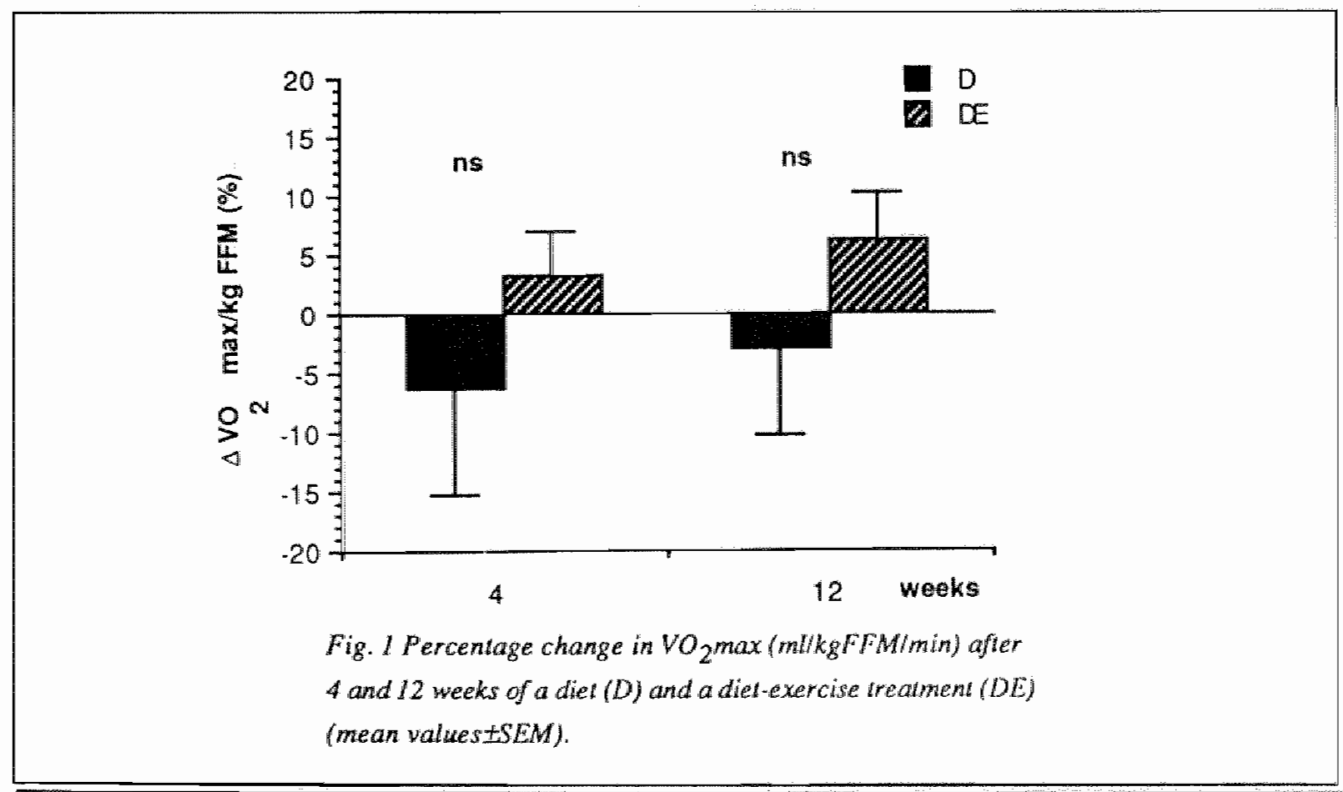


basis of $\mathrm{kg}$ body weight $\mathrm{DE}$ showed a significant increase of $15 \%$ after 13 weeks, while D had a non-significant increase of $2.3 \%$ (Table 4 ).

\section{Discussion}

\section{Comparison with other studies}

Because exercise promotes energy expenditure, in weight reduction programs exercise is often combined with dietary restriction. However, studies of this combination do not show consistent results in crucial factors like an accelerated weight loss, selectivity of weight loss and prevention of the decrease of RMR during dieting. In Table 5 all known studies with a combination of a low energy $\operatorname{diet}$ (intake $<5 \mathrm{MJ} / \mathrm{day}$ ) and exercise are tabulated. An estimation was made for the intensity of the training program. The differences between the D and DE groups were calculated for the changes in body weight and, when possible for body fat. Table 5 shows no systematic differences in the changes of the body composition parameters between the $\mathrm{D}$ and the DE group on basis of the duration of the study period, the frequency and intensity of the training period or the level of energy restriction. The only factor which seems to cause systematic differences is sex. As all studies with a significant extra effect in weight or fat loss for $D E$ have been performed with male subjects, it is suggested that exercise has more effect in weight and fat loss in males than in females (Krotkiewski \& Björntorp, 1986). This effect may be attributed to the difference in distribution of adipose tissue. Male subjects are characterized by a storage capacity of adipose tissue in the abdominal region. Female subjects have often their storage of adipose tissue in the femoral region. Adipose tissue in the abdominal region is more influenced by physical training than adipose tissue in the femoral region (Krotkiewski \& Björntorp, 1986).

With respect to weight there is an indication that the DE group results in more weight loss and in particular more fat loss. But the differences are small and, most probably due to the limited number of subjects, in most studies statistical significance is not reached. Furthermore information about fat loss is not always reported. Therefore, an analysis of studies, in which essential factors like energy intake, training regimen and changes in body weight are recorded, does not give clear evidence in favour of the combination of diet and exercise in the treatment of obese people. However, there is a tendency of an extra fat loss of $0.1-0.2 \mathrm{~kg}$ per week. The results of our study are in agreement with this observation.

\section{Energy costs of weight loss}

Analyzing the data in another way it is possible to calculate the expended energy costs in terms of fat loss and loss of FFM. The energy value of 1 $\mathrm{kg}$ of pure fat provides $38.3 \mathrm{MJ}$ and $1 \mathrm{~kg}$ of FFM provides $3.5 \mathrm{MJ}$ ( $730 \mathrm{~g}$ water, $205 \mathrm{~g}$ protein and $25 \mathrm{~g}$ minerals). In our study FFM decreased with $2.8 \mathrm{~kg}=9.8 \mathrm{MJ}$ for the D group and fat loss was 9.4 $\mathrm{kg}=360 \mathrm{MJ}$. For the DE group FFM decreased with $2.3 \mathrm{~kg}=8.0 \mathrm{MJ}$ and the fat mass with $10.9 \mathrm{~kg}=417 \mathrm{MJJ}$. If the loss of FFM is expressed as a percentage of the loss fat mass, FFM appears to be significantly more used in the D group (2.7\%) than in 
the DE group $(1.9 \%)(\mathrm{P}<0.01)$. Similar results were shown by $\mathrm{Mc}$ Murray et al. (1985) in a diet or exercise study in endurance athlletes.

\section{Food intake}

In contrast with other studies (Woo et al., 1982; Reger et al., 1986) in the present study the food intake tended to be higher for the DE group. Woo et al. (1982) and Reger et al. (1986) could not show an increase in food intake with the addition of moderate exercise. However, in these studies the diet was not restricted. The higher food intake might be an adaptation to the extra physical activities during a low energy intake. Other studies did not report very clearly about the actual food intake. In the present study a consistent effort was made to record food intakes and these findings are reported. However, food intake is difficult to control. Conclusions must be considered carefully. Only inpatient studies can strictly monitor the food intake, which has done by Garrow et al. (1978) and Warwick \& Garrow (1981).

\section{Reduction in normal daily life activities?}

An explanation for the lack of difference in weight and fat loss between D and DE groups is suggested by Epstein \& Wing (1980): By decreasing the activities outside the training hours, DE may compensate for the extra training, which may result in a similar daily energy expenditure to the diet group. However, thus far no data are available to confirm this hypothesis.

\section{RMR}

In the appearance or non-appearance of an extra fat loss for a diet-exercise group compared to a diet group the possible counteracting effects of exercise on the dietaryinduced fall of RMR may play an important role. Schultz et al. (1980) demonstrated this suppressive effect of exercise during dieting on $R M R$ with 20 min moderate exercise per day. The decrease in RMR during dieting can vary from $12-29 \%$ (Thompson et al., 1982). The addition of exercise should prevent the decrease in RMR, which should result in no change in $R M R$ for $D E$ and a decrease for $D$. With a RMR of $6.3-6.8 \mathrm{MJ}$ in $24 \mathrm{~h}$ and a decrease of RMR of 12-29\% the difference in fat loss between $D$ and $D E$ can be $2.6-6.0 \mathrm{~kg}$. In our study RMR decreased in both groups during the diet, although the decrease was $10 \%$ less in the DE group. Lennon et al. (1985) suggested that the lack of effect of exercise on the decrease of RMR can be caused by a rather low intensity of the exercise. In their study there was a correlation between RMR and $\mathrm{VO}_{2}$ max. They found no change in RMR with an increase of $9 \%$ of the estimated $\mathrm{VO}_{2}$ $\max$ whereas an increase of 11-12\% did restore RMR significantly compared to base line walues. However, in our study a $15 \%$ increase of $\mathrm{VO}_{2}$ max per $\mathrm{kg}$ body weight did not prevent the fall of RMR. Our results are in agreement with the results of the studies of Garrow et al. (1978), Warwick \& Garrow (1981) and Mathieson et al. (1986). Horton (1986) outlined the two major mechanisms by which exercise can prevent the diclary induced decrease of RMR: either by a carryover effect of the previous day"s exercise or by an increase of fat free mass. Although in the present study the DE group tended to have a 
smaller decrease of RMR there were no indications that at this level of exercise there was a significant carry-over effect on RMR. Freedman-Akabas et al. (1985) suggested the same based upon the results of the $\mathrm{VO}_{2}$ measurement of 1 to $4 \mathrm{~h}$ after moderate or intensive exercise of 20-40 min. Similarly, Pacey et al. (1985) did not find significant increases of RMR over $24 \mathrm{~h}$ after exercise. Others found significant effects (Hermansen et al., 1984; Maehlum et al., 1986).

\section{Maximal aerobic power and intensity of the training}

The intensity of the training is an important factor in explaining the differences of the effects on RMR. But in the case of treatment of obesity it is questionable whether highly intensive exercise will be appropriate for overweight people. Because of their overweight, obese people have problems with exercise (like weight bearing stress on joints, limited mobility, instability and heat intolerance), and with a higher intensily of exercise these problems may be more pronounced and may result in lack of motivation to continue the exercise program. Another obvious reason concerning the contradictory results about the effects of physical activity on RMR is that RMR is not always related to fat free mass. In our study the RMR results are expressed per kg FFM, which cancelled the difference between the $D$ and DE group.

The difference in maximal aerobic power, expressed per kg FFM, was significant between the groups after 4 and 12 weeks. The decline in oxygen uptake for D may be attributed to the depletion of muscle glycogen content, which was found by Phinney et al. (1980) as a cause of the reduction in exercise endurance with a very low carbohydrate diet. The V02 max per kg FFM did not show a signilicant increase for the DE group, but expressed per $\mathrm{kg}$ body weight the increase was significant. The lack of significant improvement per $\mathrm{kg}$ FFM can be attributed to the low intensity of 50 $60 \%$ of the maximal aerobic power. Another study (Wallberg et al., 1984) also showed no increases with a comparable intensity of exercise.

\section{Conclusion}

Summarizing the results we can conclude that with moderate levels of exercise there are no indications that in women the combination of diet and exercise results in a significant extra weight loss after 12 weeks. 


\section{EFFECTS OF ADDING EXERCISE TO ENERGY RESTRICTION ON 24-HOUR ENERGY EXPENDITURE, RESTING METABOLIC RATE AND DAILY PHYSICAL ACTIVITY}

\section{Introduction}

The combination of diet and exercise has not resulted in consistently better results in weight and fat loss or in prevention of the dietary-induced fall of RMR, compared to energy restriction alone (Schultz et al. 1980, Warwick \& Garrow, 1982; Lennon et al., 1985, Pavlou et al., 1985; Henson et al., 1987; Hill et al., 1987b). Although methodological differences between studies may play a role in the inconsistency of results (Belko et al., 1987a; van Dale et al., 1987) they provide no conclusive explanation for the lack of signficant differences between a diet and a diet-exercise treatment.

Another factor which might contribute to the absence of significant differences between a diet and a diet-exercise group has been suggested by Epstein \& Wing (1980). Since the extent of adaptation in energy expenditure is related to the magnitude of the energy deficit, subjects in the diet-exercise group might reduce their normal daily life activities or non-exercise activities in order to compensate for the greater negative energy balance due to exercise. Such a possible reduction in daily life activities might completely
D. van Dale, P.F.M.

Schoffelen, F. Ten Hoor, W.H.M. Saris

Accepted for Eur J Clin Nutr

\section{ABSTRACT}

Body composition, resting metabolic rate (RMR), twenty-lour hour Energy Expenditure (24-ER) and daily pliysical activity were determined in 12 obese women during and after 12 weeks of exercise (4h $\mathrm{p} / \mathrm{w}$ on $55 \%$ of $\mathrm{VO} 2 \mathrm{max}$ ) and/or enerby restriction (2.9-3.5 MJ/day). Diet (D) and dictexercise (DE) groups were formed by matching the subjects on their body mass index (BMI kg//n ${ }^{2}$; mean 30.3 ).

After 12 weeks no significant differences were shown in loss of weight (D 12.2 and DE $13.2 \mathrm{~kg}$ ) and loss of fat mass (D $9.4 \mathrm{vs}$ DE $10.9 \mathrm{~kg}$ ). Both groups reduced their RMR (D 29.9 vs DE $21.7 \%$ ) and their metabolic rate during the entire nighe incasured by indirect catorimetry (12-CE) (D $36.4 \%$ and DE $21.7 \%$ $P<0.05$ ). $24 . \mathrm{FL}$, estimated by means of heart rate monitorimg. was reduced by $221 \%$ for $\mathrm{D}$ and by $19.6 \%$ for DE (N.S). DaiIy physical activity, which was determined during 5 days using an actometer, was increased after 4 and 12 wceks for DE $(27 \%$; 10.05 and D $10 \%$ N S.

The suggestion that a reduction in normal dailly life activitics in a diet-exercise group is the explanation for the absence of significant differences in weight and fat loss betwecn a diciexcrcise and a dict group is not confimed in this study. Daily physical activity showed a significantly higher increase for the dief-exercise group than for the diet group, while the decline of RMR and 24-EE iended to be smaller. 
compensate the energy expenditure of the extra physical training, resulting in a similar energy expenditure and activity level for the diet-exercise and the diet group. With similar values for energy expenditure and activity level no differences in weight and fat loss can be expected. In a previous study (van Dale et al., 1987) comparing a diet and diet-exercise treatment we found no differences between the treatments in the changes in body composition and resting metabolic rate. Using the data of the afore mentioned study, the aim of the present study was to compare the changes in 24-EE, RMR and daily physical activity during twelve weeks of diet or dietexercise treatment.

\section{Methods}

\section{Subjects}

Twelve healthy female subjects, aged 20-45 years, were matched on the basis of their BMI (mean 30.3) and admitted to a Diet (D) or a Diet-Exercise group (DE). Descriptive data of the subjects are shown in Table 1. They were fully informed about the nature of the investigation and gave their informed consent.

\section{Procedure}

The study period lasted 12 weeks. Measurements of body composition, RMR, 24-EE and daily activities were made before the start of the study, after 4 weeks (week 5) and after 12 weeks (week 13). An outline of the study design is given in Fig. 1.

\section{Diet}

For the first 4 weeks the diet consisted of a low energy formula diet (2.9 MJ/day; Meritene $(1)$, Sandoz, Switzerland). During the next 8 weeks the diet was a combination of the low energy formula diet (1.7 MJ/day) and normal food (1.8 $\mathrm{MJ} /$ day), resulting in an intake over the last 8 weeks of $3.5 \mathrm{MJ} /$ day. A detailed description of the content of the diet is given in Van Dale et al. (1987).

Table 1 Descriptive data of the experimental subjects

\begin{tabular}{lcccc}
\hline \multirow{2}{*}{ Variables } & \multicolumn{3}{c}{ Diet group $(\mathrm{N}=6)$} & \multicolumn{2}{c}{$\begin{array}{c}\text { Diet-exercise group }(\mathrm{N}=6) \\
\text { mean }\end{array}$} & SEM & & \\
& & & & \\
\hline Weight $(\mathrm{kg})$ & 87.3 & 2.0 & 81.2 & 4.0 \\
Height $(\mathrm{cm})$ & $170.0^{*}$ & 2.1 & $163.0^{*}$ & 2.4 \\
Body Mass Index $\left(\mathrm{kg} / \mathrm{m}^{2}\right)$ & 30.3 & 1.1 & 30.3 & 0.8 \\
Body fat $(\%)$ & 37.4 & 1.5 & 39.0 & 0.6 \\
Body fat $(\mathrm{kg})$ & 32.9 & 1.8 & 31.7 & 1.7 \\
\hline
\end{tabular}

- $P<0.05$ D vs DE 
Group: 12 temales

Study period (weeks)

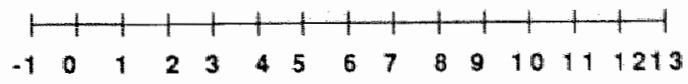

DIET ( $N=6)$

DIET +

EXERC\|SE $(\mathbf{N}=6)$

$\frac{2.9 \mathrm{~mJ} / \mathrm{d} \mid}{\mid 2 \mathrm{~h} / \mathrm{W} \text { aerobic training and } 2 \mathrm{~m} / \mathrm{w} \text { fitness }}$

Measurements

12-EE resp/RMA

24-EE $E_{h r}$

Densitometry

$\mathrm{VO}_{2} \max$

Daily physical

activity

training at $55 \%$ of $\mathrm{VO}_{2}$ max

Fig. I Design of the sindy.

\section{Exercise}

The training was performed four times per week at a professional fitness centre and consisted of two $h$ aerobic training and two h of weight resistance training combined with 20 min aerobic dancing per week. On the basis of heart rate measurements the intensity of the training was calculated to be $55 \%$ of the $\mathrm{VO}_{2}$ max. All trainings were under guidance of a professional trainer and attendance of the subjects was monitored.

\section{Body composition}

Body composition was estimated by means of hydrostatic weighing. At the moment of underwater weighing the residual lung volume was measured using the helium dilution method. The average of 6 trials was used as the true body weight under water. The percentage of body fat was calculated from body density by the method of Siri (1956).

\section{RMR}

For the measurement of RMR each subject stayed for $12 \mathrm{~h}(20.00-08.00)$ in a computerized open-curcuit indirect calorimeter $\left(14 \mathrm{~m}^{3}\right)$, equipped with a bed, toillet, television set and chair. The volume of air drawn through the chambers was measured by a dry gasmeter (Dort, The Netherlands) and continuously analysed by a paramagnetic $\mathrm{O}_{2}$-analyser (Servomex Taylor, England) and an infrared $\mathrm{CO}_{2}$-analyser (Hartmann and Braun, West Germany). From the air flow rate, and the $\mathrm{O}_{2}$ and $\mathrm{CO}_{2}$ - 
concentration of the in-and outflowing air $\mathrm{VO}_{2}$ and $\mathrm{VCO}_{2}$ were computed on line through an automatic acquisition system interfaced with an Apple 2E computer (Schoffelen et al., 1985). RMR was callculated during the period of sleeping from 03.00-06.00 h a.m; t the metabolic rate during the $12 \mathrm{~h}$ stay in the respiration chamber was also determined (12-EE resp). Metabolic rate determined during sleeping is demonstrated to be about $5 \%$ lower as RMR and is usually called sleeping metabolic rate (Goldberg et al., 1988a). Although aciually sleeping metabolic rate is determined, for reasons of convenience, in the present study the term RMR is used.

\section{Maximal aerobic power}

Maximal aerobic power was measured using an incremental exercise test on an electrically braked bicycle ergometer (Lode, The Netherlands). After an initial period of 4 min of cycling at $0 \mathrm{~W}, 4$ $\min$ at $40 \mathrm{~W}$ and 4 min at $80 \mathrm{~W}$, the workload was increased by 20 W/min until the subjects were exhausted. Criteria for maximal exercise were: levelling off of oxygen uplake, forced ventilation, and a Rvalue higher than 1.1. The highest $\mathrm{VO}_{2}$ achieved on the test was taken as $\mathrm{VO}_{2}$ max. During the test, ventilatory and gas exchange responses were measured continuously, using a computerized open system (Ergoscreen, Switzerland).

\section{4-h Energy \\ Expenditure(24-EE)}

For the estimation of 24-EE, the heart rate was recorded continuously for $24 \mathrm{~h}$ using a heart rate memory system (24-EE hoven). Heart rate (Hr) was measured before the study, after 4 weeks (in the beginning of week 5), and after 12 weeks (week 13), when the subjects were still exercising and/or dieting. The recordings took place on a day without physical training, because of practical problems like showering after exercise. The heart rate memory system was worn in a side pocket attached to a belt around the waist. Two electrodes were attached to the thorax, one at the manubrium sterni and the other at the ictus cordis. Heart rate was recorded and stored in the memory system. Using a read-out unit, the mean heart rate and actual time spent in the various heart rate registers were read and analyzed by computer. Detailed description of the HRM system is given by Saris (1982). Using heart rate as an indicator of physical activity, it is necessary to establish individual calibration curves because of interindividual differences between heart rate and oxygen uptake. Various standard activities were used for calibration : lying, sitting, and walking on a treadmill $(3 \mathrm{~km} / \mathrm{h}, 4.5 \mathrm{~km} / \mathrm{h}$ and $4.5 \mathrm{~km} / \mathrm{h}$ with a $10 \%$ slope). Furthermore the bicycle ergometer was used with 3 work loads: 4 min with no workload, $4 \mathrm{~min}$ at $40 \mathrm{~W}$ and $4 \mathrm{~min}$ at $80 \mathrm{~W}$. Measurements were carried out after $5-10 \mathrm{~min}$ rest. During the calibration measurements, expiratory gases were collected in Douglas bags. Gas volumes were measured with a dry gasmeter (Dort, The Netherlands). Gas samples were analysed for $\mathrm{O}_{2}$ and $\mathrm{CO}_{2}$ content with a computerized open system (Ergoscreen, Switserland). The ergoscreen was calibrated before each test using room air and calibration gas. Heart rate was continuously recorded during the standard ac- 
tivities by using a conventional electro-cardiogram apparatus. In addition to these calibration points, mean oxygen consumption and heart rate during the sleeping period from 03.00-06.00 a.m. were used.

Since the linear relationship between heart rate and exercise is less clear in the lower ranges than in the higher ranges, two regression equations were calculated: one for the activities lying, sitting and standing and one for the activities walking and cycling. It was necessary to determine a critical heart rate, above which the regression equation of dyramic activities such as walking and cycling was used to calculate
$\mathrm{VO}_{2}$, and below which the regression equation for the resting activities was used. The cut-off point was determined by calculating the average value between the highest heart rate at rest and the lowest heart rate during cycling or walking. For each individual, heart rate and oxygen uptake during calibration activities were plotted, and two linear regression equations

$\mathrm{VO}_{2}=\mathrm{a}+\mathrm{bHr}$ were calculated. An example is given in Fig 2. It was then possible to substitute the mean heart rate over $24 \mathrm{~h}$ in the regression line and to calculate energy expenditure. The amount of energy expended per minute was calculated

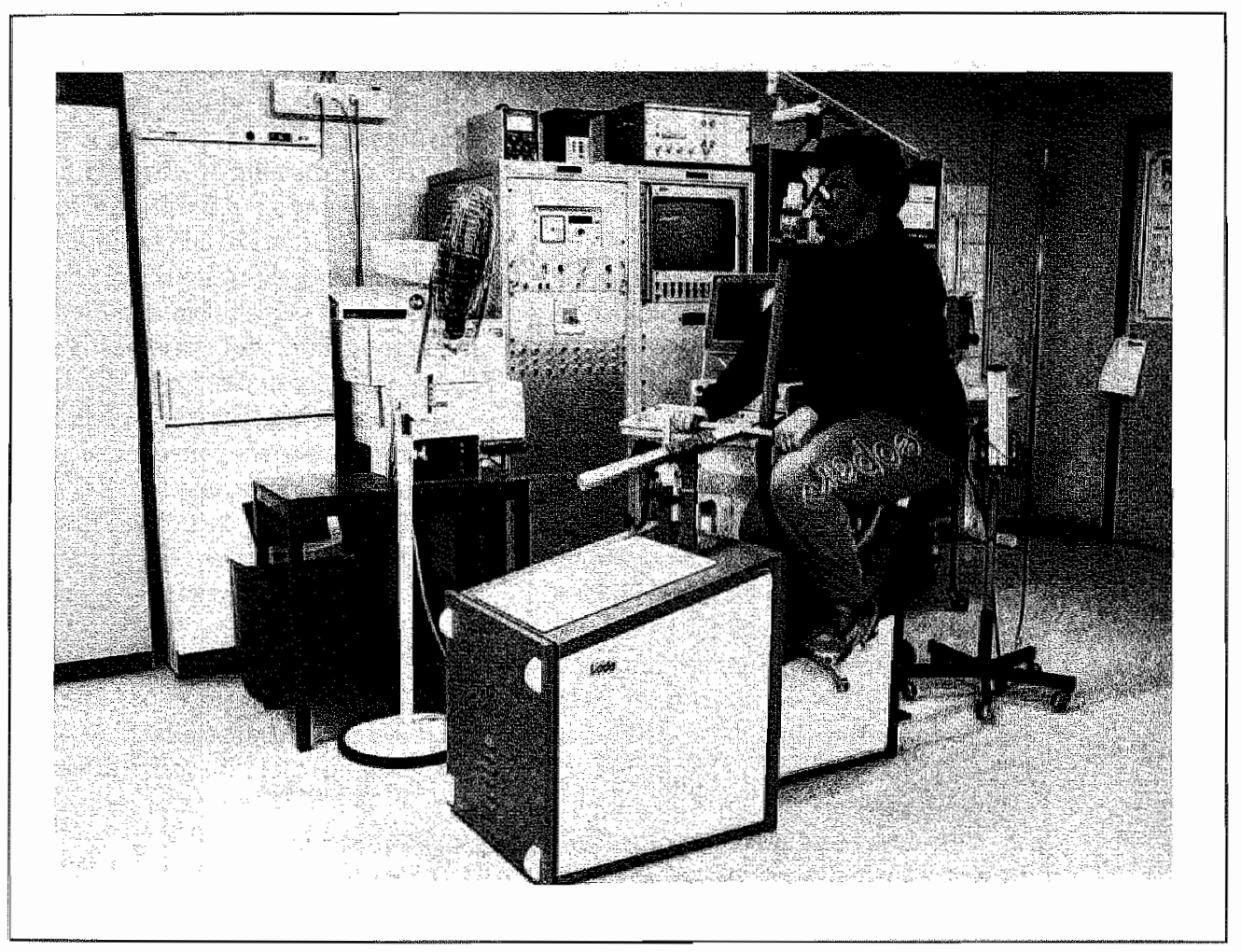

Maximal aerobic power was measured using an incremental exercise test on an electrically braked bicycle ergomerer. 

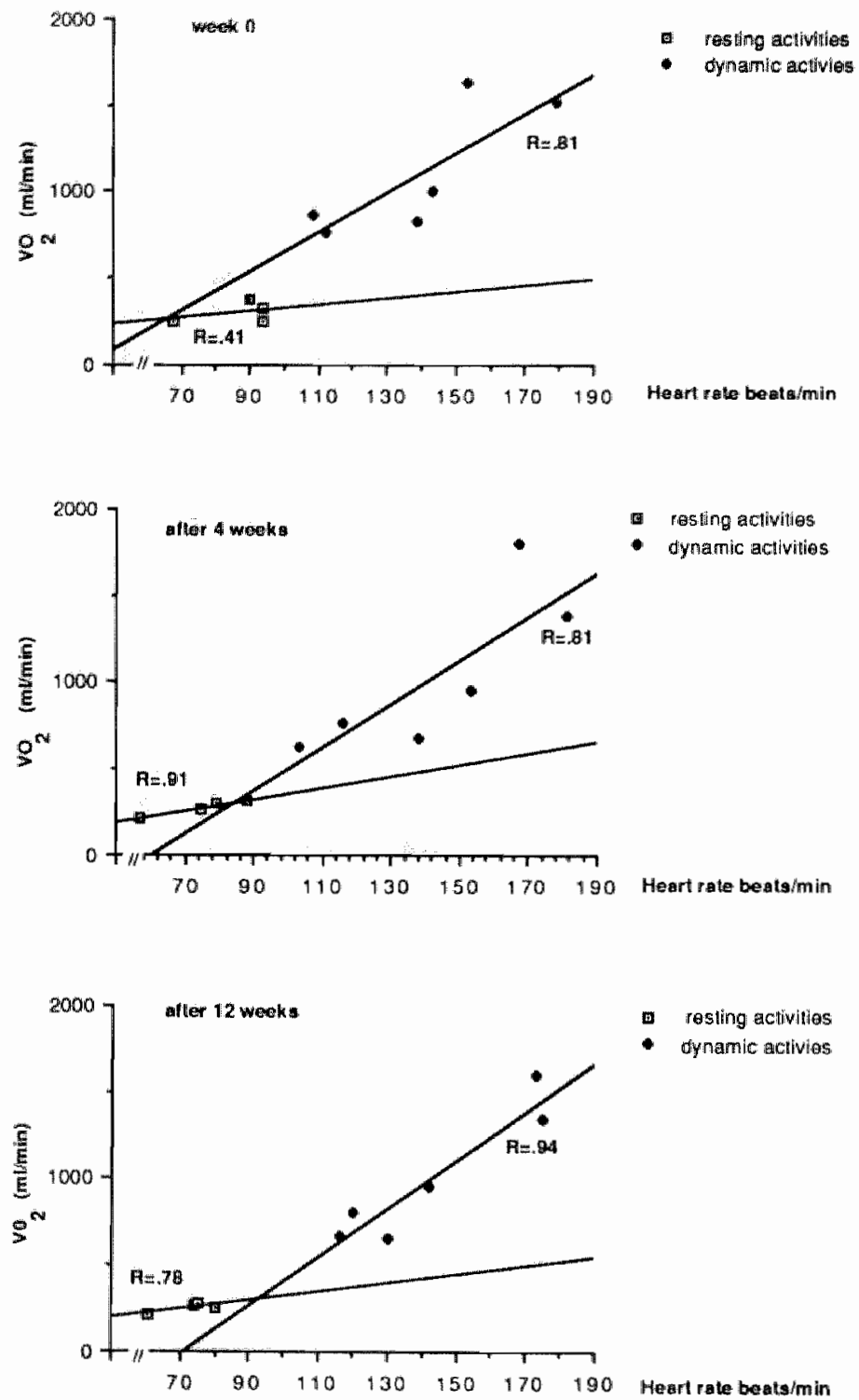

Fig. 2 Calibration curves of one subject assessed as the start of the study, after 4 weeks and after 12 weeks of a diet-exercise treatment.

Two calibration curves were calculated: one dwring resting activities such as lying, sitting, and standing, and one during dynamic activities such as walking and cycling. 
using the formula proposed by Consolazio (1971a), with a conversion factor of 4.92, as used by Passmore et al. (1952). To calculate energy expenditure for the dynamic activities (walking and cycling) over $24 \mathrm{~h}$, the $30 \%$ level of $\mathrm{VO}_{2} \max$ was taken as a minimal level. The heart rate recordings above this level were used in the regression equation to calculate the active 24-EE.

\section{Daily physical activities}

For the measurement of daily physical activity over a longer period a movement counter was used (actometer). The actometer is a selfwinding wrist watch from which the escape mechanism has been removed, so that the rotor is directly connected to the hands of the watch. The results can be read in days and hours (actometer units). The instrument records acceleration and deceleration with a component in the same plane as the face of the watch. In effect, it records not only the movement but also the intensity. The rotor turns more often as the intensity of the movement increases. A detailed description of this apparatus is given by Saris \& Binkhorst (1977a). The actometer was worn on the left ankle for 5 consecutive days, including 2 days of training, and during a weekend.

\section{Statistics}

Results are expressed as means \pm SEM. Statistical differences between the diet and the diet-exercise groups were assessed using Student's t-test for unpaired means. Within-group comparisons were calculated using Student's t test for paired means.

\section{Results}

As shown in Table 2, no significant differences in weight loss, fat loss or loss of fat free mass between the diet and the diet-exercise group were observed. Similarly, exercise did not have a preventive effect on the decrease in RMR due to energy restriction, although the diet-exercise group tended to have a smaller decline in RMR after 12 weeks. An important and determining factor in the appearance of differences in weight and fat loss between diet and diet-exercise groups is the intensity or frequency of the exercise. In order to evaluate the influence of frequency and intensity of the exercise on aerobic capacity, $\mathrm{VO}_{2}$ max was measured. After 4 weeks the diet-exercise group showed a significantly improved aerobic capacity $(\mathrm{P}<0.05)$, whereas the diet group showed a tendency to decrease its aerobic capacity. After 12 weeks the diet group had adapted to energy restriction and returned to base line levels, whereas the diet-exercise group remained on the improved aerobic capacity level attained in the fifth week.

The total daily energy expenditure, based on the $24 \mathrm{~h}$ heart rate recordings (24-EE $\mathrm{Er}_{\mathrm{hr}}$ ), varied considerably between the subjects (range 7.0-14.6 MJ). At the start, 24-EE same for the diet and the diet-exercise groups (11.2 and 10.8 MJ) (Table 3). Similarly, no significant differences were observed in the changes in $24-E_{\mathrm{hr}}$ after a period of exercise and/or dieting. Twenty-four hour energy expenditure in the diet group decreased 19.2 and $22.1 \%$ after 4 and 12 weeks respectively, 


\section{Diet and Daily Physical Activities}

Table 2 Weight and fat loss, RMR and $\mathrm{VO}_{2}$ max at week 0 , after 4 weeks and after 12 weeks (miean \pm SEM)

\begin{tabular}{|c|c|c|c|c|}
\hline & $\begin{array}{l}\text { Weight } \\
\text { loss (kg) }\end{array}$ & $\begin{array}{l}\text { Fat } \\
\text { loss }(\mathrm{kgg})\end{array}$ & $\begin{array}{l}\text { RMR } \\
\mathrm{kJ} / \mathrm{kgFFM} / \mathrm{h}\end{array}$ & $\begin{array}{l}\mathrm{VO}_{2} \max \\
\mathrm{m} / \mathrm{kgBw} / \mathrm{min}\end{array}$ \\
\hline $\begin{array}{l}\text { Week o } \\
D \\
D E\end{array}$ & & & $\begin{array}{l}5.6 \pm 0.2 \\
5.6 \pm 0.2\end{array}$ & $\begin{array}{l}28.3 \pm 3.6 \\
31.3 \pm 1.9\end{array}$ \\
\hline $\begin{array}{l}\text { Afier 4 weeks } \\
\text { D } \\
\text { DE }\end{array}$ & $\begin{array}{l}7.9 \pm 0.9 \\
8.2 \pm 0.7\end{array}$ & $\begin{array}{l}6.0 \pm 0.8 \\
6.7 \pm 0.6\end{array}$ & $\begin{array}{l}4.5 \pm 0.4^{* *} \\
4.9 \pm 0.3\end{array}$ & $\begin{array}{l}24.6 \pm 2.1 \\
34.2 \pm 2.2\end{array}$ \\
\hline $\begin{array}{l}\text { Alter } 12 \text { weoks } \\
\text { D } \\
\text { DE }\end{array}$ & $\begin{array}{l}12.2 \pm 1.9 \\
13.2 \pm 0.6\end{array}$ & $\begin{array}{r}9.4 \pm 1.4 \\
10.9 \pm 0.6\end{array}$ & $\begin{array}{l}4.1 \pm 0.3^{* *} \\
4.5 \pm 0.3^{* \prime \prime}\end{array}$ & $\begin{array}{l}28.5 \pm 2.0^{1} \\
36.0 \pm 2.7^{\circ}\end{array}$ \\
\hline
\end{tabular}

$\mathrm{D}=$ diet group. $\mathrm{DE}=$ diet-exercise group.

RMF $=$ resting metabolic ratte

"P<0.05/ $\cdot P<0.01$ within D or DE vs. start: ${ }^{1} P<0.01$ between D and DE

Table $324-E E_{\text {hru }}$ 12-EE, and RMR at week 0 , afier 4 weeks and after 12 weeks for $D$ and $D E$ (mean $\pm S E M$ )

\begin{tabular}{|c|c|c|c|c|c|c|}
\hline & & woek 0 & 4 weeks & 12 weeks & $\begin{array}{l}\text { \% change } \\
0-4 \text { weeks }\end{array}$ & $\begin{array}{l}\text { \%change } \\
0-12 \text { weeks }\end{array}$ \\
\hline $24-E E_{h r}$ & $D$ & $11.2 \pm 0.5$ & $9.0 \pm 0.7$ & $8.5 \pm 11,0$ & $\left(9.2 \pm 4.2^{* 11}\right.$ & $22.1 \pm 6.3^{* 4}$ \\
\hline (M) & DE & $10.8 \pm 0.3$ & $9.1 \pm 0.7$ & $9.0 \pm 0.6$ & $16.6 \pm 6.6^{\circ}$ & $19.6 \pm 2.5^{\circ}$ \\
\hline 24-EE & $\mathrm{D}$ & $205 \pm 12.3$ & $171 \pm 9.5$ & $164 \pm 13.2$ & $16.3 \pm 4.2^{* *}$ & $20.3 \pm 5.3^{* *}$ \\
\hline$(\mathrm{k} / / \mathrm{kgFFM})$ & DE & $227+8.3$ & $191 \pm 7.1$ & $190 \pm 4.7$ & $15.3 \pm 7 . \theta^{*}$ & $17.3 .17 .1^{\circ}$ \\
\hline 12-Eresp. & D & $4.6 \pm 0.2$ & $3.2+0.3$ & $2.9 \pm 0.3$ & $28.6 \pm 3.8^{* *}$ & $\left.36.4 \pm 5.6^{\circ}+1\right)$ \\
\hline (M) & $D E$ & $4.1 \pm 0.3$ & $3.4 \pm 0.3$ & $3.1 \pm 0.2$ & $15.1 \pm 6.8^{\mathrm{m}}$ & $21.7 \pm 4.8^{*}$ \\
\hline 12-EErosp. & $\mathrm{D}$ & $84.5 \pm 2.5$ & $61 \pm 4,3$ & $56.5 \pm 5.3$ & $28.2 \pm 4.4^{\circ}$ & $33.1 \pm 5.7^{*}$ \\
\hline$(\mathrm{kJ} / \mathrm{kg} \mathrm{FFM})$ & $\mathrm{DE}$ & $83.5 \pm 4.2$ & $72 \pm 3.9$ & $65.5 \pm 2.9$ & $12.1 \pm 6.2^{*}$ & $20.4 \pm 5.6^{\circ}$ \\
\hline RMA (24 h) & $\mathbb{D}$ & $7.3 \pm 0.3$ & $5.5 \pm 0.5$ & $5.2 \pm 0.6$ & $24.1 \pm 4.8^{\prime \prime}$ & $29.9 \pm 6.4$ \\
\hline (M) & DE & $6.7 \pm 0.4$ & $5.4 \pm 0.5$ & $5.2 \pm 0.3$ & $13.9 \pm 6.8^{\circ}$ & $24.7 \pm 5.0^{\circ}$ \\
\hline $\begin{array}{l}24-E E_{i h r} \\
12-E E_{\text {resp }} \\
\text { 1) }\end{array}$ & $\begin{array}{l}\text {-Twenty-to } \\
\text { Energy ex } \\
P<0.05 \text {;" } \\
P<0.05 D\end{array}$ & $\begin{array}{l}<0.01 \text { paired } \\
D E\end{array}$ & $\begin{array}{l}\text { didure, dete } \\
\text { d during } 12 \\
\text { ruations with }\end{array}$ & $\begin{array}{l}\text { hed by heart fa } \\
\text { the respiratio } \\
\text { spect to week }\end{array}$ & $\begin{array}{l}\text { onitloring during } \\
\text { amber }(20.00-08\end{array}$ & $h\left(24-E E_{h r}\right)$ \\
\hline
\end{tabular}


while that in the diet-exercise group decreased 16.6 and $29.6 \%$ respective1y. Standardized for FFM, 24-EE was still reduced for both groups and there were no significant differences between the diet and the diet-exercise groups (D 16.3 and 20.3\%; DE 15.3 and $17.3 \%$ ).

Energy expenditure during the entire night (12-EE $\left.E_{\text {resp }}\right)$, measured during the 12 hour stay in the respiration chamber, showed a large decrease for the diet group (28.6 and $36.4 \%$ after 4 and 12 weeks respectively). For the diet-exercise group the decline of metabolic rate during the night was significantly smaller after 4 and 12 weeks compared to the diet group (15.1 and $21.7 \%$ respectively; $\mathrm{P}<0.05$ ).

Similar decreases were found for RMR, which dropped by 24.1 and $29.9 \%$ after 4 and 12 weeks respeclively for the diet group, whereas the diet-exercise group tended to show a smaller decline (13.9 and $21.7 \%$ after 4 and 12 weeks respectively). In Fig. 3 the energy expenditure above the $30 \% \mathrm{VO}_{2} \max$ level is shown as a measure for the dynamic activities such as walking and cy. cling. Fig. 3 shows that at the start of the study the groups were not significantly different in their dymamic activities. After 4 weeks on a restricted diet the diet group had not changed, whereas the diet-exercise group tended to increase their activities. The increase was not significant, probably because of the large variation between the individuals. At the end of the study a slight increase was also observed for the diet group.

The actometer was used to measure daily physical activities over a longer period, including days of physical training. Adding exercise resulted in a significant increase of $32 \%$ for $\mathrm{DE}$ after 4 weeks $(P<0.05)$ (Fig. 4$)$.

After 12 weeks the activities still. showed an increase or remained increased with $27 \%(\mathrm{P}<0.05)$. For $\mathrm{D}$ no significant increase in activities was observed after 4 and 12 weeks (an increase of 7.5 and $10 \%$ respectively).

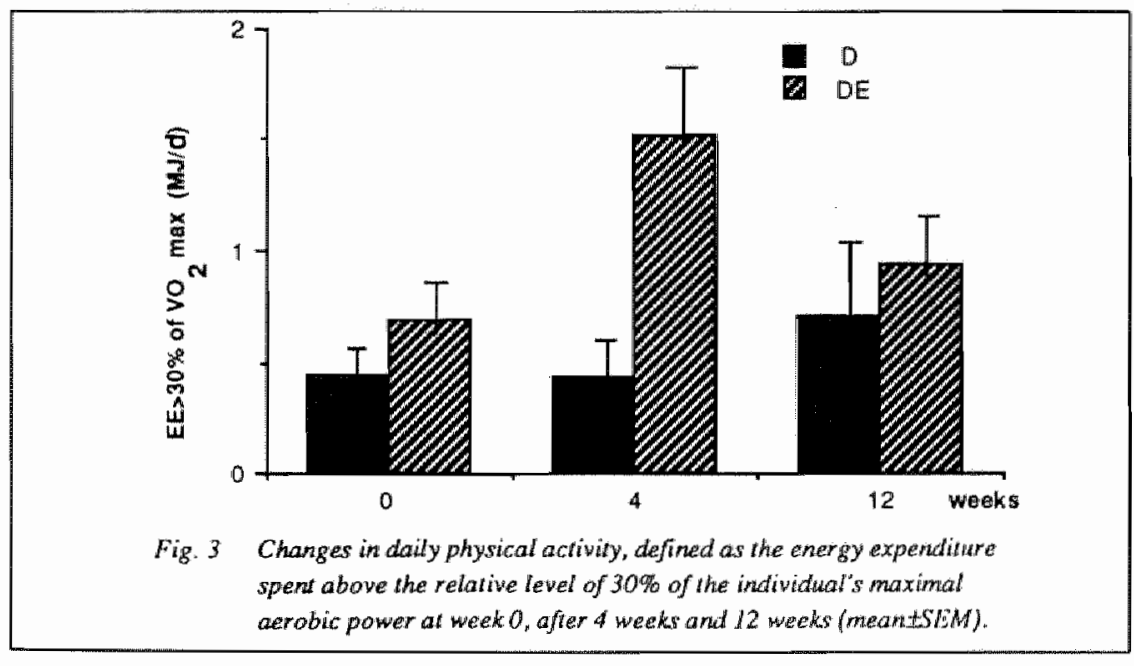




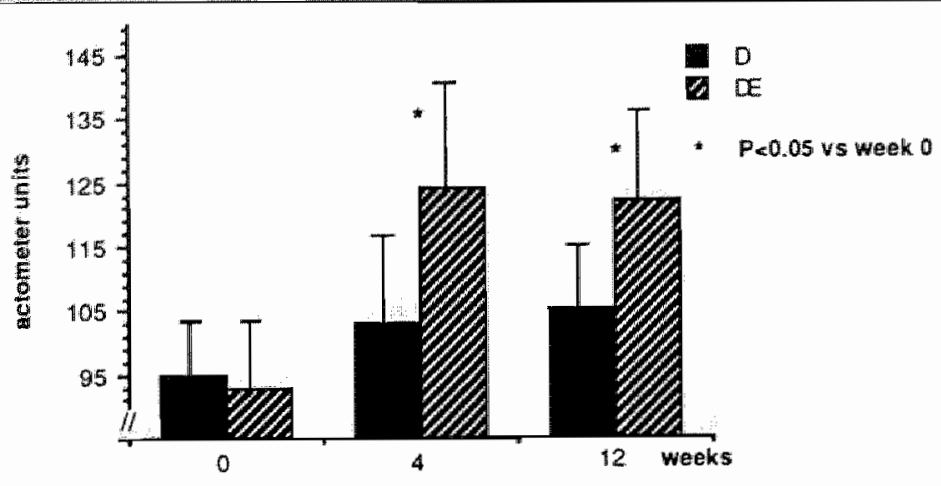

Fig. 4 Changes in daily physical activity measured with the actometer during 5 consecutive days, including exercise days, and during a weekend, at week $0_{n}$ after 4 and after 12 weeks (meantSEM).

\section{Discussion}

\section{Heart rate monitoring and actometer: (dis)advantages}

In the present study total daily energy expenditure during an exercise and/or weight reduction treatment was assessed using a combination of the heart rate method and actometer measurements, logether with the determination of energy expenditure by indirect calorimetry. Recently, the combination of heart rate recordings and actometer measurements has been shown to yield a satisfactory estimation of energy expenditure in free living conditions (Avons et al., 1988). Similarly also the heart rate method, which had been validated against indirect calorimetry, has been reported to estimate closely total daily energy expenditure (Spurr et al., 1988). However, both the heart rate method and the actometer have their drawbacks (Christensen et al., 1983;
Geissler et al., 1986). Many psychological and physiological factors may affect heart rate, especially at low levels of activity, without appreciably affecting EE. This may result in an overestimation of 3 to $26 \%$ (Dauncy \& James, 1979). However, at higher oxygen comsumption levels the prediction from heart rate recordings is more accurate (Spurr et all., 1988) and less affected by non-physical constraints like emotional stress. Therefore, in the present study the change in physical activity was analysed separately to adjust for possible psychological influences on heart rate. Of special interest were activities like walking, running or cycling. These so-called dynamic activities have an expenditure level above $30 \%$ of the individual $\mathrm{VO}_{2}$ $\max (\AA ̊ s s t r a n d ~ \& ~ R o d a h l, 1977)$. In the present study physical activity was defined as the energy expenditure above the $30 \%$ level of the individual $\mathrm{VO}_{2} \max$. The actometer enables us to measure for severall days, which reflects more accurately the actual activity level than only one 
day of measurements. The actometer recorded acceleration of the movements of the leg. It has been suggested (Saris \& Binkhorst, 1977b) that differences in physical activity are mainly due to differences in the levels of activity of the lower extremities, i.e. walking and running. Furthermore, a large intra-instrumentall variation has found (Saris \& Binkhorst, $1977 \mathrm{a}, \mathrm{b})$. To adjust for this variation, each subject consistently wore the same actometer and only the changes in actometer units were used for analysis.

\section{4-EE/12-EE and RMR}

With the methods used in this study, no indications of a compensation for the extra physical trainung in normal daily life activities were detected. 24$E E$, measured with the heart rate method (24-EEhr), showed decreases after 4 and 12 weeks of exercise and/or diet. No significant changes were detected between the $\mathrm{D}$ and $\mathrm{DE}$ groups, although the DE group tended to maintain their level of EE after 4 weeks, whereas for the D group a further decrease was observed (N.S.). Other studies using similar energy intakes and showing similar weight losses, demonstrated the same decreases in 24-EE (Bessard et al., 1983; Ravussin et al., 1985c; De Boer et al., 1986), while smaller energy deficits resulting in less weight loss did not have an effect on 24-EE (Warnold et al., 1978).

Furthermore the decline of 24-EEhr was found to be smaller than the

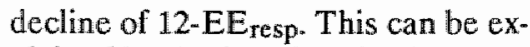
plained by the fact that the determination of 12-EE $E_{\text {resp }}$ is for the most part based on measurements during the night. As a result of their weight loss, subjects are probably more ac- tive during the day, because of their improved mobility due to weight loss. Although 24-h energy expenditure decreased as result of the decrease in RMR, the increase in activities could have contributed to a smaller decline in 24-h EE than in 12-EE or RMR.

Like the total energy expenditure, $R M R$ also decreased as a result of body weight loss and fat loss. After standardization for differences in fat free mass both RMR and 24-EE still remained decreased compared to baseline values. This finding is in contrast with the results of $R$ avussin et al. (1985), who found no decrease in RMR after adjusting for differences in fat free mass; the loss of fat free mass completely accounted for the decline in RMR. Our results were in accordance with the results of Hill et al.,1987; De Boer et al, 1986; De Groot, 1988, who also observed a greater decrease in RMR than could be explained by the loss of fat free mass. Adaptations in hormones and the sympathetic nervous system might play an important role in the decrease of RMR (Jung et al, 1980). Recently, it has been demonstrated that $\mathrm{NA}^{+}-\mathrm{K}^{+}$ATPase activity is decreased during dieting. Since this activity is controlled by the sympathetic nervous system, it may be concluded that during dieting sympathetic nervous system activity is also decreased (Pasquali et al., 1988).

Adding exercise to dieting did not result in a prevention of the decrease in RMR for DE, although smaller decreases were obserwed for DE. Up to now only a few investigators (Donahoe et al, 1984; Lennon et al., 1985) have confirmed the study of Schultz et al. (1980), which reported a significant increase in 
RMR after the addition of exercise to energy restriction. Other studies did not demonstrate preventive effects of exercise (Krotkiewski et al., 1981; Henson et all., 1987; Hill et al, 1987b). The degree of energy restriction might play an important role, leading to a less favourable effect of exercise on RMR when food intake is severely restricted.

\section{Consequences of the lower body weight at start}

With respect to differences in $24-\mathrm{EE}$ and weight loss, one important remark has to be made. In this study selection of the subjects for both groups was based on BMI. At the start of the study it turned out that, although the percentage body of fat was the same for both groups, the diet group weighed $6.1 \mathrm{~kg}$ more than the diet-exercise group. This higher body weight was reflected in a higher energy expenditure at the start. Since the same diet was provided for both groups during the study, the energy deficit, calculated from energy intake and $24 \mathrm{~h}$ RMR, was larger in the diet group than in the diet-exercise group (total energy deficit over 12 weeks for D: 509.6 $\mathrm{MJ}$; for DE: $506.6 \mathrm{MJ}$ ). On the other hand the diet-exercise group was involved in a training program for $4 \mathrm{~h}$ per week. Assuming that the activity level in the diet group was about $15 \% \mathrm{VO}_{2} \max$ compared to the measured $55 \% \mathrm{VO}_{2}$ max in the dietexercise group, an extra energy deficit of $4 \mathrm{MJ}$ per week or $48 \mathrm{MJ}$ due to the extra physical activity over the entire 12 weeks can be calculated for the DE group. Although these calculations are partly based on theoretical considerations, the difference in energy expenditure deficit between the two groups, which amounted to be about $40 \mathrm{MJ}$ in favour of the DE group, supports the idea, based on the heart rate recordings that no compensation in daily activities occurred in the $\mathrm{DE}$ group.

In addition, the body composition changes in the two groups and an estimated energy value for adipose tissue and fat free mass of $32 \mathrm{MJ}$ and 4 MJ respectively, allows the calculation of an extra energy release of about $45 \mathrm{MJ}$ in the DE group over the entire period. This is in accordance with the theoretical calculations.

When body weight was about $6 \mathrm{~kg}$ more for the diet-exercise group energy expenditure might have been higher (1 kg weight gain raises $\mathbb{R M R}$ $50 \mathrm{~kJ} / \mathrm{d}$ (Ravussin et al., 1982)), which is an increase of $300 \mathrm{~kJ} / \mathrm{d}$ for 6 $\mathrm{kg}$ ). In 12 weeks this $300 \mathrm{~kJ} / \mathrm{d}$ extra could result in $21600 \mathrm{~kJ}$ extra energy expenditure for the diet-exercise group, assuming that the adaptation to the diet is the same for both groups. This $21600 \mathrm{~kJ}$ is equivalent with about $0.73 \mathrm{~kg}$ adipose tissue. The difference between the groups could have been $0.73 \mathrm{~kg}$ in favour of the diet-exercise group.

Moreover the purpose of this study was to find out if there was compensation in activities for the diet-exercise group. The $6 \mathrm{~kg}$ lower body weight was not crucial for the possible compensation in activities. This compensation due to the extra energy expenditure during training could appear even though their body weight was $6 \mathrm{~kg}$ lower. A theoretical compensation in daily activities leading to a reduction of $5 \%$ yields a surplus of energy of $42 \mathrm{MJ}$. In such a situation no difference in body weight loss is to be expected between the D and DE groups. Since 
there was an observed difference of about $40 \mathrm{MJ}$, based on the calculation of body composition, one can deduce from these theoretical considerations, together with the data obtained, that there is no compensation in daily activity for the diet-exercise group.

\section{Daily physical activity and the actometer}

It may be objected that the measure. ments of daily physical activities on the basis of heart rate recordings were done on a non-exercise day. This excluded the direct measurement of the increase in energy expenditure due to the increase in exercise and a possible compensation in the period directly after the training. It was for that reason that the actometer was used to measure decrease in activity immediately after exercise. Similar values in actometer units for the diet and dietexercise group were expected, in case of a decrease in activities. At the start the values were indeed similar, but during a period of training the values for $\mathrm{DE}$ increased significantly, while those for $D$ increased only slightly. Should compensation only occur in quiet activities like silting, then our conclusion that there is no compensation becomes doubtful, because the actometer cannot measure such changes (e.g. in the way of sitting). On the other hand, if that is the case such decreases will not lead to important changes in total EE and daily physical activity. After all, the decrease in quit activities such as sitting cannot counterbalance the increase in activity due to the added exercise. Changes in activities like walking and cycling between the training sessions are indeed. measured by the actometer and if these activities are carricd out at a lower rate after training, the increase as a result of training should be counterbalanced by the decrease in these activities. However, there was a considerable increase in the diet-exercise group, which contradicts this possibility.

\section{Conclusion}

In summary, the unexpectedly similar weight and fat losses in the diet and diet-exercise groups cannot be attributed to reduced levels of physical activity of DE outside the exercise sessions. Although there was a decrease in 24-EE, this decrease was found in both groups and was due to the decline in RMR and reduced weight bearing activities. Exercise training increased daily physical activity for the diet-exercise group. 



\title{
4. CHANGES IN RESTING METABOLIC \\ RATE AND GLUCOSE-INDUCED \\ THERMOGENESIS DURING A DIET \\ OR DIET-EXERCISE TREATMENT
}

\author{
D. van Dale, E. Beckers, \\ Introduction \\ P.F.M. Schoffelen, F. Ten Hoor, \\ W.H.M. Saris
}

The combination of energy restriction and exercise in the treatment of obesity has been subject of great interest. Several studies have been performed to investigate the effects of this combination on RMR (Donahoe et al., 1984; Henson et al., 1987; Hill et al., 1987b; Nieman et al., 1988). Little attention, however, has been paid to the effects of diet and exercise, compared to diet alone, on Diet-induced Thermogenesis (DIT) or Glucose Induced Thermogenesis (GIT). The effects of energy restriction alone or exercise alone on DIT or GIT have been studied more frequently, but these studies have provided no consistent results. In various studies energy restriction resulted in a small decrease (Bessard et al., 1983; Schutz et al., 1984; Schutz et al., 1987), no change (Belko et al., 1987a) or even in an increase in DIT (den Besten et al., 1988).

Similar conflicting results were found with respect to the effects of physical training. Athletes revealed decreased values of DIT compared to DIT in untrained subjects (Tremblay et al., 1983; Leblanc, 1985; Poehlman et al., 1988). In contrast with these results were the in- 
creased values shown in sedentary subjects after physical training. In these studies DIT was found to increase proportionally to the increase in $\mathrm{VO}_{2} \max$ (Hill et al., 1984;

Tagliaferro et al., 1986).

The few studies investigating the effects of a combined diet and exercise treatment have shown no change in DIT (Belko et al., 1987a), or an increase in GIT (Ravussin et al., 1985a). However, in the latter study subjects revealed insulin resistance, which has been hypothesized as the cause of a blunted GIT (Golay et al., 1982; Golay et al., 1985; Ravussin et al., 1985b). After a diet and exercise treatment insulin sensitivity was improved, also resulting in an in- creased GIT (Ravussin et al. 1985a).

Although the effects of the combination of diet and exercise on RMR have been studied more frequently, no consistent results were obtained. (Krotkiewski et al., 1981; Donahoe et al., 1984; Lennon et al., 1985; Hill et al., 1987b). One important methodological problem in these studies concerns the moment of measuring RMR (Thompson \& Blanton, 1987), as exercise is suggested to have a post-exercise carry-over effect. This carry-over effect has been demonstrated in a number of studies (Bielinski et al., 1985; Maehlum et al., 1986; Thompson \& Blanton, 1987), but results of other studies.

Toble 1 Descriptive dava of the experimental subjects (meantsEM)

\begin{tabular}{|c|c|c|c|c|c|c|c|c|c|}
\hline $\begin{array}{l}\text { Subject } \\
(\mathrm{nr})\end{array}$ & $\begin{array}{l}\text { Age } \\
\text { (v) }\end{array}$ & $\begin{array}{l}\text { Woight } \\
\text { (kg) }\end{array}$ & $\begin{array}{l}\text { Height } \\
\text { (cm) }\end{array}$ & $\begin{array}{c}\text { Body Fat } \\
(\%)\end{array}$ & $\begin{array}{l}\text { Body mass } \\
\text { index }\left(\mathrm{kg} / \mathrm{m}^{2}\right)\end{array}$ & $\begin{array}{l}\text { Fat mass } \\
(\mathrm{kg})\end{array}$ & $\begin{array}{l}\text { Fat free } \\
\text { mass (kg) }\end{array}$ & $\begin{array}{c}\mathrm{WO}_{2} \max w \\
\text { mi/kgBW }\end{array}$ & $\begin{array}{l}\text { waisthip } \\
\text { ratio }\end{array}$ \\
\hline & \multicolumn{9}{|c|}{ Diet group } \\
\hline 5 & 31 & 92.3 & 160 & 46.6 & 33.9 & 43.0 & 49.3 & 23 & 0.82 \\
\hline 6 & 45 & 79.3 & 165 & 33.1 & 29.8 & 26.2 & 53.1 & 29 & 0.83 \\
\hline 7 & 36 & 102.0 & 168 & 45.0 & 35.7 & 45.9 & 56.1 & 25 & 0.90 \\
\hline 8 & 44 & 98.5 & 165 & 44.0 & 36.2 & 43.3 & 55.2 & 19 & 0.75 \\
\hline 11 & 46 & 81.6 & 169 & 40.4 & 31.9 & 33.0 & 48.6 & 24 & 0.81 \\
\hline 12 & 43 & 87.0 & 166 & 41.2 & 31.5 & 35.8 & 51.2 & 20 & 0.87 \\
\hline mean & 40.8 & 90.1 & $165^{*}$ & 41.7 & 33.2 & 37.9 & 52.3 & 23.3 & 0.83 \\
\hline \multirow[t]{2}{*}{ SEM } & 2.4 & 3.7 & 1.3 & 2.0 & 1.0 & 3.1 & 1.3 & 1.5 & 0.02 \\
\hline & & \multicolumn{8}{|c|}{ Diet-Exercise group } \\
\hline 1 & $3 B$ & 102.3 & 170 & 42.1 & 35.4 & 43.1 & 59.2 & 24 & 0.94 \\
\hline 2 & 42 & 85.0 & 161 & 36.1 & 32.8 & 30.7 & 54.3 & 29 & 0.94 \\
\hline 3 & 43 & 92.4 & 164 & 42.2 & 34.4 & 39.0 & 53.4 & 29 & 0.80 \\
\hline 4 & 44 & 83.0 & 155 & 45.9 & 34.6 & 38.1 & 44.9 & 21 & 0.80 \\
\hline 9 & 32 & 69.3 & 152 & 38.1 & 30.0 & 26.4 & 43.2 & 21 & 0.85 \\
\hline 10 & 44 & 75.7 & 150 & 46.5 & 33.6 & 35.2 & 40.5 & 29 & 0.83 \\
\hline mean & 40.5 & 84.6 & $159^{*}$ & 41.8 & 33.5 & 35.3 & 49.2 & 25.5 & 0.86 \\
\hline SEM & 1.9 & 4.8 & 3.1 & 1.7 & 0.8 & 2.5 & 3.0 & 1.6 & 0.03 \\
\hline
\end{tabular}

- P< 0.05 D vs DE 
Freedman-Akabas et al., 1985; Garrow, 1987) did not confirm these findings. However, a post-exercise elevation in metabolic rate cannot be excluded. Recently, Tremblay et al. (1988) showed a carry-over effect of exercise on the metabolic rate of athletes. After a three-day rest period RMR declined compared to the RMR determined on the day after the physical training. It was concluded that exercise may be a confounding factor in the determination of a possible restoration of the diet-induced fall of RMR.

The purpose of the present study was to investigate the effects of intensive exercise plus diet, after a period of dieting only, on GIT, RMR, and on plasma concentrations of tritiodothyronine (T3), glucose, insulin and FFA.

\section{Methods}

Twelve apparently healthy women, aged $30-45$, selected from volunteers on the basis of their body mass index (average BMII $33.3 \mathrm{~kg} / \mathrm{m}^{2}$ ) entered the study: They were given a medical examination to exclude disorders such as hyperlipidemia or thyroid dysfunction. Diet (D) and diet-exercise (DE) groups were formed by matching on the basis of body mass index and percentage of body fat. All subjects showed a stable weight over the previous six months.

Subjects' characteristics are presented in Table 1. The protocol of the experiment was approved by the medical ethics committee of the university of Limburg.

\section{Procedure}

The total study period lasted eight weeks (Fig. 1). In the week preceding the study baseline measurements were performed on body composition, fat distribution, RMR, GIT, $\mathrm{VO}_{2}$ max and blood chemistry. After these measurements all subjects followed a low energy formula diet (3.0 $\mathrm{MJ} /$ day) for a period of four weeks. At the end of these four weeks the assessment of body composition, GIT and RMR was repeated.

During the next four weeks diet
12 obese females

week

\section{Measurements}

Respiration chamber:

-24-h Energy Expenditure

-Resting Metabolic Rate

-Glucose Induced Thermogenesis

Densitometry

Blood chemistry

Fig. I Design of the study.

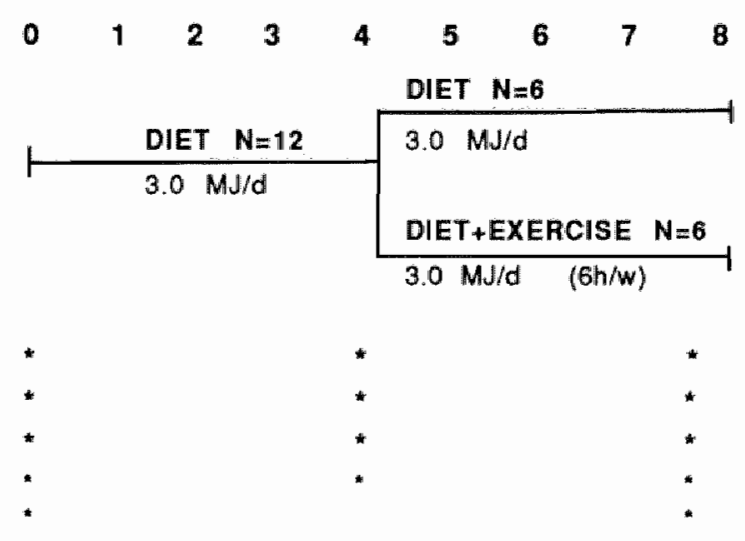


remained the same for all subjects, but for six subjects (diet-exercise group, DE) physical training was added. At the end of the 8-week period all measurements and blood sampling were repeated.

\section{Diet and exercise}

During the study diet consisted of a low energy formula diet of 3.0 MJ/day (Meritene(i), Sandoz, Bern, Switzerland). The exercise which took place in the last four weeks of the study, lasted six $h$ per week. Training consisted of two $h$ aerobic training, two h swimming, one h cycling on a bicycle ergometer and one $h$ weight resistance per week. Intensity was estimated on the basis of heart rate measurements in combination with the results of the $\mathrm{VO}_{2} \max$ test.

\section{Body composition}

Body weight was measured weekly after voiding, with the subjects wearing light underwear. Body fat and fat free mass were estimated by determination of body density, with simultaneous measurement of residual lung volume by the helium dilution technique. Body fat was calculated using Siri's equation (1956).

Fat distribution was determined using the waist-10-hip ratio calculated from maximal waist and maximal hip circumference measured with a metal tape.

\section{Maximal aerobic power}

Maximal oxygen uptake ( $\mathrm{VO}_{2}$ max) was determined by a stepwise increasing bicycle ergometer test until subjective exhaustion, using a computerized open circuit gas analysis system (Ergoscreen, Venyvus and Gut, Switzerland). During this test the highest value of oxygen uptake which could be kept up for $1 \mathrm{~min}$ in combination with an $\mathrm{R}$ value above 1.1 was taken as $\mathrm{VO}_{2}$ max.

\section{Thermogenic measurements.}

For the measurements of RMR and GIT, subjects stayed for $36 \mathrm{~h}$ (from $19.00 \mathrm{~h}$ until $08.00 \mathrm{~h}$ two days later) in a respiration chamber with a computerized open-circuit gas analysis system (Schoffelen et al., 1985).

RMR was determined from 03.00$06.00 \mathrm{a} . \mathrm{m}$. during the night before and the night following the GIT test. In fact, we actually measured sleeping metabolic rate, which has been shown to be about $5 \%$ lower than BMR or RMR (Goldberg et al., 1988a). For reasons of convenience in this study the term RMR is used. The next morning after waking up, the subjects were allowed to void and prepare themselves for a $3.5 \mathrm{~h}$ sit in a chair. During this period the subjects were to read or to watch T.V. Room temperature was kept at $23-24 \mathrm{C}^{\circ}$. After $30 \mathrm{~min}$ of rest in a chair, subjects drank $100 \mathrm{~g}$ glucose in $400 \mathrm{ml}$ water, and gas exchange was measured continuously over the whole period, with levels being recorded at 30 min intervals.

For the rest of this respiration chamber day no specific program was followed. The subjects were free to watch T.V., write or read etc. Food intake was ad libitum during the baseline measurement whereas in week 4 and week 8 only the formula diet was given.

\section{Blood chemistry}

After the second night spent in the respiration chamber the subjects left the room, and the oral glucose test was performed. Alter the introduction of a catheter into the antecubital vein and $30 \mathrm{~min}$ of rest, a baseline 
blood sample was taken. Subsequently $100 \mathrm{~g}$ glucose in $400 \mathrm{ml}$ water was drunk and blood samples were taken over a period of $150 \mathrm{~min}$, at $30 \mathrm{~min}$ intervals.

\section{Analytical procedures}

Plasma glucose was determined by an enzymatic method (GOD-Perid method; Boehringer Manntheim, Germany) and plasma insulin by a radioimmunoassay (Pharmacia Diagnostics AB, Uppsala, Sweden).
FFA was determined with a NEFA $C$ test kit (Boehringer Mannheim, Germany).

\section{Data analysis}

GIT was defined as the mean increase in energy expenditure $(\mathrm{kJ} / 1 / 180$ min) over resting energy expenditure $30 \mathrm{~min}$ before the glucose load.

Similar calculations were performed for insulin, glucose and FFA. Data are expressed as mean \pm SEM. Comparisons between data were made

Table 2 Changes in body composition, RMR and 2A-kE EE afler 4 weeks of dieting and affer 8 weeks of dieting with (DE) or without exercise (D) (meantSEM).

\begin{tabular}{|c|c|c|c|c|c|c|c|c|}
\hline \multirow[b]{2}{*}{ Weight (kg) } & \multirow{2}{*}{ group } & \multicolumn{2}{|c|}{ week 0} & \multicolumn{2}{|c|}{ week 4} & \multicolumn{2}{|c|}{ week 8} & \multirow{2}{*}{$\frac{D v s E^{*}}{\text { N.S. }}$} \\
\hline & & $90.1 \pm$ & 3.7 & $82.1 \pm$ & $3.5^{*}$ & 76.1 & $\pm 3.2^{* 0}$ & \\
\hline & DE & $84.6 \pm$ & 4.8 & $76.4 \pm$ & $4.3^{*}$ & 71.4 & $\pm 3.4^{* *}$ & \\
\hline \multirow[t]{2}{*}{ Fat mass (kg) } & D & $37.9 \pm$ & 3.0 & $31.3 \pm$ & $2.8 * *$ & 27.3 & $\pm 2.5^{* *}$ & N.S. \\
\hline & $\mathrm{DE}$ & $35.4 \pm$ & 2.5 & $29.1 \pm$ & $2.2^{* m}$ & 25.0 & $\pm 1.9^{m *}$ & \\
\hline Fat Free Mass & D & $52.2 \pm$ & 1.3 & $50.8 \pm$ & $1.3^{* *}$ & 46.8 & $\pm 1.1^{* *}$ & N.S. \\
\hline$(\mathrm{kg})$ & $\mathrm{DE}$ & $49.2 \pm$ & 3.0 & $47.3 \pm$ & $2.6^{*}$ & 46.3 & $\pm 2.4^{m *}$ & \\
\hline $24 \mathrm{~h}$-EE & $\mathrm{D}$ & $164.2 \pm 1$ & 11.7 & $153.8 \pm$ & $6.0^{\prime \prime}$ & $\| 41.4$ & $\pm 7.4^{\circ}$ & N.S. \\
\hline (kJ/kgFFM) & DE & $160.0 \pm 1$ & 11.3 & $153.6 \pm$ & $8.4^{\prime \prime}$ & $\| 48.3$ & $\pm 6.2^{\circ}$ & \\
\hline $\operatorname{RMP}^{x}$ & $\mathrm{D}$ & $6.7 \pm$ & 0.4 & $5.9 \pm$ & $0.2^{*}$ & 5.6 & $\pm 0.2^{\circ}$ & N.S. \\
\hline$(\mathrm{MN} / 24 \mathrm{~h})$ & DE & $6.2 \pm$ & 0.2 & $5.4 \pm$ & $0.3^{*}$ & 5.5 & $\pm 0.2 *$ & \\
\hline $\mathrm{RMA}^{1}$ & $\mathrm{D}$ & $130.8 \pm$ & 6.2 & $114.5 \pm$ & $3.4^{\mathrm{m}}$ & 112.6 & $\pm 3.4^{*}$ & N.S. \\
\hline$(\mathrm{k} / \mathrm{kgFFM} / 24 \mathrm{~h})$ & DE & $129.8 \pm$ & 5.3 & $\| 12.6 \pm$ & $4.3^{\mathrm{m}}$ & 116.2 & $\pm 4.9^{*}$ & \\
\hline $\mathrm{RMA}^{2}$ & $\mathrm{D}$ & $128.8 \pm$ & 6.2 & $117.6 \pm$ & $4.33^{\prime \prime}$ & 113.3 & $\pm 4 . *$ & Nis. \\
\hline$(\mathrm{kJ} / \mathrm{kgFFM} / 24 \mathrm{~h})$ & $D E$ & $125.8 \pm$ & 5.3 & $117.2 \pm$ & $5.0^{\mathrm{m}}$ & 118.2 & $\pm 5.7^{\circ}$ & \\
\hline $\mathrm{NO}_{2} \max$ & $D$ & $23.3 \pm$ & 1.5 & $25.3 \pm$ & 1.2 & 240 & \pm 1.0 & $p<0.05$ \\
\hline$(\mathrm{mi} / \mathrm{kgBW} / \mathrm{min})$ & $\mathrm{DE}$ & $25.5 \pm$ & 1.6 & $27.2 \pm$ & 1.8 & 29.2 & \pm 2.1 & \\
\hline $\mathrm{NO}_{2} \max$ & $\mathrm{D}$ & $42.3 \pm$ & 1.9 & $40.6 \pm$ & 2.2 & 38.2 & $\pm 2.7^{H}$ & $P<0.05$ \\
\hline$(\mathrm{m} / \mathrm{kgFFM} / \mathrm{min})$ & DE & $46.7 \pm$ & 2.5 & $44.4 \pm$ & 2.6 & 45.4 & \pm 3.5 & \\
\hline \multicolumn{9}{|c|}{ + D ws DE in weok 8 . After 4 woeks there were no signilicant differences } \\
\hline \multicolumn{9}{|c|}{$x$ mean of two nights: } \\
\hline \multicolumn{9}{|c|}{1 Night belore glucose load: 2 Night after glucose load } \\
\hline \multicolumn{9}{|c|}{ " P<0.05 compared to week $0: "$ "P<0.01 compared lo week 0 . } \\
\hline
\end{tabular}




\section{Glucose-Induced Themagenesis}

Table 3 Baselime wallest and A Increasie over 180 min of EE, and plasma glucose, insulint, FFA and T3 concentrations afier ingestion of 100 is glucose (meantSEM)

group week 0 week 4 week 8 DvsDE

\section{Basseline EE}

(kingin)

\section{$\triangle E E$}

(kj/min)

Percentago

increase in $E^{X}$

Percentage

increase EE as to glucose load"

Fasting glucose (mmol/l)

a glucose* (mmol///150 min)

D

D $\quad 10.1 \pm \quad 4.4$

$5.38 \pm 0.30$

DE

$5.00 \pm 0.19$

D

$0.76 \pm 0.28$

DE

$0.73 \pm 0.19$

D $\quad 18.1 \pm \quad 2.8$

DE

$14.4 \pm \quad 3.4$

DE

$8.4 \pm \quad 2.2$

$\mathrm{D}$

$5.21 \pm 0.17$

DE

$5.88 \pm 0.53$

Fasting insulin

(umol/)

D

DE

$14.3 \pm 1.60$

$12.9 \pm 2.00$

$A$ insulin ${ }^{+}$

(himol// / $150 \mathrm{~min}$ )

D

$75.8 \pm 19.0$

DE

$83,0 \pm 18,0$

Fasting FFA

mequ

$\triangle$ decroaso FFA

meq//150 min)*

Tribodothyronine

T3 (nmol/l)
D $\quad 0.59 \pm 0.04$

DE $\quad 0.71 \pm 0.03$

D $\quad-0.56 \pm 0.07$

DE $\quad-0.31 \pm 0.09$

D $\quad 1.84 \pm 0.05$

DE $\quad 1.60 \pm 0.08$

$\begin{array}{ll}4.71 \pm 0.12^{* *} & 4.47 \pm 0.13^{* *} \quad \text { N.S. } \\ 4.30 \pm 0.20 & 4.38 \pm 0.13\end{array}$

$0.60 \pm 0.12$

$0.61 \pm 0.12$

N.S

$0.54 \pm 0.22$

$0.45 \pm 0.05^{*}$

$13.0 \pm 2.7$

$13.8 \pm 2.5$

N.S.

$12.0 \pm 5.0$

$10.4 \pm 1.2 *$

$7.1 \pm 1.4$

$7.1 \pm 1.4$

$6.2 \pm 2.5$

$5.2 \pm 0.6$

N.S.

$4.77 \pm 0.12^{*} \quad$ N.S.

$4.94 \pm 0.33^{*}$

$2.00 \pm 0.71^{*} \quad$ N.S

$2.70 \pm 0.55$

$5.60 \pm 0.42 *$

N.S.

$5.70 \pm 1.10^{\mathrm{*}}$

$53.0 \pm 11.0^{\circ}$

N.S.

$51.5 \pm 11.0^{*}$

$0.63 \pm 0.04$

N.S.

$0.75 \pm 0.03$

$-0.51 \pm 0.07 \quad$ N.S $\quad P_{1<0}<0.05$

$-0.25 \pm 0.07^{*}$ week o week 8

$1.58 \pm 0.04 \quad$ N.S.

$1.55 \pm 0.11$

Baseline EE: EE over 30 min balore a glucose load

$x$ mean porcentage increase compared to baseline FMA over a period ol $180 \mathrm{~min}$

+ mean increase above baseline values over a period of 150 min

- calculated as the mean uncrease in EE above baseline AMAl energy content of $100 \mathrm{~g}$ glucose (1564 $\mathrm{kJ})$

* P<0.05 compared to week o; " $P<0.01$ compared lo week $O$ 
using Student's t-test. Pearsons' product-moment correlation coefficient was used for a further description of the data.

\section{Results}

For all subjects dietary restriction resulted in similar changes of body weight, fat and fat free mass after four weeks. After eight weeks these changes were still similar for all subjects, despite the addition of exercise for the six subjects of the DE group (Table 2).

Resting metabolic rate, which was determined on two successive nights, revealed no differences between the two nights (Table 2). The within subject variation between the first and the second night in week 0 was $1.8 \%$ for the D group and $4.8 \%$ for the DE group, with a range of $0-9 \%$. In weeks 4 and 8 this was 3.5 and $2.4 \%$ respectively for the D group and 4.1 and $4.3 \%$ for the DE group respec- tively. Because separate analysis yielded no significant differences, the results of both groups were pooled and showed a C.V. of 13.8, 12.1 and $14.1 \%$ at week 0 , week 4 and week 8 respectively.

Four weeks of dieting resulted in a significant reduction in $R M R$, of $12 \%$ for $\mathrm{D}$ and of $13.5 \%$ for DE (mean of two nights). For the RMR per $\mathrm{kg}$ of fat free mass this reduction was 8.5 and $9.7 \%$ for the D and DE groups respectively. Four weeks of intensive exercise was not enough to restore metabolic rate to baseline values in the DE group but resulted in a further decline of RMR for both groups (D 16\%; DE 13\%) However, there was a slight tendency towards an increase lor the DE group (3.5\%) as compared to their data obtained after 4 weeks, whereas the $D$ group showed a trend to decline $(-2.4 \%)$. Twenty-four hour energy expenditure showed similar changes as RMR, which was to be expected, as 65 to $70 \%$ of $24-\mathrm{h} \mathrm{EE}$ is determined by RMR.
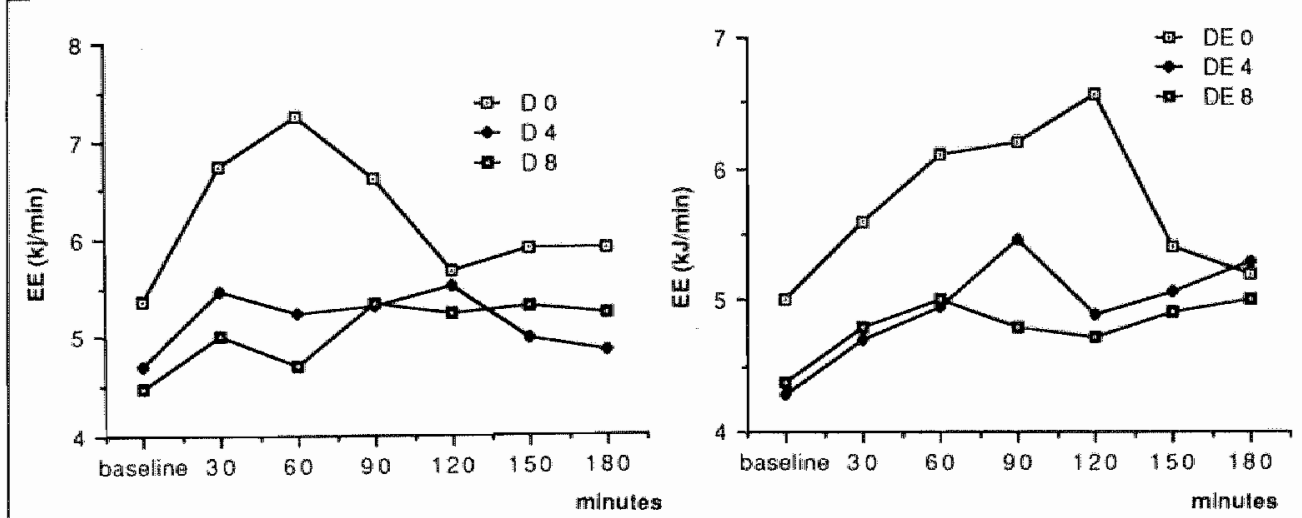

Fig. 2 Time course of EE, ajter a 100 g oral load (ingeshed al baseling) before dieving, afier 4 and 8 weeks of dieting ( $D$ ) and after 8 week of dieting including 4 weeks of exercise $(D E)$. DO, D4, D8; restuls of the dien group at week 0,4 and week 12 .

$D E 0, D E 4, D E 8:$ restuls of the diet-exercise group at week 0,4 and weak 12 . 

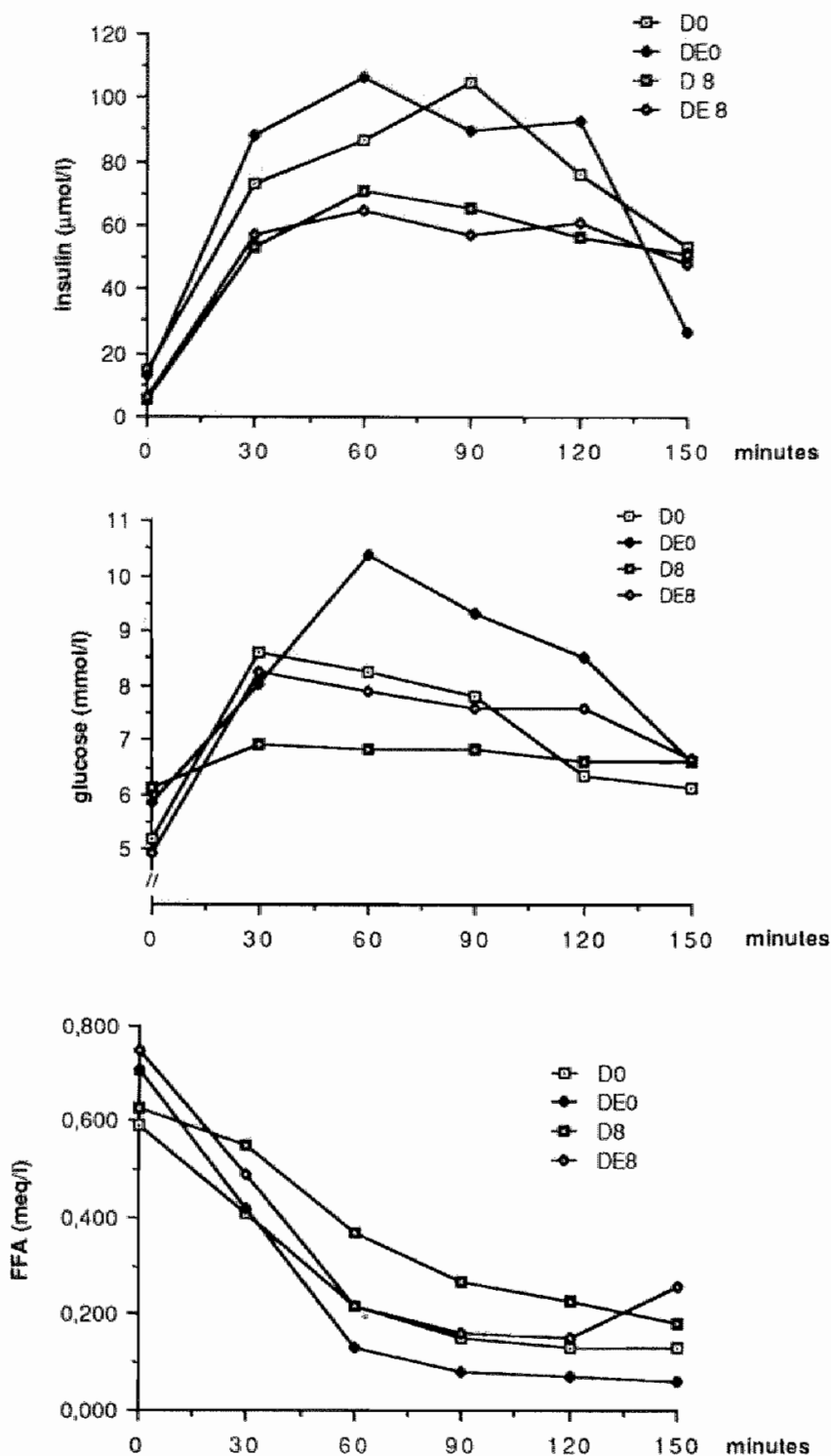

Fig. 3 Time course of plasma concentrations of glucose, insulin and FFA after a $100 \mathrm{~g}$ oral glucose laad (ingested at time of before and after 8 weeks of dieting ( $D$ ) and after 8 meeks of dieting plus 4 weeks of exercise during the last 4 weeks (DE). 
Changes in the other important component of 24-h EE, diet-induced thermogenesis, are frequently claimed as a plausible cause for the development of obesity. In Fig 2. the increase in $\mathrm{EE}$ (over a period of 180 min) after ingestion of glucose is presented. EE increased as a response to the glucose load, but, probably due to dieting the increase. in $E E$ tended to be lower in both groups after 4 and 8 weeks. After 4 and 8 weeks there was a slight increase in EE at the end of the $3.5 \mathrm{~h}$ period, especially in the DE group. This slight increase could perhaps be attributed to minor movements of the subjects at the end of the experiment.

From Table 3 it can be concluded that at the start the ingested glucose resulted in a stimulated energy expenditure for both groups (D and DE 0.76 and $0.73 \mathrm{~kJ} / \mathrm{min}$ respectively). As shown in Fig. 2 and Table 3 , the thermogenic response to glucose tended to decrease after 4 weeks of dieting (D 0.60 and DE $0.54 \mathrm{~kJ} / \mathrm{min}$ ) but differences were not sigmificant. After 8 weeks the values for the $\mathrm{DE}$ group decreased further $(0.45 \mathrm{~kJ}$; $\mathrm{P}<0.05$ ), whereas for the $\mathrm{D}$ group values were simular to the results obtained after 4 weeks $(0.61 \mathrm{~kJ} / \mathrm{min})$. Similar, but not significant, changes were found when data are expressed as a percentage of the glucose load: there was still a tendency to decrease, although no level of significance could be calculated (Table 3).

Important factors in the regulation of diet-induced thermogenesis are insulin sensitivity and glucose tolerance. Abnormal values of 26-33 mol/I insulin have been shown to result in a blunted thermogenesis after a meal. However, in none of the subjects abnormal values of insulin or glucose concentration in blood plasma were observed (Table 3). Similarly, plasma values of FFA were within the normal range. The changes in glucose, insulin and FFA concentrations over a period of 150 min are presented in Fig. 3.

Besides insulin, thyroid hormone is also involved in the facultative thermogenesis. Baseline values, which are presented in Table 3 , showed no sigficant differences at the start of the treatment. After 8 weeks T3 tended to show a lower decrease for the diet-exercise subjects compared to the subjects from the diet group (N.Sin).

Recently GIT has been suggested to correlate with several variables such as $\mathrm{VO}_{2}$ max and body fat distribution (Tagliaferro et al., 1986). Following these suggestions, correlations were calculated. However, no significant correlations were shown between the increase in $\mathrm{VO}_{2}$ max or the decrease in body fat and changes in GIT, most probably due to the small number of subjects. Significant correlations were shown between changes in GIT and changes in insulin (D 0.94; DE 0.95) and glucose concentrations (D $0.75 ;$ DE 0.86 ) before and after the diet and diet $-\mathrm{ex}$ ercise treatment.

\section{Discussion}

\section{Weight and fat loss}

In the present study 4 weeks of intensiwe plyysical training was added to energy restriction after 4 weaks of dieting for 6 oul of 12 subjects. The results with respect to changes in body composition confirm reports of 
other short-term studies (Krotkiewski et al., 1981; Warwick \& Garrow, 1981; Hill et al., 1987b): diet plus exercise did not induce a significantly higher weight and fat loss or preservation of fat free mass. Krotkiewski and co-workers (1981) calculated that physical training in such a short period can induce a maximum fat loss of 1 to $1.5 \mathrm{~kg}$, which is similar to the standard deviation within both the $\mathrm{D}$ and $\mathrm{DE}$ groups found in our and other studies (Krotkiewski et al., 1981; Warwick \& Garrow, 1981).

\section{Changes in RMR and T3}

However, it was not the purpose of this study to show significant short term differences in weight and fat loss but to study the suggested favourable effects of exercise on RMR and GIT, which might induce a better long term effect in fat and weight loss for the combined treatment. RMR, which was determined during two consecutive nights, showed no important differences ( 0 $9 \%$ ) between the two nights, proving the reliability of the measurements. Similar data have been reported with respect to 24-EE (Ravussin et al., 1986; de Boer et al., 1987).

Resting metabolic rate during dieting decreased by about $13 \%$ for both groups after 4 weeks, and did not improve to baseline or above baseline levels after the addition of 4 weeks of physical training. However, there was a slight increase of $+3.5 \%$ for the $\mathrm{DE}$ group in the last 4 weeks, whereas $D$ decreased by a further $2.4 \%$. Together with the smaller decrease in $\mathrm{T} 3$ values $(-12.0 \%$ for $\mathrm{D}$ and $-3.5 \%$ for DE (N.S.)) one could interprete this observation as an indication for a restoration effect. However, since there are no sig- nificant effects and the increase is very small with a large S.E.M. this observation will have to be verified in further studies, especially over a longer treatment period.

\section{Exercise and RMR}

Several studies have reported a similar lack of significant results in the preventive effects of exercise on the diet-induced fall of RMR (Henson et al., 1987; Hill et al., 1987b), but there were also studies with contrasting data (Schultz et al., 1980; Donahoe et al., 1984; Nieman et al., 1988). Tremblay et al. (1988) attributed this inconsistency in results to the possibility of an involvement of acute exercise effects of the previous day. In contrast to his observations, the present study showed no lower values of RMR for the diet-exercise group during the second night, although at least $36 \mathrm{~h}$ had passed since the last exercise session. From our results it may be concluded that exercise on the previous day has no short term elfect on the energy exchange the following night. It has been suggested that the lack of preventive effects of exercise on the diet-induced drop in RMR can be expained by a low intensity of exercise (Lennon et al., 1985). However, studies with more intensive exercise have not reported any restoration of the decline in RMR during dieting either (Krotkiewski et al., 1981; Warwick \& Garrow, 1981). In addition, studies in which metabolic rate during and directly after exercise was determined also showed equivocal results. High intensity of exercise has been demonstrated to raise metabolic rate for several hours (Thompson \& Blanton, 1987), but other studies reported a normalisation of metabolic rate within $1-2 \mathrm{~h}$ 
after intensive exercise (FreedmanAkabas et al., 1985; Garrow, 1987b). Thus there is so far no consensus about the favourable effects of exercise during dieting. However, the observation of a great variety in the level of energy restriction between studies, which was moderate in studies showing favourable effects and severe in studies without any preventive effect of exercise on RMR, might explain the conflicting results. Severe energy restriction was provided only in the study of Schultz. et al. (1980) and this study showed a preventive effect of exercise on RMR, but there is no detailed information about the methods used in that study.

Belko and colleagues (1987a) state that it is difficult to compare diet and diet-exercise groups because of the dissimilarity in energy deficit. Due to the greater energy deficit, RMR in the diet-exercise group might be more strongly reduced than in the D group, finally resulting eventually in a decline in RMR similar to that in the diet group. In order to correct for this inequality the dietary restriction was made less severe in the diet-exercise group, providing similar energy deficits for the diet and the diet-exercise groups. However, despite this correction no favourable effects of exercise were shown (Belko et al., 1987a).

\section{Diet and GIT}

One of the most frequently studied topics in recent years is dietary-induced thermogenesis. Although a possible defect in obese subjects has not been firmly established, there is growing agreement about lower responses in energy expenditure after a meal or a glucose load in subjects with insulin resistance and im- paired glucose tolerance (Golay et al., 1985; Ravussin et al., 1985b). At the start of the present study plasma values of insulin and glucose were within the normal range. Similarly, energy expenditure was stimulated in a normal way after the ingestion of glucose. However, there was considerable variation between subjects. Recently, it has been reported that there is a large variability in thermogenic responses to stimuli such as a meal, glucose and norepinephrine in both obese and lean subjects (Schwartz et al., 1987; Sims \& Danforth, 1987; Connacher et al., 1988). The fact that we measured GIT in the respiratory chamber might also be responsible for a larger variation (C.V. about $45 \%$ ). However from calibration experiments the reliability of the measurements in the respiration chamber was found to be $3 \%$ during a period of $3 \mathrm{~h}$ and for $0.5 \mathrm{~h}$ measurements $10 \%$. The trend towards a GIT lowering effect of D and DE treatment (Table 3 ) is in agreement with the results of Shultz and colleagues (1984 and 1987). Like the decrease in RMR per $\mathrm{kg}$ fat free mass, the decrease in GIT during dieting may be explained by a change in sympathetic activity. Recently, Ravussin et al. (1985a) demonstrated this effect after a glucose load by means of the glucose clamp technique and the use of the $\beta$-blocking agent propranolol. It was concluded that about one-third of the energy costs of glucose storage could not be attributed to obligatory costs of glucose oxidation and storage. This unexplained part of the increase in energy expenditure has been called the facultative thermogenesis, which probably involves processes such as $\mathrm{Na}^{+}-\mathrm{K}^{+}$ATPase activity, glucose recycling and 
protein turnover (Ravussin et al, 1985a). Since it has also been shown that $\mathrm{Na}^{+}-\mathrm{K}^{+}$ATPase activity, which is sympathetically mediated, is reduced during dieting, the decreasing effects on GIT may also be explained by a reduced sympathetic acvivity (Pasquali et al., 1988). Similarly, lower diurnal urinary norepinephrine excretion was found during dieting, which also indicates a lower sympathetic activity (Bessard et al., 1983).

\section{The combination of diet and exercise and GIT}

A remarkable observation was the fact that in the present study after 8 weeks GIT showed a larger decrease in the DE group than in the D group. Belko et al. (1987) did not find any differences in DIT after a diet-exercise or a diet treatment, while a decreased thermogenic response similar to the one shown in the present study has previously been demonstrated in trained athletes (Tremblay et al., 1983; Leblanc, 1985; Poehlman et al., 1988). Others (Hill et al., 1984; Tagliaferro et all, 1986) did show an improved DIT after physical training in untrained subjects coupled with an increase in $\mathrm{VO}_{2} \mathrm{max}$, and concluded that DIT and $\mathrm{VO}_{2}$ max were closely related. However, like Poehlman and coworkers (1988) we could not demonstrate a correlation between $\mathrm{VO}_{2}$ max and thermic response to glucose.

The suggestion by Tremblay et al. (1988) that an increased glycogen sparing effect is responsible for a lower DIT might also hold for our subjects in the diet-exercise group. After a frequent depletion of glycogen stores during physical training, adaptative mechanisms will develop and the glycogen restoring capacity will be increased. This results in an increased glucose disposal, a lower glucose oxidation and an increased lipid mobilization. Similarly, the capacity for lipid mobilization and oxidation is improved during dieting. These two adaptations together result in greater glucose disposal and a lower glucose oxidation, providing glycogen sparing. This mechanism may appear in the night/morning following the exercise session. Higher values might have been found if GIT had been measured three days affer exercise, which was the case in the study with athletes (Tremblay et al., 1988).

Another remarkable observation was that insulin sensitivity was improved, whereas GIT tended to decrease. Other studies (Golay et al., 1982; Ravussin et al., 1985a) reported increased values of the thermogenic response when insulin sensitivity was improved. However, in contrast to these studies in the present study no decreased insulin sensitivity was observed initially. Other factors also seem to be of importance in the regulation of the thermic response after a meal or glucose, when insulin concentrations are within the normal range. In accordance with the results of the present study Schutz et al. (1984) did not show any increase in GIT after weight reduction either, despite improved insulin sensitivity. Similarly, in athletes, who showed a low insulin concentration, also a lower DIT was demonstrated compared to untrained individuals. This lower response GIT was coupled with a lower increase in heart rate after ingestion of a meal, which might indicate a lower sympathetic 
activity after a meal (Poehlman et al., 1988).

\section{Conclusion}

Summarizing the results, it can be concluded that 4 weeks of intensive physical training after 4 weeks of dieting did not induce significantly a larger weight and fat loss or restoration of the diet-induced fall in $R M R$. The response of energy expenditure. to a glucose load tended to decrease during dieting, and tended to decrease further when exercise was added. 


\section{VITAMIN STATUS IN PLASMA DURING DIETING AND EXERCISE}

\section{Introduction $\mid$ D. van Dale, J. Schrijver, W.H.M. Saris}

Many popular energy restricted diets are not well-balanced. Several have been shown to be marginal or deficient in micronutrients such as thiamin, ribollavin, vitamin B-6, B12 , calcium, iron, zinc and magnesium (Fisher \& Lachance, 1985). These diets cannot be maintained for long periods without the danger of deficiencies presenting a healt $h$ risk. In accordance with the results of nutrient intake, blood concentrations of thiamin, riboflavin and B-6 were shown to decrease to almost deficient levels (Consolazio, 1971b). With the introduction of very low energy formula diets, micronutrient intake could be controlled and better results in fat loss and prevention of loss of fat free mass were obtained. Several authors have reported on the effect of these diets on mineral status (Fisler et al., 1984; Henry et al, 1986; Stallings et $\mathrm{al}_{\text {, }}$ 1988). However, only a few studies with respect to vitamin status have been performed. Recent studies have shown drastic reductions in vitamins $\mathrm{A}$ and $\mathrm{E}$ after a short period with a low energy formula diet and a follow-up of 6 months (Zwiauer et al., 1986; Widhalm et al., 1988). However, no clinical symptoms were detected. Similar decreases in vitamin $A$ and $\mathbb{E}$ levels with clinical symptoms, were shown in obese patients after $1-6$ years following a gastric bypass operation

\section{ABSTRACT}

The micronutrient siatus of 12 obese male subjects was evaluated before and after a 14 -week period of low energy Giet $(3.0-3.9 \mathrm{MJ})$ with or without an exercise $(5 \mathrm{~h} \mathrm{p} / \mathrm{w})$ trest ment. The subjects were matched on the basis of their body mass index (BMI kg/m²) into a diet group (D; a werage BMI 32.2) and a diet-exencise group (DL; average BMI 32.9).

After 14 weeks boih groups showed similar results in terms of weight loss (D 15.1; DE $16.4 \mathrm{~kg}$ ), fat loss (D 11.7; DE 13.6 $\mathrm{kg}$ ) and loss of fat free nuss (FFM) (D $34 ;$ DE $2.8 \mathrm{~kg}$ ).

With respect to changes in the micronutrients in blood plasm ma only the decrease in ferritin was significantly different. for $\mathrm{D}$ and $\mathrm{DE}$ ( $\mathrm{P}<0.05)$, with a larger decrease for $\mathrm{DE}$. In both groups significant decreases of about $20 \%$ in fat soluble vitamins were observed. Water soluble vitamins demonstrated a large variation between individuals and decreases were not significant.

(Rogers et al., 1980).

Recently, the addition of exercise to energy restriction programs also attracted considerable interest as a preventive measure for the breakdown of fat free mass. However, no data are available on the vitamin status during dieting in combination with exercise. Therefore, as part of a larger project, we studied the effects on vitamin status of a low energy formula diet with or without an exercise program. 


\section{Methods}

\section{Subjects}

Fifteen healthy male volunteers from the surrounding community, aged between $25-50$ years, were studied during a period of fourteen weeks. By matching the subjects on the basis of their BMI $\left(30 \mathrm{~kg} / \mathrm{m}^{2}\right)$, a diet and a diet-exercise group were formed. All subjects were in good health and had a stable weight for 6 months preceding the study. The physical characteristics of the subjects are presented in Table 1 . All subjects participated voluntarily after giving their informed consent. The study was approved by the medical ethics committee of the university.

\section{Experimental design}

With respect to the dietary regimen, a fourteen-week period was divided into a first five-week period, and followed by a nine-week period. Before admission, all subjects underwent baseline measurements for body composition, Resting Metabolic Rate (RMR) and maximal aerobic power ( $\left.\mathrm{VO}_{2} \mathrm{max}\right)$. These measurements were repeated after 5 and 14 weeks. Non-fasting blood samples were drawn from an antecubital vein before and after the study.

\section{Diet}

During the first period the diet consisted of a low energy formula diet (Meritene@, Wander, Switzerland). Energy and nutrient intakes were as shown in Tables 2 and 3 . In the second period the same formula diet, but with a lower energy intake, was supplemented with normal food up to 3.6-3.8 MJ. It is our experience that with formula diets compliance is good. However, previous food habits will not change and the risk of gaining weight after completion of the diet is very high. Therefore normal food was added in order to teach

Table I

Physical characteristics of the experimental subjects at the start of the stucty (meantSEM)

\begin{tabular}{lrr}
\hline Variables & $D(\mathrm{n}=6)$ & $\mathrm{DE}(\mathrm{n}=6)$ \\
\hline Height $(\mathrm{cm})$ & $173.0 \pm 3.7$ & $177.0 \pm 1.2$ \\
Weight $(\mathrm{kg})$ & $97.8 \pm 4.8$ & $102.5 \pm 5.7$ \\
Body mass index $\left.(\mathrm{kg} / \mathrm{m})^{2}\right)$ & $32.0 \pm 2.0$ & $33.4 \pm 1.8$ \\
Percentage Fat $(\%)$ & $32.3 \pm 2.0$ & $31.7 \pm 1.5$ \\
Fat mass (kg) & $31.9 \pm 3.2$ & $34.4 \pm 3.6$ \\
Fat Free mass (kg) & $65.9 \pm 2.6$ & $68.1 \pm 2.1$ \\
Age (years) & $41.0 \pm 4.0$ & $37.0 \pm 2.5$ \\
Sleeping Metabolic Rate (MJ/24 h) & $8.6 \pm 0.3$ & $9.3 \pm 0.6$ \\
Sleeping Metabolic Rate (MJ/kgFFM/h) & $5.5 \pm 0.2$ & $5.5 \pm 0.2$ \\
Maximal aerobic power (ml/kgBW/min) & $33.7 \pm 3.2$ & $34.7 \pm 2.1$ \\
Maximal aerobic power (m//kgFFM/min) & $49.5 \pm 2.3$ & $51.4 \pm 2.4$
\end{tabular}

D=diet group / DE Ediet-exercise group

There are no significant differences between $D$ and $D E$. 
Table 2 Daily energy and macronutrient intake of the formula and the mixed formulalfood diet (meantSEM)

\begin{tabular}{lrrr}
\hline Week & \multicolumn{1}{c}{1.5} & \multicolumn{2}{c}{$6-14$} \\
\hline group & D + DE & \multicolumn{1}{c}{ D } \\
\hline Energy (MJ) & 3.0 & $3.9 \pm 0.2$ & $3.8 \pm 0.2$ \\
Protein (g) & 51.6 & $58.6 \pm 2.8$ & $57.2 \pm 1.3$ \\
Fat (g) & 21.7 & $36.2 \pm 1.8$ & $33.9 \pm 2.8$ \\
Carbohydrate (g) & 75.5 & $90.3 \pm 2.8$ & $91.3 \pm 4.5$ \\
\hline
\end{tabular}

Dediet group

$D E=$ diet-exercise group

subjects to change their food habits under supervision during the study period. Actual dietary intake for the second period was estimated from a day-to-day food record using the Dutch food-composition table (Nevo Table, 1986). The importance of completing the diaries precisely was. strongly stressed and weekly checks were made.

\section{Training}

Subjects in the diet-exercise group trained live times per week at $60 \%$ of their $\mathrm{VO}_{2}$ max. Training consisted of aerobic training $(3 h)$ and weight resistance combined with 20 min aerobic training ( $2 \mathrm{~h}$ ). $\mathrm{VO}_{2}$ max as well as pulse rate were determined to estimate the intensity of training. All training sessions were performed at a professional fitness centre and were supervised by trained teachers.

\section{Measurements}

Body density was determined by the hydrostatic weighing technique as previously described (van Dale et al., 1987). Siri's equation (1956) was used to calculate the percentage of body fat from body density.
Maximal aerobic power, determined as $\mathrm{VO}_{2}$ max, was measured by an incremental bicycle ergometer test to the point of exhaustion. The highest value of oxygen uptake observed during the test for $1 \mathrm{~min}$ was regarded as the $\mathrm{VO}_{2} \max$.

\section{RMR}

Gas exchange measurements were made continuously with a computerized open-circuit ergo analyser (Venyvus and Gut, Basel, Switzerland).

RMR was determined by a computerized indirect calorimeter. Subjects stayed in a respiration chamber for $12 \mathrm{~h}$ and RMR was measured from 03.00-06.00 a.m... The procedure and a description of the system have been described previously by van Dale et al. (1987) and Schoffelen et al. (1985).

\section{Blood Chemistry}

Whole blood samples were used to determine the thiamin status as total thiamin concentration, the riboflavin status as the concentration of flavin adenine dinucleotide (FAD); the vitamin B-6 status as pyridoxal $5^{-1}$ 
phosphate (PLP). Detailed information about the aforementioned analysis and the methods used for the analyses of vitamins $A, D$ and $E$ and vitamin $B-12$ is give $n$ in Schrijwer et al. (1985). The mineral status was evaluated on the basis of serum iron, using the bathophenanthroline method (Lauber, 1965). Ferritin was determined using an immuno radio assay.

\section{Statistics}

Results are expressed as mean \pm SEM. For comparisons between the diet and diet-exercise group Student 's $t$ - test for paired and unpaired means was used. Pearson's product moments correlation coefficent was used to examine the relationship between changes in body composition and vitamin concentrations in plasma.

\section{Results}

Three subjects did not complete the study because of non-compliance (initial weight and BMT of these 3 subjects were: $100 / 32$ (DE), 120/42 (D), $85 / 31$ (D)). Their data were excluded from further analysis. The other subjects completed the treatment successfully, with a significant weight loss (Fig. 1). Neither after 5 weeks nor after 14 weeks significant differences were seen between the D and DE group in weight loss (D 12.6 and 15.1 and DE 11.2 and $1.6 .4 \mathrm{~kg}$ after 5 and 14 weeks respectively). As shown in Fig. 1, similar results were observed for the loss of fat mass (D 9.8 and $11.7 \mathrm{~kg}$ vs DE 9.3 and $13.6 \mathrm{~kg}$ ) and fat free mass (D 2.8 and 3.4 vs DE 2.1 and $2.8 \mathrm{~kg}$ ). Despite the addition of exercise, no significant differences between the

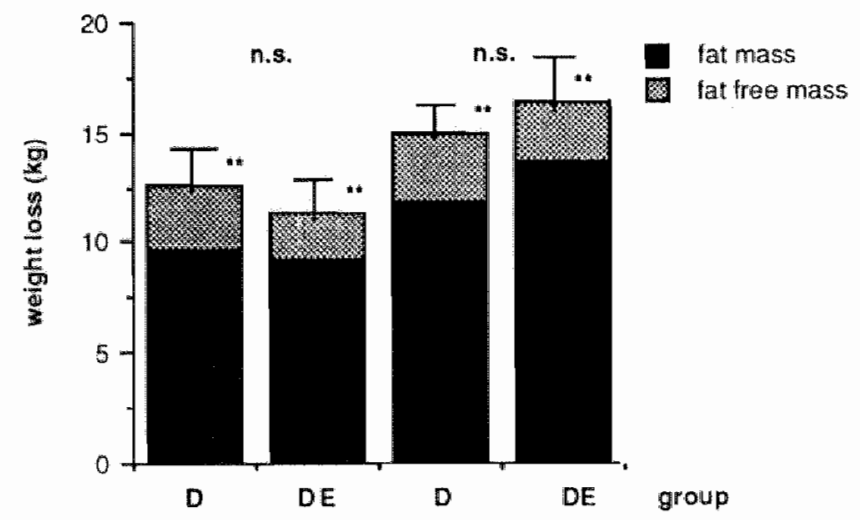

Fig. 1 Weight and for loss and lass of fat free mass a her 5 and lit wheks of a diet ireatmens (D) and a diet plus: exercise treatment (DE) (mean values $5 E M$ ) m.s. = mat significans (D v DE)

* $P<0.01$ paired t test with respect to week 0 
$D$ and DE group were observed with respect to $\mathrm{VO}_{2}$ max per $\mathrm{kg}$ body weight. For the $\mathbb{D}$ group improvement of maximal aerobic power was $3.5 \pm 1.7 \%$ after 5 weeks and $5.5 \pm$ $2.2 \%$ after 14 weeks (N.S.). The DE group showed almost the same improvements in $\mathrm{VO}_{2}$ max per $\mathrm{kg}$ body weight $(4.0 \pm 1.2 \%$ and $8.8 \pm 1.3 \%$ (N.S)). However, when $\mathrm{VO}_{2} \max$ was expressed per $\mathrm{kg}$ fat free mass only the DE group demonstrated a significant increase (5.5 and $5.4 \%$ $(\mathrm{P}<0.05)$ vs D 1.5 and $0.9 \%$ N.S. $)$. Table 3 shows the micronutrient intake of the two groups over the whole study period. Intake of all vitamins decreased in the second period for both groups. No significant differences in micronutrient intake were observed between the D and $D E$ group during the second period (Table 3).

As shown in Table 4, initial vitamin status of the subjects did not differ significantly between the $\mathrm{D}$ and the DE group. After 14 weeks of dieting and exercise or dieting, only differences in the vitamin status of both groups were not significant. The water soluble vitamin concentrations showed only slight decreases, although the DE group tended to show larger decreases compared to the D group. However, for both groups a considerable variation was observed in the change of the water soluble vitamins and no significant differences were shown.

Significantly depressed values were observed for the fat soluble vitamins. The levels of vitamins A, D and E

\begin{tabular}{|c|c|c|c|}
\hline \multicolumn{4}{|c|}{$\begin{array}{l}\text { Table 3. Daily mineral and vilamin intake of the subjects during a low } \\
\text { energy formula diet period and a mixed formulatood diet } \\
\text { period (mean } \pm S E M \text { ) }\end{array}$} \\
\hline \multirow{2}{*}{$\begin{array}{l}\text { Weak } \\
\text { Group }\end{array}$} & \multirow{2}{*}{0.5} & \multicolumn{2}{|c|}{$6-14$} \\
\hline & & $\mathrm{D}$ & $\mathrm{DE}$ \\
\hline Sodium (mg) & 660 & $1395 \pm 152$ & $1303 \pm 131$ \\
\hline Potassium (mg) & 2365 & $2098 \pm 91$ & $2067 \pm 15$ \\
\hline Calcium (mg) & 1270 & $1012 \pm 160$ & $1294 \pm 162$ \\
\hline Phosporus (mg) & 1095 & $1159 \pm 101$ & $1214 \pm 90$ \\
\hline Iron (mg) & 15.0 & $8.20 \pm 0.24$ & $8.50 \pm 0.39$ \\
\hline vitamin $\mathrm{A}(\mathrm{mg})$ & 0.600 & $0.441 \pm 0.03$ & $0.517 \pm 0.04$ \\
\hline vitamin $\mathrm{D}(\mu \mathrm{g})$ & 2.0 & $1.78 \pm 0.21^{x}$ & $1.70 \pm 0.18^{x}$ \\
\hline vitamin $E(\mathrm{mg})$ & 10.0 & $8.1 \pm 1.10^{x}$ & $7.84 \pm 1.08^{x}$ \\
\hline thiamin (mg) & 1.45 & $0.98 \pm 0.113$ & $0.94 \pm 0.13$ \\
\hline riboflavin $\mathrm{B} 2$ (mg) & 2.45 & $1.75 \pm 0.26$ & $1.67 \pm 0.17$ \\
\hline vitamin B-6 (mg) & 1.65 & $1.24 \pm 0.06$ & $1.26 \pm 0.05$ \\
\hline Niacin (mg) & 12.0 & $10.1 \pm 0.63$ & $10.5 \pm 0.74$ \\
\hline vitamin C (mg) & 65.0 & $47.9 \pm 6.6$ & $59.4 \pm 2.7$ \\
\hline \multicolumn{4}{|c|}{$\begin{array}{l}{ }^{X} \text { Calculated from macronutrient intake } \\
D=\text { Diet group; } D E=\text { Diet-exercise group }\end{array}$} \\
\hline
\end{tabular}


Table 4 Hemoglobin, ferritit and witamin concentrations in plasma in the diel and the diet-exercise group (mean $A S E M$ )

Week 0

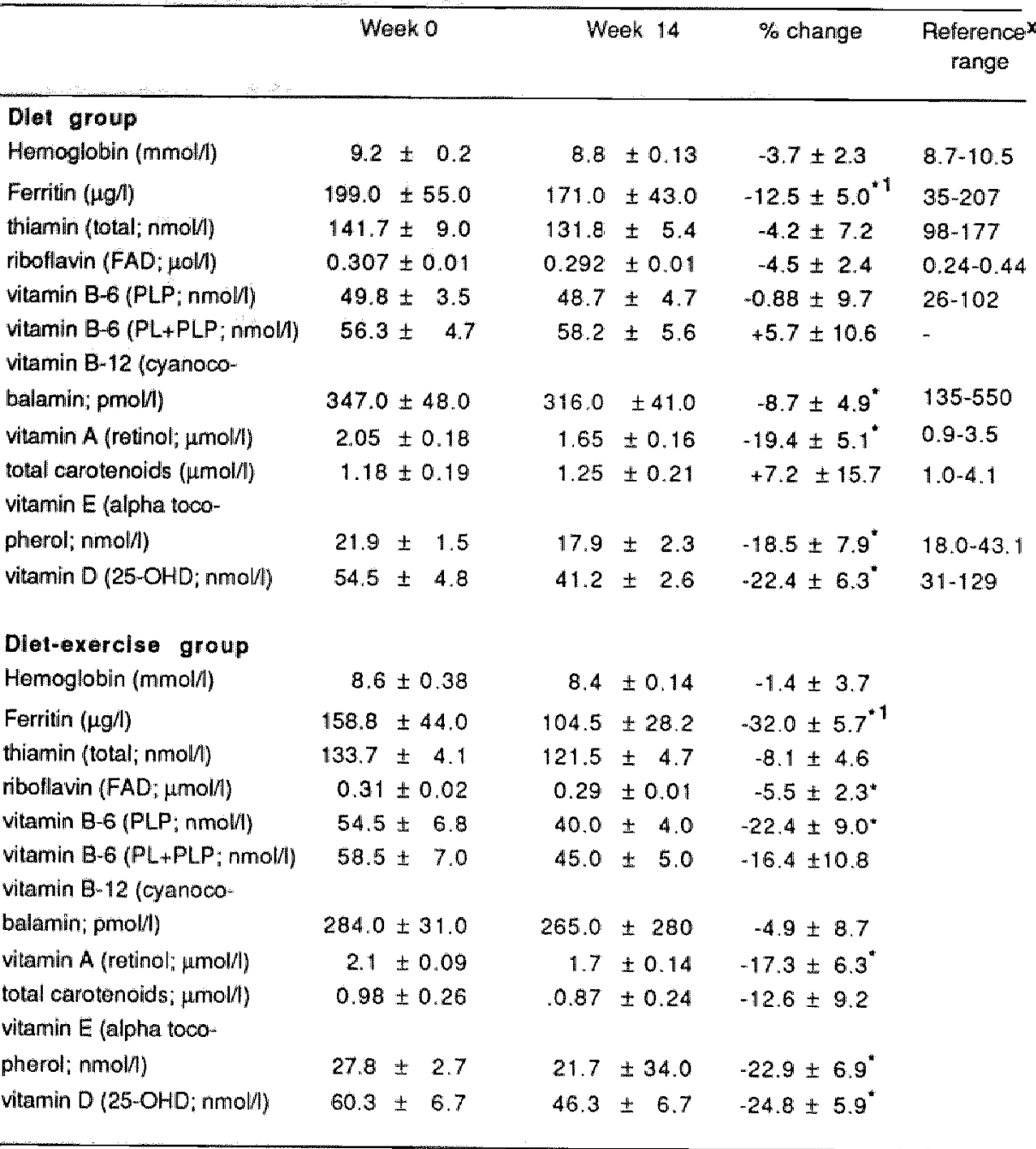

1\% change: D vs DE unpaired t-1est $P<0,05$

- $p<0.05$

x Relerence walues of a control group (blood donors) determined in the same laberatory 
decreased by about $20 \%$ for both groups. The small change in total carotenoids is remarkable when compared to the large decrease in vitamin $\mathrm{A}$ in the blood plasma. The only significant difference between the D and DE group was shown in the change in ferritin $(\mathrm{P}<0.05)$.

In Table 5 the correlations between vitamin change and reductions in weight, fat and fat free mass are shown. As the two groups did not differ in their vitamin status, they were combined in the correlation study. Only a few significant correlations were found. The percentage of change in the vitamin $A$ and $E$ status correlated significantly with the weight loss. For vitamin E a correlation with the loss of FFM was found as well. Significant correlations with fat loss were not observed.

\section{Discussion}

Energy restricted diets in combination with exercise may have strong effects on micronutrient status. Although several studies, with conflicting results, have been published on the effects of exercise on vitamin status (Schneider, 1979), no data are available about the consequences of a low energy diet combined with exercise.

In this study a combination of an exercise program and a low energy formula diet resulted in a considerable weight and fat loss with minimal loss of fat free mass as did the low energy formula diet alone. However, the addition of exercise did not result in significant differences between the D group and the combined diet-exercise group with regard to weight and

Table 5 Correlation between percent changes in micromutrient shatus and weigh, fat and FFM loss respect ively. after 14 weeks of a diet or diet plus exercise treatment

\begin{tabular}{lccc}
\hline$\%$ change of & weight loss & fat loss & loss of FFM \\
\hline Hemoglobin & .425 & .185 & .039 \\
Thiamin & .153 & .076 & .267 \\
Ribotlavin & .235 & .173 & .428 \\
Vitamin B-6 (PLP) & .028 & .066 & .091 \\
Vitamin B-6 (PLP+PL) & 167 & .308 & .180 \\
Vitamin B-12 & .279 & .384 & .054 \\
Vitamin A & $.661^{\circ}$ & .485 & .089 \\
Vitamin E & $.526^{*}$ & .210 & $.581^{*}$ \\
Vitamin D & .056 & .186 & .280 \\
Caarotenoids & .021 & .031 & .267 \\
Ferritin & .165 & .145 & .161 \\
\hline Po.05 & & & \\
\hline
\end{tabular}


fat loss and loss of fat free mass. It can be argued that the DE group in the present bad a greater food inlake, although the results of the selfreported food diaries did not indicate this. However, results obtained with self-reported data can be criticized, because of the well-known poor reliability of obese people in completing diaries (Hallfrisch et al, 1982). Another possibility might be that exercise had a too low intensity to induce a larger weight and fat loss for the DE group than the D group. However, the significant increase in $\mathrm{VO}_{2}$ max per $\mathrm{kg}$ fat for the $\mathrm{DE}$ group and not for the D group, contradicted this possibility.

\section{Energy and nutrient intake}

During the first 5 weeks food intake was similar for all subjects, who completed the period with the formula diet. Compared to the Recommended Daily Allowances (RDA) (National Research Council, 1980), the micronutrient intake in this diet was not entirely sufficient. Due to the low fat content of the diet the intake of the fat soluble vitamins $A, E$ and D was lower than the RDA, as were those of sodium and niacin. The differences, however, were not large and are within the range of the RDA's of various countries (Hegsted, 1972; Round Table on Dietary recommendations, 1977). After 5 weeks the subjects could make a free choice of normal food in one meal, although the energy content was restricted to $2 \mathrm{MJ}$. The energy content of the second period was increased to $3.8-3.9 \mathrm{MJ}$ with no significant dilferences between the $D$ and DE group. The increase in energy was mainly due to the increase in fat and carbohydrate intake. Within the restrictions of the limited energy content imposed on the meal there was a tendency to choose fatty foodstuffs, which has been suggested as one of the main causes of the obese state (R omieu et al., 1988). However, the energy $\%$ fat (about $30 \%$ ) was still lower than the normal daily food intake of the Dutch population (about $42 \%$ ). During the mixed diet period micronutrient intake decreased for all micronutrients inwolved, with the exception of sodium. Im accordance with the results of Fisher \& Lachance (1985) it was especially the intake of thiamin, riboflavin and vitamin B-6 and iron which decreased for both groups. Similar intake values were demonstrated for the $D$ and DE group. Micronutrient intake during the second period tended to be toollow, but for the relatively short period of 14 weeks no health risks are to be expected.

\section{Vitamin and mineral status}

At the start of the study micronutrient values in blood plasma appeared to be within the normal range. Neither did the changes in vitamin concentrations show indications of marginal or deficient levels after 14 weeks. At the end of the study the only significant difference between diet and diet-exercise group was that in ferritin concentration, which showed a greater reduction for the DE group. The diet-exercise group also showed a tendency towards a larger decrease in vitamin B-6 than the D group, which only showed a very slight decrease. The larger decrease for the $\mathrm{DE}$ group can be attributed to the greater activity in protein turnover and an increased gluconeogenesis caused by the adding of exercise (Belko, 1987b). 
However, other tendencies or significant differences could not be observed. In athletes it has been argued that extra thiamin, riboflavin and vitamin $B-6$ are needed because of the increased energy turnover (Schneider, 1979; Belko, 1987b). In our study it was expected that the DE group would show a greater decrease in the levels of thiamin. riboflavin and vitamin B-6. However, it was only the vitamin B-6 concentration, which tended to decrease more in the DE group than in the D group. For thiamin and ribollavin, no significant differences were detected between the $\mathrm{D}$ and $\mathrm{DE}$ group. Contrasting results have been obtained in obese females who first followed a diet and than a diet/exercise program. During the diet/exercise period, riboflavin requirements were almost doubled compared to the diet period (Belko et al., 1985) The ribollavin content of the diet., however, was lower than in the present study $(0.80 \mathrm{mg} / 4.2 \mathrm{MJ}$ vs $1.12 \mathrm{mg}$ in our study). On the other hand many of the conclusions about increased requirements during exercise are based on studies using intensive or long duration exercise. An explanation for the minimal decreases. in thiamin and riboflavin in the $\mathrm{DE}$ group compared to the D group, might be that the intensity was moderate and the training was of relative short duration.

Just like in the study by Zwiauer et al. (1986), who also used a low energy formula diet, a significant decline in the fat soluble vitamins $A$ and $E$ was found. At the 6 months followup low levels were still found, but these had not led to biochemical deficiencies. Longer periods of a deficient intake, which occurred in severely obese subjects who had un- dergone a jejunolleal bypass operation, did indeed show deficiencies in vitamins $A, E$ and 25-OHD up to 6 years after operation (Rogers et al., 1980). It was remarkable that supplementation for especially vitamin $A$ did not result in an increase in vitamin A values in plasma (Rogers et al., 1980; Widhalm et al., 1988). Vitamin $A$ intake does not seem to be the most important determining factor for plasma values. Apparently, another mechanism determines plasma values during dieting. Decreased values of plasma proteins such as retinol binding protein (RBP) have been claimed to be the cause of depressed values of vitamin A in serum (Rogers et al., 1980; Zwianer et al., 1986; Widhalm et al., 1988). This RBP concentration is a better indicator for the nutritional status of vitamin $A$ than vitamin $A$ itself, because vitamin A status depends on RBP concentration and does not reflect liver storage until that storage is depleted. Recovery of vitamin A status has been shown after refeeding (Zwiauer et al., 1986) and not during supplementation, indicating the important role of RBP. This decrease in plasma proteins has been found especially for dietts low in protein or low in carbohydrate (Meritt et al., 1981).

Depressed plasma values of vitamin $E$ have been explained by the reduced levels of Low Density Lipoprotein (LDL), which serves as a carrier for vitamin $\mathbb{E}$ (Zwiauer et al., 1986; Vandewoude et al., 1987), combined with an increased need for vitamin $\mathbf{E}$ because of the increased level of FFA. Reduced LDL values have commonly been shown after weight reduction (Stevenson al, 1988). As with vitamin $A$, the availability of the carrier is more im- 
portant for the ultimate plasma values of vitamin $E$ than the intake of the vitamin. However, supplementation with vitamin $\mathrm{E}$ has been shown to lead to increased plasma values (Vandewoude ef al., 1987; Widhalm et al, 1988).

The lower concentrations of vitamins $A$ and $E$ indicate a change in protein levels in the circulation. Similarly, ferritin, a protein linked to ir on storage, showed decreased values after the weight reduction period. These lower protein concentrations in plasma contrasted with the relatively small decreases in fat free mass in both groups, but especially in the DE group. This discrepancy might be caused by variations in the determinations of body composition.

Just like the other fat soluble vitamins, vitamin $\mathrm{D}$ also showed a decrease after the exercise and/or weight reduction period. Little is known about the actual need of vitamin $D$, but for adults there is probably only a small need (Garrow, 1981). Despite this small requirement, a considerable decline was shown. This could partly be attributed to the low fat content of the diet. On the other hand this study took place in the period from November to March, a period without much exposure to intensive sunlight. Since decreases in vitamin $D$ can be attributed to seasonal variation, as has often been found in northern countries (Punnonen et al., 1988), this seasonal interaction may also have affected the results.

In conclusion it may be said that in the present study no significant differences between the diet and dietexercise group in weight and fat loss, and in loss of FFM were found. Both groups showed similar decreases in the fat soluble vitamins. With respect to the water soluble witamins, the DE group showed a tendency towards a greater reduction in the vitamin B-6 status, most probably due to the addition of exercise.

The authors thank the technicians of the laboratory of CIVO-TNO Zeist who carried out the chemical anallyses. 


\section{METABOLIC EFFECTS OF REPETITIVE WEIGHT LOSS DURING AN EXERCISE AND/OR DIET TREATMENT}

\section{Introduction}

The long term results of the treatment of obesity are very poor. Only a small percentage of the subjects who enter treatment maintain their target weight (Wing \& Jeffery, 1979). The other part, the majority of the subjects, shows a repeating cycle of losing, regaining, and losing weight (yo-yo-effect), often resulting in more weight gain than weight loss. This increased weight after several periods of weight loss and gain might indicate an increasing adaptation of the body to the energy restriction. Finally these repeating periods of weight loss and weight gain might result in a resistance to weight loss. Miller \& Parsonage (1975) showed that women who were resistant to slimming were characterized by a long history of dieting. This increasing weight gain and the resistance to weight loss for the yo-yo-dieters (Blackburn et al., 1987) might be explained by an increasing "food efficiency" after energy restriction. Similarly, in animals this increased "food efficiency" has been demonstrated following a single bout of restriction and refeeding (Boyle et al., 1978; Boyle et al., 1981; Björntorp et al , 1982). A larger increase was shown when dieting was preceded by several periods of weight loss and regain (Brownell et

\section{D. van Dale,}

W.H.M. Saris

\section{ABSTRACT}

Body composition, VO2 max, Resting Metabolic Rate and lipolytic activity of abdominal adipocytes were measured in 20 women (mean BMI $=33.5$ ) during 14 weeks of exercise 1 raining ( 4 h/wk at $60 \%$ of $\mathrm{VO}_{2}$ max) and dietary restriction ( 3.5 MJ/day). Groups were formed on basis of yo-yo (frequent dieters), non-yo-yo (women without a dieting history) and the treatment of diet with or without exercise: (Diet - Exercise Yo-yo (DE-Y), Diet-Exercise Non-Yo-yo (DE-Nr) and Diet-Non-Yo-yo group (D-NY).

Significant differences in weight loss and fat loss we re observed between $\mathrm{D}$ and $\mathrm{DE}$ groups but not between yomo and non-yo-yo dieters. RMR decreased in all groups but there was a significantly smaller decline after 14 weeks for the diet-exercise groups. No effects of frequent dieting or exercise on basall and stimulated lipolytic activity we re observed.

al., 1986b).

A possible mechanism for this increased metabolic efficiency is the decline in metabolic rate. After dieting the RMR is demonstrated to be temporarily decreased (Bray, 1969; Garrow et al, 1978; Ravussin et al., 1985 c). Repeated periods of weight cycling might cause a permanently reduced $\mathrm{RMR}$, which makes it more difficult to maintain weight. An indication of this effect is observed by Stcen et al. (1988) in wrestlers. Yo- 
Repetitive Weight Loss and RMR

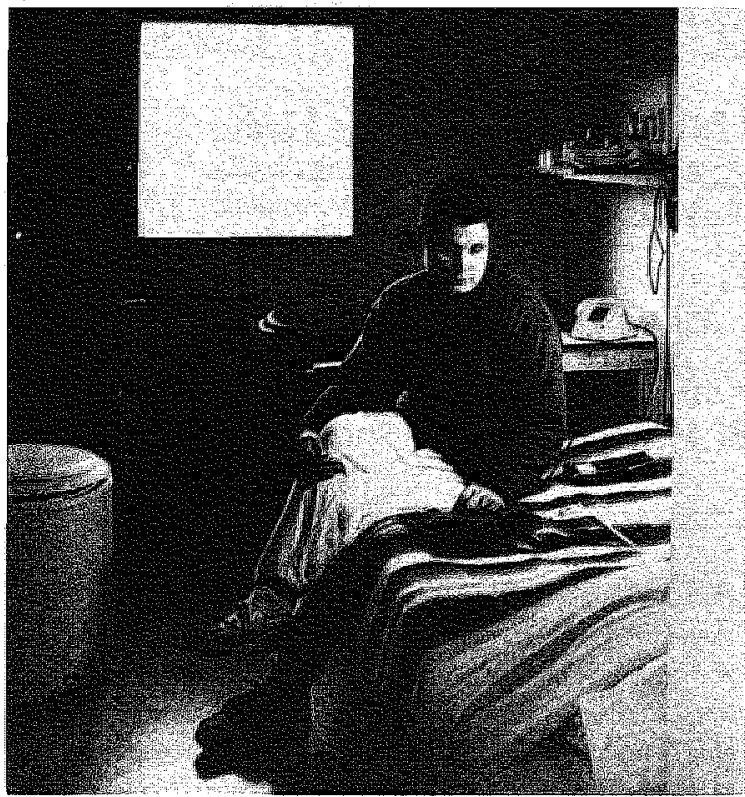

RMR was measured by indirect calorimetry in a respiration chamber.

yo wrestlers were characterized by a lower metabolic rate than wrestlers without a dieting history.

In animals other effects of weight cycling such as differences in lipoprotein lipase (LPL)-activity and in fat cell morphology have been demonstrated (Fried et al., 1983; Miller et al. 1983). In humans the effects of weight cycling on fat cell morphology and LPL-activity have not yet been studied. An indication towards similar effects in humans is given by Leibel et al. (1985), who suggested an increased efficiency in the re-esterification of FFA in formerly obese subjects. However, Lillioja et al. (1986) reported that this increased re-esterification was associated with the still increased amount of body fat.

The objective of the present study as part of a project on the effects of exercise and dieting on weight reduc- tion, is to compare subjects with a history of dieting and regain (yo-yodieters) with non-yo-yo subjects with respect to body composition, RMR, and lipolytic activity of abdominal adipocytes.

\section{Methods}

\section{Subjects}

From a group of 98 female obese volunteers 23 euthyroid subjects (aged 20-45 years) were selected. Before being accepted in this study, the subjects were given a medical examination in order to exclude subjects with abnormalities which could affect their ability to sustain a very low energy formula diet. Each individual was fully informed about the nature of the study and gave her informed consent. The study was reviewed and approved by the ethical committee of the University of Limburg.

\section{Procedure}

The subjects were divided into three groups on the basis of BMI and history of dieting. Subjects were characterized as yo-yo subjects if they had frequently dieted and had lost and regained $10 \mathrm{~kg}$ or more at least twice in the five years preceding the study. In the six months preceding the study the subjects had a stable body weight. Non-yo-yo subjects were characterized by a history of a non-restricted food intake in general and no frequent diet periods. Non-yo-yo subjects had never lost more than $3 \mathrm{~kg}$ body weight in the five years preceding the study.

Furthermore groups were formed using BMI, diet, exercise and yo-yo 
or non-yo-yo history as criteria:

- group 1 Diet-Exercise Yo-Yo (DE-Y)

- group 2 Diet-Exercise Non-YoYo (DE-NY)

group 3 Diet Non-Yo-Yo

(D-NY)

For capacity reasons, such as respiration chamber measurements a fourth experimental group (Diet- Yo-yo;D$Y)$, was not included in this study. From a previous study with a similar experimental set-up it appeared to be possible to select a group of five women with a yo-yo history and a diet treatment (van Dalle et al., 1987). However, this group was different with respect to fat mass and BMI. As a consequence the data of this fourth group are not included in the results. In order to get a complete picture of weight cycling, the data of this fourth group (D-Y) are presented in the discussion to compare the rate of weight and fat loss and of RMR with those of other groups.

The study took place over a 14 -week period. Before the start of the study, after 5 weeks, and after 14 weeks the measurements of body composition, acrobic power ( $\mathrm{VO}_{2} \max$ ), $\mathrm{RMR}$, and blood chemistry were performed.

\section{Diet}

During the study dieting was split into three phases. The first 5 weeks the diet consisted of a very low energy diet of $3.0 \mathrm{MJ} /$ day (Meritene $\$$ ), Wander-Sandoz, Bern, Switzerland) which consisted of $51.6 \mathrm{~g}$ protein. $21.7 \mathrm{~g}$ fat, $75.5 \mathrm{~g}$ carbohydrate and micronutrients according to the Dutch RDA (Nederlandse Voedingsmiddelen Tabel, 1983). During the second phase (week 6 to week 14) the diet consisted of the same low energy diet now containing $2.2 \mathrm{MJ} /$ day which was supplemented with 1.3 MJ/day as normal food stuffs. To check the compliance of the subjects, the maintenance of a dietary record was required. "The subjects were instructed and motivated to record all foods and beverages consumed. Every week the results were discussed with the subjects.

The analysis of the dietary records indicated that during the first 6 weeks there was a good adherence to the formula diet. In the second phase there was less homogenety in food intake, but no significant differences between groups were shown. The different treatments groups consumed the following mean amounts of energy (MJ):

- DE-Y:3.35 \pm 1.20 (96 g carbohydrate, $40 \mathrm{~g}$ protein and $27 \mathrm{~g} \mathrm{fat}$ ) - DE-NY:3.20 \pm 0.86 (79 g carbohydrate, $39 \mathrm{~g}$ protein and $31 \mathrm{~g} \mathrm{fat})$ - D - NY: $3.46 \pm 0.95$ (94 g carbohydrate, $52 \mathrm{~g}$ protein and $25 \mathrm{~g}$ fat) - D- Y: $3.26 \pm 1.10$ (84 g carbohydrate, $62 \mathrm{~g}$ protein and $20 \mathrm{~g}$ fat)

In the last two weeks of the treal. ment only the low energy formula diet (3.0 MJ) was provided to check the compliance to the the mixed diet. It was expected that, if compliance was poor, the rate of weight loss should increase in the lavist two weeks, when only the low energy diet was provided as compared to the weight loss during the weeks when the mixed diet was given. However, the rate of weight loss did not change in the three groups in the last two weeks, which indicated a good compliance. Mean weight loss \pm SEM $(\mathrm{kg})$ for all groups in week 11 was $0.83 \pm 0.14$, in week $12: 1.03 \pm$ 
0.04 , in week $13: 0.83 \pm 0.12$ and in week 14:0.93 \pm 0.08 . Every week the subjects had to visit the laboratory to check their weight and to discuss problems relating to maintaining their diet.

\section{Exercise}

For both exercise groups training took place at a professional sports centre. The weekly trainings consisted of two $\mathrm{h}$ aerobic dancing, one $h$ weight resistance training and one $h$ jogging. The exercise intensity was calculated from heart rate recordings using a calibration line made during a maximal exercise test.

Heart rate was recorded with a heart rate memory system (Depex, BilHoven, Holland) at the start of the study, after 5 weeks and in the last week of the study. From these heart rate recordings the intensity of the training was estimated to be $60 \%$ of $\mathrm{VO}_{2}$ max. All training sessions lasted one hour and were done under supervision of a professional trainer. Subjects' attendance was controlled.

\section{Body composition and circumferences}

Bodly composition was determined by hydrostatic weighing, estimating respiratory volume with the helium dilution method. Waist/hip ratio was calculated from the minimum circumference between the rib cage and the illiac crest and the maximum circumference between the waist and the thighs, whille the subject was standing and breathing quietly (Ashwell et al., 1981).

\section{Energy metabolism}

RMR was measured by indirect calorimetry in a respiration chamber during the sleeping period from 03.00-06.00 a.m.. Detailed informa- tion concerning this method has been described previously (van Dale et al.,1987).

\section{Maximal aerobic power}

For the assessment of maximal aerobic power ( $\mathrm{VO}_{2} \mathrm{max}$ ) each subject performed an incremental exercise test on an electrically braked bicycle ergometer (Lode NV, Groningen, The Netherlands). The subjects started with 4 min unloaded cycling ( $0 \mathrm{~W}), 4 \min 40 \mathrm{~W}, 4 \min 80$ $W$, followed by a sequential increase in work rate of $20 \mathrm{~W}$ every minute until subjective exhaustion. Criteria for maximal exercise were: levelling off of oxygen uptake, forced ventilation and a respiratory quotient ( $R$ ) higher than 1.1. The highest $\mathrm{VO}_{2}$ achieved during the test was taken as $\mathrm{VO}_{2}$ max. During the test ventilatory and gas exchange responses were measured continuously, using a computerized open system (Ergoscreen, Basel, Switzerland). Computer-calculated average values for each minute were obtained during the last $30 \mathrm{~s}$ ofeach minute of the test.

\section{Blood chemistry}

Fasting blood samples were taken after an overnight fast of $12 \mathrm{~h}$ in the respiration chamber. All samples were collected in tubes and kept on ice. FFA was determined with the NEFA C test kit (Wako), which utilizes an in vitro enzymatic

colorimetric method for the quantitative determination of non-esterified fatty acids in serum (coefficient of variation of this method is $1.6 \%$ ). Glycerol was determined with the enzymatic triglyceride assay without saponification (Boehringer, Germany; C.V $4.6 \%$ ).

With the subjects still lying in bed a biopsy was taken from subcutaneous 
fat in the abdominal region $(5-10 \mathrm{~cm}$ lateral to the imbilicus). After superficial anesthesia with $1 \%$ lidocaine a 5-mm incision was made and adipose tissue was removed using the needle technique according to Evans et al. (1982). After aspiration of at least $250 \mathrm{mg}$ tissue, fat cells were isolated in a Krebs-Ringer solution with $1 \%$ albumine, $5 \mathrm{mmol} / 1$ glucose and $1 \mathrm{mg} / \mathrm{ml}$ of collagenase (Sigma, type I)).

After incubation for $30 \mathrm{~min}$ at $37^{\circ} \mathrm{C}$ cells were freed from connective tissue and blood by filtering through a nylon screen and washed 4 times by floating. The cells were resuspended in the same K- $\mathrm{R}$ solution $(5.5 \mathrm{ml})$ without collagenase. Cell concentration was determined by counting all cells in 10 samples of $10 \mu \mathrm{l}$ from three samples of $100 \mu \mathrm{l}$ with all suspension in $900 \mu \mathrm{l} \mathrm{K-R}$ solution. Extracellular glycerol was chosen as the indicator of adipocyte lipolytic activity. Four aliquots of $1.4 \mathrm{ml}$ cell suspension were incubated in stoppered plastic vials under $\mathrm{O}_{2}+\mathrm{CO}_{2}$ $(95 \%+5 \%)$ for $180 \mathrm{~min}$, with or without $10^{-4} \mathrm{M}$ isoproterenol (Janssen Chimica, Belgium). Incuba- tion was stopped by placing the vials for 10 min at $0^{\circ} \mathrm{C}$. The glycerol concentration of the infranatant was analyzed enzymatically (Boehringer, Germany).

\section{Statistics}

Results are expressed as mean $\pm S E M$. For statistical analysis Student's $t$ test for paired and unpaired means was used.

\section{Results}

Twenty out of the 23 subjects completed the entire research protocol. There were 3 drop-outs due to dietary non-compliance $(\mathrm{N}=2)$ and failure to sustain the formula diet $(\mathrm{N}=1)$. The weight loss of these drop-outs after 5 weeks was $6.9,8.2$ and $3 \mathrm{~kg}$ respectively. Physical characteristics of the remaining subjects are presented in Table 1. Initially no differences between DE-Y, DE-NY and D-NY were observed. After 5 weeks of treatment all groups showed a decline in body weight but no significant differences between yo-yo and non-yo-yo dieters

Table 1 Physical characteristics of the subjects at the start of the treatment (mean $\pm S E M$ )

\begin{tabular}{lcrr}
\hline & $\begin{array}{l}\text { Diet-Exercise } \\
\text { Yo-yo } \\
\text { DE-Y; } n=6\end{array}$ & $\begin{array}{l}\text { Diet-Exercise } \\
\text { Non-Yo-yo } \\
\text { DE-NY: } n=7\end{array}$ & $\begin{array}{l}\text { Dlet } \\
\text { Non-Yo-yo } \\
\text { DE-NY; } n=7\end{array}$ \\
\hline Age & $36.0 \pm 2.2$ & $32.9 \pm 3.3$ & $36.0 \pm 3.2$ \\
Height $(\mathrm{cm})$ & $165.0 \pm 2.1$ & $164.0 \pm 2.3$ & $161.0 \pm 3.3$ \\
Body weight $(\mathrm{kg})$ & $92.6 \pm 3.6$ & $91.1 \pm 3.9$ & $87.5 \pm 5.0$ \\
BMI (kg/ $\left./ \mathrm{m}^{2}\right)$ & $34.4 \pm 1.3$ & $34.0 \pm 1.1$ & $33.7 \pm 1.9$ \\
Body fat $(\mathrm{kg})$ & $39.4 \pm 2.7$ & $39.0 \pm 3.7$ & $36.0 \pm 3.7$ \\
FFM $(\mathrm{kg})$ & $53.2 \pm 1.3$ & $52.1 \pm 1.7$ & $51.5 \pm 2.6$ \\
Walsthip ratio & $0.81 \pm 0.02$ & $0.83 \pm 0.04$ & $0.80 \pm 0.05$
\end{tabular}

There are no significant differences between groups 
were detected. Furthermore the effects of exercise did not result in significant differences between the dietexcreise and the diet group after 5 weeks (Table 2). After 14 weeks the diet-exercise groups had lost significantly more weight than the diet group (DE-Y $19.4 \mathrm{~kg}$, DE-NY 18.9 $\mathrm{kg}$ vs D-NY $15.2 \mathrm{~kg}(\mathrm{P}<0.05)$.

The same changes were demonstrated with respect to fat loss. After 5 weeks the fat loss was for DE-Y $9.5 \mathrm{~kg}$, for DE-NY $9.9 \mathrm{~kg}$ and for D-NY $8.2 \mathrm{~kg}$ (N.S). After 14 weeks the addition of exercise to the diet resulted in both exercise groups in significantly more fat loss (DE-Y $15.4 \mathrm{~kg}, \mathrm{DE}-\mathrm{NY} 15.2 \mathrm{~kg}$ vs D-NY $11.9 \mathrm{~kg}(\mathrm{P}<0.05)$. No significant differences in fat free mass (FFM) were observed between the three groups after 5 and 14 weeks.
If "energy efficiency" is increased after weight loss and especially after several periods of weight loss and regain, an imitial difference between yo-yo and non-yo-yo dieters in RMR might be expected. However, expressed in absolute values, RMR $(\mathrm{kJ} / \mathrm{min})$ did not differ between the groups (Table 3). Expressed per $\mathrm{kg}$ FFM, however, a significant difference between DE-NY and D-NY was observed ( 5.9 and $5.4 \mathrm{~kJ} / \mathrm{h}$ respectively; $\mathrm{P}<0.05$ ) but no difference was shown between DE-Y $(5.5 \mathrm{~kJ} / \mathrm{h})$ and the two non-yo-yo groups.

The decline in RMR expressed in absolute values also did not differ after 5 and 14 weeks between the yo-yo and the non-yo-yo groups. In all groups RMR decreased significantly after 5 and 14 weeks by 22.4 and

Table 2 Changes in body composition after 5 and 14 weeks of a diet or a diet-exercise treatment (mean $\pm S E M$ )

\begin{tabular}{|c|c|c|c|c|c|}
\hline & group & 5 weeks & $\%$ & 14 weeks & $\%$ \\
\hline Woight & $D E \cdot Y$ & $11.6 \pm 0.9$ & 12.7 & $19.4 \pm 1.4^{1}$ & 20.8 \\
\hline \multirow[t]{2}{*}{ loss (kg) } & $D E-N Y$ & $12.0 \pm 0.4$ & 13.8 & $18.9 \pm 1.6^{1}$ & 21.0 \\
\hline & D-NY & $10.4 \pm 0.9$ & 11.9 & $15.2 \pm 2.1^{\Uparrow}$ & 17.2 \\
\hline Fat & $D E-Y$ & $9.5 \pm 0.3$ & 23.1 & $15.4 \pm 0.9^{1}$ & 37.5 \\
\hline \multirow[t]{2}{*}{ loss $(\mathrm{kg})$} & DE-NY & $9.9 \pm 0.8$ & 23.1 & $15.2 \pm 1.0^{1}$ & 39.9 \\
\hline & D-NY & $8.2 \pm 0.7$ & 23.3 & $11.9 \pm 1.4^{1}$ & 33.5 \\
\hline FFM & DE-Y & $2.2 \pm 0.3$ & 4.1 & $4.0 \pm 0.6$ & 6.9 \\
\hline \multirow[t]{2}{*}{ loss $(\mathrm{kg})$} & DE.NY & $2.1 \pm 0.3$ & 4.5 & $3.7 \pm 0.6$ & 7.2 \\
\hline & DNY & $2.4 \pm 0.3$ & 4.4 & $3.3 \pm 0.5$ & 6.3 \\
\hline
\end{tabular}

$\%$ pencent difference with respect to the values at the start of the experiment

$D E-Y=$ Diet-exercise yo-yo group (frequent dieters)

DE-NY Diet-exercise non-yo-yogroup (no frequent dieters)

$\mathrm{D}-\mathrm{NY}=$ Diet non-yo-yo group (no frequent dieters)

1 P $<0.05$ DE-Y, DE-NY $>$ D-NY 
$18.9 \%$ respectively for DE-NY, 19.9 and $14.5 \%$ respectively for $\mathrm{DE}-\mathrm{Y}$, 20.5 and $22.4 \%$ respectively for $D$ NY.

The drop in RMR per $\mathrm{kg}$ FFM after 14 weeks was significant for all groups. It is interesting to note that in both exercise groups RMR per $\mathrm{kg}$ FFM increased significantlly $(\mathrm{P}<0.05)$ from week 5 to week 14 , while in the diet group RMR per $\mathrm{kg}$ FFM decreased significantly $(\mathrm{P}<0.05)$.

After 5 weeks $R$-values during the sleeping period from $3.00-6.00 \mathrm{a} . \mathrm{m}$. dropped significantly for all groups after 5 weeks, indicating maximal combustion of fat. After 14 weeks only in the yo-yo group $\mathrm{R}$ remained significantly decreased, while the non-yo-yo groups increased to base line levels. However, at the end of the study there were no significant differences between the $R$ of the three groups (Table 3).

Training status was evaluated using the measurement of maximal aerobic power ( $\mathrm{VO}_{2} \mathrm{max}$ ). Training status at the start was the same for all the groups. Due to training, $\mathrm{VO}_{2}$ max in

Table $3 \quad \mathrm{RMR}_{4} \mathrm{R}$ and $\mathrm{VO}_{2}$ max al the start after 5 weeks and after 14 weeks (mean $\pm S E M$ )

\begin{tabular}{|c|c|c|c|c|c|c|c|c|}
\hline & Group & Start & 5. weeks & $\%$ & $\mathrm{P}^{+}$ & 14 weeks & $\%$ & $\mathrm{P}+$ \\
\hline \multirow[t]{4}{*}{ RMA (kulmin) } & DEY & $5.0 \pm 0.7$ & $4.1 \pm 0.2$ & 19.9 & $*$ & $4.1 \pm 0.2$ & 4.8 & ith \\
\hline & DE-NY & $5.3 \pm 0.3$ & $4.1 \pm 0.2$ & 22.4 & $*$ & $4.2 \pm 0.3$ & $\$ 8.9$ & 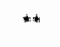 \\
\hline & DNY & $4.9 \pm 0.3$ & $3.8 \pm 0.3$ & 20.5 & ** & $3.8 \pm 0.2$ & 22.4 & + \\
\hline & & NS & \multicolumn{2}{|l|}{ MS } & & \multicolumn{3}{|l|}{ NS } \\
\hline RMA & DEY & $5.5 \pm 0.1$ & $4.9 \pm 0.1$ & 15.5 & " & $5.1 \pm 0.1$ & 13.2 & * \\
\hline \multirow[t]{2}{*}{$(\mathrm{kJ} / \mathrm{kgFFM} / \mathrm{h})$} & DENY & $5.9 \pm 0.3$ & $4.9 \pm 0.3$ & 16.1 & m* & $5.2 \pm 0.3$ & 14.5 & $*$ \\
\hline & DNY & $5.4 \pm 0.1$ & $4.7 \pm 0.3$ & 12.3 & * & $4.5 \pm 0.3$ & 17.1 & $\cdot$ \\
\hline$P<0.05$ & \multicolumn{3}{|c|}{ DE-NY>D-NY } & & & \multicolumn{3}{|c|}{$D E-Y, D E N Y>D-N Y$} \\
\hline \multirow[t]{3}{*}{$\mathrm{A}$} & DE-Y & $.82 \pm .02$ & $.68 \pm .01$ & 17.1 & $*$ & $.75 \pm 02$ & 8.5 & $*$ \\
\hline & $D E N$ & $78 \pm 01$ & $.70 \pm .02$ & 8.0 & $* *$ & $.77 \pm 0.01$ & 1.3 & NS \\
\hline & DAY & $.75 \pm .02$ & $.65 \pm .01$ & 13.3 & $*$ & $.74 \pm 02$ & 1.3 & MS \\
\hline$P<0.05$ & & $\begin{array}{c}D E-Y>D E \cdot N Y \\
D N Y\end{array}$ & NS & & & \multicolumn{3}{|l|}{ NS } \\
\hline $\mathrm{VO}_{2} \max$ & DEYY & $22.7+2.0$ & $27.4 \pm 2.3$ & 18.9 & $*$ & $32.2 \pm 1.9$ & 42.6 & $*$ \\
\hline \multirow[t]{2}{*}{$(\mathrm{m} / \mathrm{kgBW} / \mathrm{min})$} & DE-NY & $23.0 \pm 1.5$ & $28.4 \pm 0.5$ & 20.6 & $*$ & $30.7 \pm 1.7$ & 35.3 & $*$ \\
\hline & DNY & $22.0 \pm 0.9$ & $23.8 \pm 0.5$ & 8.1 & NS & $26.7 \pm 1.4$ & 18.7 & "* \\
\hline \multirow[t]{2}{*}{$P<0.05$} & \multirow{2}{*}{\multicolumn{2}{|c|}{ NS }} & \multirow{2}{*}{\multicolumn{2}{|c|}{$D E-Y, D E-N Y>D N Y$}} & & \multicolumn{3}{|c|}{$D E Y>D E-N Y$} \\
\hline & & & & & & \multicolumn{3}{|c|}{$D E N Y>D N Y$} \\
\hline
\end{tabular}

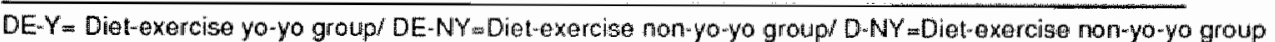
$\%$ Percentage changes with respect week 0

RMA . Resting metabolic rate measured during a period of steep from 03.00-06.00

$\mathrm{R}=$ Respiration quotient

$+\quad$ Paired test with respect to week 0 -P<0.05 * P 00.01 


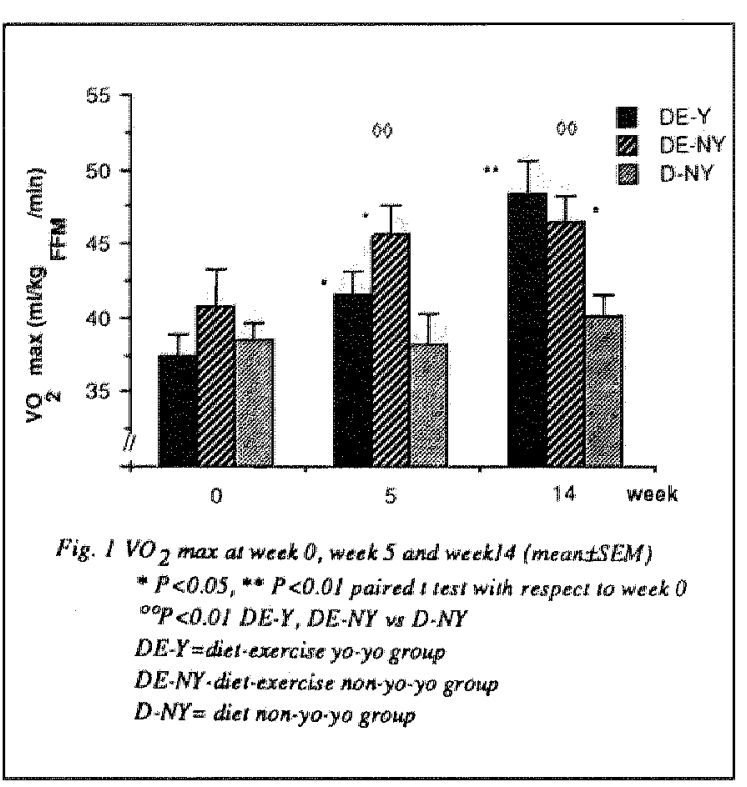

the exercise groups increased significantly after 5 and 14 weeks. The same change was observed per $\mathrm{kg}$ FFM (Fig. 1). At the start there were no significant differences between the groups (DE-Y $39.7 \mathrm{ml}$, DE-NY
$40.5 \mathrm{ml}$ and $\mathrm{D}-\mathrm{NY} 38.5 \mathrm{ml}$ $\mathrm{VO}_{2} / \mathrm{kgBW}$ ). After 5 weeks the addition of exercise resulted in signifficant increases of maximal oxygen consumption. DE-Y increased by $10.7 \%$ and DE-NY by $14.4 \%$. The diet group did not increase significantly and was significantly different from the diet-exercise groups (D-NY decreased by $-0.7 \%: \mathrm{P}<0.01$ (Fig. 1). Moreover, after 14 weeks the differences between the DE groups and the D group remained significantly larger (DE-Y increased by $14 \%, \mathrm{DE}-\mathrm{NY}$ by $16.2 \%$ and DNY by $4.5 \%$ ).

Plasma FFA and glycerol concentrations were analysed to see whether there are differences in lipid metabolism between yo-yo dieters and nonyo-yo dieters (Fig. 2). FFA plasma concentrations (mmol/l) among the groups were different at the start: DE-NY (0.446) vs D-NY (0.268) $\mathrm{P}<0.01$ and DE-Y (0.392); NS. However, no changes among groups were observed as a result of the

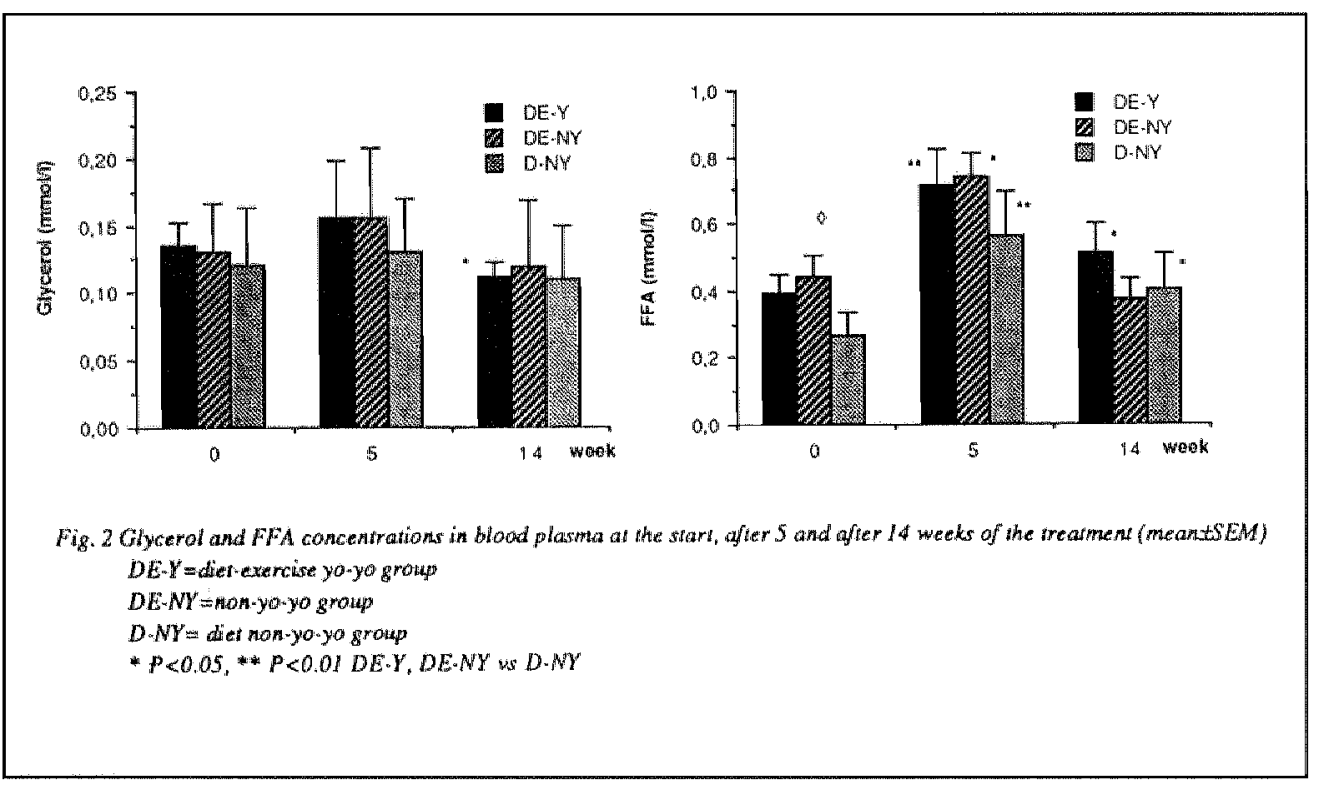


treatment. Due to the energy restriction there was a significant increase in all the groups after 5 weeks, which decreased after 14 weeks for $D E$ NY below baseline level (from 0.740 after 5 weeks to $0.375: \mathrm{P}^{*}<0.01$ after 14 weeks: NS). The other groups showed a decrease after the initial rise in FFA but did not return to baseline level at the end of the study and remained significantly increased compared to week 0 (DE-Y from 0.718 to 0.515 and $\mathrm{D}-\mathrm{NY}$ from 0.562 to $0.405: \mathrm{P}<0.05$ ).

Similar changes were observed in the glycerol plasma concentrations. From the start to week $5 \mathrm{DE}-\mathrm{Y}$ changed from 0.136 to $0.155, \mathrm{DE}$ NY from 0.130 to 0.155 and D-NY from 0.121 to $0.131 \mathrm{mmol} / 1$. At the end of the study all groups tended to have lower plasma concentrations than the baseline level, but only the yo-yo group decreased significantly DE- Y to 0.111: P $<0.05, D E-N Y$ to 0.112 and $D-N Y$ to $0.110 \mathrm{mmol} / 1$ (N.S.).

To get an impression of fat oxidation and mobilization, the lipolytic activity of abdominal adipocytes was measured (Table 4). At the start of the study there were no differences in lipolytic activily between the groups. After 5 weeks basal lipolysis was significantly increased for all the groups, while after 14 weeks basal lipolysis had returned to baseline levels. Maximal stimulated lipolysis was not different between groups at the start nor after 5 weeks. Only after 14 weeks was maximal stimnlated lipolysis significantly lower for D-NY compared to the other groups.

Table 4 In vitro glycerol release of adipocyles of the abdomimal region withoul (basal lipolysish or with stimulation of isoprotenerol (maximal stimulated lipolysis) at week 0, after 5 and after 14 weeks

\begin{tabular}{|c|c|c|c|c|c|c|}
\hline & group & week 0 & waek 5 & $\mathrm{P}$ & week $\| 4$ & $P$ \\
\hline Basal & $D E-Y$ & $0.012 \pm 0.003$ & $0.073 \pm 0.01$ & $m$ & $0.020 \pm 0.008$ & $\overline{N S}$ \\
\hline \multirow[t]{2}{*}{ Lipolysis } & DE-NY & $0.015 \pm 0.004$ & $0.094 \pm 0.01$ & $a *$ & $0.023 \pm 0.007$ & NS \\
\hline & D-NY & $\begin{array}{c}0.012 \pm 0.002 \\
\mathrm{NS}\end{array}$ & $\begin{array}{c}0.060 \pm 0.01 \\
\text { NS }\end{array}$ & " & $\begin{array}{c}0.013 \pm 0.004 \\
\text { NS }\end{array}$ & NS \\
\hline Maximal & DE-Y & $0.072 \pm 0.01$ & $0.073 \pm 0.02$ & NS & $0.094 \pm 0.02$ & NS \\
\hline Stimulated & DE-NY & $0.076 \pm 0.02$ & $0.098 \pm 0.02$ & NS & $0.089 \pm 0.02$ & NS \\
\hline \multirow[t]{2}{*}{ lipolysis } & D.NY & $0.048 \pm 0.01$ & $0.081 \pm 0.02$ & NS & $0.056 \pm 0.01$ & NS \\
\hline & & NS & NS & D-N & $\angle D E-Y, D E-N Y(P$ & $.05)$ \\
\hline
\end{tabular}

${ }^{*} P<0.05$ (paired-t-test) : $P<0.01$ (paired-t-test) with respect to wook 0

Mean waluestSEMM ( $\mu$ mol/10 $0^{5}$ cells per $180 \mathrm{~m}$ )

Basal lipolysis: no stimulation with isoprotenerol

Maximal stimulated lipolysis. stmulated with $10^{-4} \mathrm{M}$ isoprotenerol 


\section{Discussion}

\section{Criteria of (non) yo-yo dieters}

In the present study frequent obese dieters/regainers (yo-yo) were compared with obese subjects stable in weight (non-yo-yo) with respect to weight loss, fat loss and RMR. For this comparison the chosen criteria for yo-yo and non-yo-yo groups is very important, since different selection criteria may lead to different outcomes. The criteria used in this study may be criticized on two points. One point is that asking for the dieting history of obese subjects might be questionable especially for the non-yo-yo subjects. It may be argued that there are hardly any obese subjects never have attempted to lose weight. However, the subjects selected for this study as non-yo-yo subjects never had large weight changes. Another argument against the definitions might be that data with respect to weight loss and regain for only the 5 years preceding the study were involved. It is possible that there are non-yo-yo subjects who have tried several times to lose weight with no success, but gave up before these 5 years. They might still suffer from metabolic alterations due to the repetitive weight loss and regain. However, there are no data available on the long term effecls of weight cycling and data about the effects after a single weight cycle are contradictory (Jung et al., 1980; Barrows \& Snook, 1987; Geissler et al., 1987). Furthermore, according to the medical history questionnaire, the non-yo-yo subjects in this study never had lost $3 \mathrm{~kg}$ or more before the 5 year period.

\section{Fat distribution}

A difference in fat distribution between the groups could have influenced the results as fat tissue in the lower part of the body has been shown to be more resistant to lipolysis during starvation and/or exercise than fat in the abdominal region (Lafontan et al., 1979; Rebuffé-Scrive et al., 1986). However, in this study, no differences in fat distribution were found between yo-yo and non-yo-yo dieters.

\section{Weight and fat loss}

Weight loss, fat loss, and loss of fat free mass in the various groups did not indicate that yo-yoing leads to a more efficient use of energy. After 5 and 14 weeks the only differences in weight and fat loss between groups were shown between the diet and the diet-exercise groups. To get a better picture of the effects of various periods of weight loss and regain, the results of a study on a Diet-yo-yo group (D-Y), a study with the same diet protocol, were used to compare weight and fat loss with the other groups, in particular with D-NY. However, the data have to be interpreted carefully because the starting values of BMI and fat mass of both groups were significantly different. At the end of the study D-Y demonstrated differences in weight loss $(11.8 \mathrm{~kg})$ and fat loss $(6.9 \mathrm{~kg})$ with the exercise groups but not with D-NY. Moreover, it must be kept in mind that the study period of the present study was two weeks longer (14 weeks compared to 12 weeks for D-Y). Taking into account the shorter treatment period, differences between the non-yo-yo diet group and the yo-yo diet group should have been smaller. 
With respect to weight and fat loss the intensity and frequency of exercise is very important. Studies which have found significantly better effects report an exercise intensity of 60-80\% of $\mathrm{VO}_{2}$ max (Pavlou et al., 1985; Henson et al., 1987). From the results of the present study, although no exact figures about energy expenditure were given, one can conclude that the intensity of exercise was sufficient because $\mathrm{VO}_{2}$ max (per $\mathrm{kg}$ FFM) was significantly increased, indicating an increase in endurance capacity. For the diet groups, only a significant increase in $\mathrm{VO}_{2}$ max per $\mathrm{kg}$ body weight was noticed, which is most probably due to the decreased body weight (Hagan et al., 1986). The increase in $\mathrm{VO}_{2}$ max per $\mathrm{kg}$ FFM is a good indicator for the adherence to the intensity and frequency of exercise.

\section{RMR}

Despite the fact that the subjects of the yo-yo groups had several weight changes in their diet history, at the start of the experiment no differences were found between the yo-yo and the non-yo-yo groups with respect to RMR. Only RMR, expressed per kg FFM, was significantly higher for DE-NY. This is difficult to interprete as a characteristic of non-yo-yo dieters because the other non-yo-yo group (D-NY) had the lowest value. In contrast with our findings Steen et al. (1988) did show a decreased RMR in yo-yo wrestlers than non-yo-yo wrestlers. These decreased values of RMR might contribute to the accelerated weight gain after several weight cycles, which was demonstrated by Brownell in rats (1986b). Observations of realimentation of 5 weeks after energy restriction showed that RMR remained depressed, which could be an indication to a yo-yo effect (Barrows \& Snook, 1987). Post-obese subjects also had lower values of RMR than their lean counterparts (Geissler et al., 1987). However, Jung et al. (1980) did not find that RMR and hormone levels remained depressed after realimentation. From these equivocal results no clear indication of a yo-yo effect on RMR can be derived.

Similarly, the decline in RMR did not differ between yo-yo and non-yoyo dieters. In all groups RMR decreased significantly (in absolute values and per $\mathrm{kg}$ FFM) in the first 5 weeks. After 14 weeks both exercise groups had an increased RM.R, while that of D-NY (and D-Y) decreased further. Thus, in the last 8 weeks the difference between the exercise and non-exercise groups became apparent, suggesting a stimulating effect of exercise on RMR (Schultz et al., 1980; Donahoe et al., 1984; Tremblay et al., 1986). However, the differences were not significant. This is in accordance with the results of several in-patient studies with an excellent control on both energy expenditure and food in take, which also did not demonstrate significant differences between dietexercise and diet groups (Krot* kiewski et all., 1981; Warwick \& Garrow, 1981),

\section{Glycerol and FFA in plasma}

Plasma glycerol and FFA concentrations are indicators of fat mobiliza tion and utilization. Impairment of fat mobilization can also be a cause of relapses in weight loss. Higher plasma concentrations of FFA have been observed in obese subjects (Scheen et al., 1983; Lillioja et al., 
1986) suggesting that FFA turnover and lipid oxidation are lower in overweight persons. However it must be kept in mind that plasma FFA levels are dependent on their rates of mobilization and oxidation, so that plasma FFA will not adequately reflect adipocyte-lipolysis. Plasma glycerol is considered a more stable product of lipolysis.

Surprisingly, no signilicant increase in plasma glycerol was noticed after 5 weeks, although both exercise groups tended to higher levels. After 14 weeks the results showed a significant decrease in the DE-Y group but not in the DE-NY group. An explanation for this observation can not be given.

\section{Basal and stimulated lipolysis}

For a more direct measurement of fat cell activity, the lipolytic activity of the abdominal adipocytes was determined.

In accordance with the results of other studies (Arner et all, 1979; Arner et al., 1983; Kather, 1985) basal lipolysis is increased to maximal levels after 5 weeks fasting with no differences between the groups. After 14 weeks the basal lipolysis returned to the initial levels for all groups. The tendency for higher values for the exercise groups is also in accord with the findings of exercise studies which demonstrated that exercise induces increases in adipose tissue activity (Després \& Bouchard, 1984).

It is interesting to note the decrease in basal lipolysis after 14 weeks, which is also seen in the FFA and glycerol levels. One may argue that this is a combined effect of the increased thermogenic efficiency (lower RMR) and the resulting smaller energy deficit. Another pos- sible explanation is the suggested change in alpha2 and beta1 receptor balance during fasting (Desprês \& Bouchard, 1984). Nevertheless, no difference between the yo-yo and non-yo-yo groups was detected indicating that there is no increased thermogenic efficiency in the yo-yo group.

There is one factor which might have influenced the results on basal lipolytic activity. Rebuffé-Scrive et al. (1985) have demonstrated that the lipolytic activity in adipocytes can be influenced by sex hormones. Since the last measurement was taken in a different part of the menstrual cycle than the other measurements, the results may be influenced by effects of sex hormones. However, the effects of these hormones were shown in adipocytes of the femoral region, while those adipocytes of the abdominal region were hardly influenced. Furthermore this possible influence of hormonal cycle is the same for yo-yo and non-yo-yo dieters.

Stimulated lipolysis was not changed in either of the exercise groups.

Previous studies have shown that during fasting stimulated lipolysis is not increased, while with exercise it is (Després \& Bouchard, 1984). A possible explanation for the lack of stimulation after 5 weeks is that exercise and diet were combined. This combination might stimulate the fat cell to maximal values even in resting conditions. However, no results of other studies combining fasting and exercising are available.

\section{Comparison with animal studies}

One possibility for the inconsistent results of this study compared to animal studies in weight cycling is 
the fact that the effects of weight $c y$ cling in rats were especially shown in the weight gain periods (Brownell et al., 1986b). Probably the effects of weight cycling are more pronounced in the weight gain period than in the weight loss period. Another possibility might be that the energy deficit caused by the severe energy restriction and intensive training program overruled any possible mechanism which would make the yo-yo dieters be more thermogenically efficient. On the other hand at the start of the treatment there was also no difference in efficiency between yo-yo and non-yo-yo groups, which is in accordance with the results of a recent study of Hill et al. (1987a). In that study several periods of weight loss and weight gain did not result in an increased efficiency of energy utilization in rats.

In conclusion, the results of the present study do not show an increased energy efficiency for yo-yo dieters compared to non-yo-yo dieters before and during a diet or diet-exercise treatment. Diet plus exercise results in more weight and fat loss than diet alone, regardless of previous dieting history.

\section{Acknowledgements}

The authors wish to thank $E d$ Beckers, Boy Houben, Karin van de Kooy and Paul Schoffelen for their technical assistance. 



\section{WEIGHT MAINTENANCE AND}

RESTING METABOLIC RATE 18-42

MONTHS AFTER A DIET OR DIET/

EXERCISE TREATMENT

\section{Introduction}

One of the greatest problems in the treatment of obesity is the maintenance of the reduced weight level. Regardless of the type of treatment, most obese people regain weight often to pre-diet or even higher levels (Wing \& Jeffery, 1979; Saris, 1983; Jeffery, 1987). Many obese subjects claim that a life-long diet or extreme exercise levels are needed to maintain their weight loss. Tremblay and co-workers (1984b) indeed demonstrated that ex-obese subjects had to run 90 miles per week to maintain their weight loss and that their body fat level was still higher than that of their lean counterparts. These poor long term results have led to speculations about a posti obese syndrome of a persistently lower energy expenditure. Persistenly lower 24-hour energy expenditure (24-EE) and Resting Metabolic Rate (RMR) were shown compared to pre-diet levels in weight reduced subjects after one week of refeeding (de Boer et al., 1986; Barrows \& Snook, 1987). Moreover, the decreased RMR was demonstrated to be lower in post-obese subjects than in lean controls (Leibel $\&$ Hirsch, 1984; Jéquier, 1986; Doré et al., 1982). Leibel \& Hirsch (1984)

\section{D. van Dale, W.H.M. Saris, F. Ten Hoor}

Accepted to Int 1 Obes

\section{ABSTRACT}

Alter they had completed a diet (D) or a diet-exercise (DE) treatment the body composition of 44 subjects ( 32 females and 12 males) was assessed every 6 months, finally resulting in follow-up phase of 18,36 or 42 months (mean 29.5

at 11.6). Mean weight and lat loss during the study were 12.0 and $16.5 \mathrm{~kg}(P<0.05)$ respectively for the $D$ group and 10.6 and $13.8 \mathrm{~kg}$ for the $D E$ group $(P<0.01 \mathrm{D}$ ws DE). After 18 , 36 or 42 months follow-up the diet growp reganed $89.9 \%$ of their initial weight loss compared to $59.9 \%$ of the diet-exercise group ( $\mathrm{P}<0.05)$. A similar pattern was found for fat gain ( $77 \%$ for D and $54.1 \%$ for DE). Seven subjects out of the original DE group kept up their exercise activities, while 2 from the D group started exencising. These subjocts (DX) regained only $22.9 \%$ of their weight loss and $32.4 \%$ of rat loss, but their body weight ant the start of the sludy tended 10 be lowe $r$ cotrpyated to the diet and diet-exercise groups (86.5 $(\mathbb{E X})$ vs 91.4 and $95.2 \mathrm{~kg}$ for $\mathrm{D}$ and $\mathrm{DL}$ restectively).

During the last follow-up masurement the resting metabolic rate of 18 subjects was deiermined. RMR of successfully (weight gain after treatment less that $25 \%$ ) and moderately successfulty reduced obese subjects (25-75\%) was found to show higher values at the time of the follow-up compared to RMR of regainers (weight gain more than 75\%) dewpite the lower body weight of the surcessful subjects. Detailed andysis revealed that excreise was an imporiant factor contributing to the increased values of RMR. 
reported a $28 \%$ lower metabolic rate for successfully reduced obese subjects compared to lean and obese subjects. In other studies, however, similar RMR for successful reducedobese and lean subjects were observed (Dore et al., 1982; James et al., 1987). In addition, morbidly obese women were found to have normalized RMR values after massive weight loss (Tang et al., 1988). Differences in study results can be explained by differences in methodology and, perhaps even more important, by the fact that in some of the studies subjects were still in a dynamic phase of weight loss.

Since exercise elevates energy expenditure during an exercise session, and probably for several hours after the exercise session (Goldberg et al., 1988b), it has been suggested that this could be a stimulus, promoting weight loss and its maintenance (Epstein \& Wing, 1980; Thompson et al, 1982). Long term studies have revealed that treatment programs combining diet, behavioural treatment and exercise had significantly better results in the long-term management of obesity than diet or behavioural treatment alone (Harris \& Hallbauer, 1973; Stalonas et al., 1978; Dahlkoetter et al., 1979).

Similarly, in comparing successful maintainers and regainers exercise was found to be a key factor for a stable lower body weight (Kayman, 1986; Holden et al., 1988).

In the present study participants of three studies on the effects of a diet or a diet/exercise treatment on body

Table 1

Information about weight loss, numbers and sex of subjects of 3 dietlexercise studies and their body mass index, treatment period, diet, training and follow-up period

\begin{tabular}{|c|c|c|c|c|}
\hline & & Study & Study III & Study III \\
\hline Number and sex of subjects & & $16 \mathrm{~F}$ & $15 \mathrm{M}$ & $23 F$ \\
\hline Drop-outs during treatment & & 4 & 3 & 3 \\
\hline Mean Body Mass Index & $\mathrm{D}$ & $30.3(N=6)$ & $32.2(\mathrm{~N}=6)$ & $33.7(\mathrm{~N}=7)$ \\
\hline (BMl; $\left.k g / m^{2}\right)$ & $\mathrm{DE}$ & $30.3(N=6)$ & $32.9(N=6)$ & $34.2(N=13)$ \\
\hline Woeks of treatment & & 12 & 14 & 14 \\
\hline Mean daily energy intake & $D$ & 3.1 & 3.5 & 3.2 \\
\hline (MJ/day) & $D E$ & 3.3 & 3.4 & $3.1 / 3.2$ \\
\hline Mean weilght loss during & $\mathrm{D}$ & 12.2 & 15.1 & $15.2^{*}$ \\
\hline treatment $(\mathrm{kg})$ & DE & 13.2 & 16.4 & $19.4 / 18.9^{\circ}$ \\
\hline \multirow[t]{3}{*}{ Training (h per week) } & DE & aerobic (2) & aerobic (2) & aerobic (2) \\
\hline & & fitness (2) & fitness (2) & fitness (2) \\
\hline & & & jogging (1) & \\
\hline Months of follow-up & & $42(N=10)$ & $36(N=11)$ & $18(N=15)$ \\
\hline
\end{tabular}

- In study III groups were sellected on basis the of diet history: no dieting or frequent dieting. This resulted in D-NY( diet group/never dieting), DE-Y (diet-exercise group/ frequent diaters) and DE-NY (diet-exercise group/never dieting) (wan Dale \& Saris, 1989) 
composition and RMR, were followed over periods of 18,36 or 42 months post-treatment. The purpose of the study was to evaluate weight, fat and fat free mass loss 18,36 or 42 months after cessation of the diet or the diet-exercise treatment and to compare the exercise activities and RMR of successful maintainers with those of regainers.

\section{Methods}

\section{Subjects}

Fifty-four healthy obese subjects ( 39 females and 15 males) entered three different diet-exercise studies. Fourty-four subjects ( 32 females and 12 males) successfully completed the intervention programs with a diet treatment ( $N=19)$ or a diet-exercise treatment $(\mathrm{N}=25)$. This group was followed for periods of 18,36 or 42 months.

\section{Procedure}

For the present follow-up study subjects of 3 different diet or diet-exercise studies were pooled. Detailled information about subjects and treatment in the 3 studies is presented in Table 1. Follow-up measurements were performed every half year starting 6 months after completion of the treatment. This resulted in a followup period of 18,36 or 42 months, depending on the moment the study was started (Table 1). During the follow-up phase the subjects were not on any maintenance program with respect to diet or exercise activities.

\section{Follow-up measurements}

The follow-up measurements consisted of a determination of body composition by hydrostatic weigh- ing, as described by Wan Dale et al.. (1987) and recording of exercise activities such as aerobics, jogging, fitness training, etc. by means of a questionnaire. Activities such as brisk walks or cycle tours lasting 0.5 hour or more were also considered as exercise. From these data the hours of exercise per week were calculated. At the last evaluation session, after 18,36 or 42 months respectively, RMR measurements were also performed. For technical reasons RMR was determined in only 18 subjects. Nine of these subjects were selected on the basis of the information that they had continued exercise activities during the follow-up phase. The other 9 subjects were randomly selected from the subjects who had had no exercise activities during the post treatment period. Subjects had not been on any energy restricted diet six months before the RMR measurements. The day before the RMR measurements no exercise was allowed.

Energy exchange was determined in a respiration chamber as previously described (Schoffelen et al., 1985).

RMR was calculated from energy exchange measurements during the sleeping period from 03.00 to 06.00 a.m. Although we actually measured sleeping metabolic rate, the term RMR is used in the present study, as sleeping metabolic rate has been reported to be on average only about $5 \%$ lower than resting metabolic rate (Goldberg et al., 1988a).

\section{Data analysis}

Results are expressed as means \pm SEM. Comparisons between groups were made using a one-way analysis of variance. Significant comparisons were analysed in detail using student's t test. Within group 

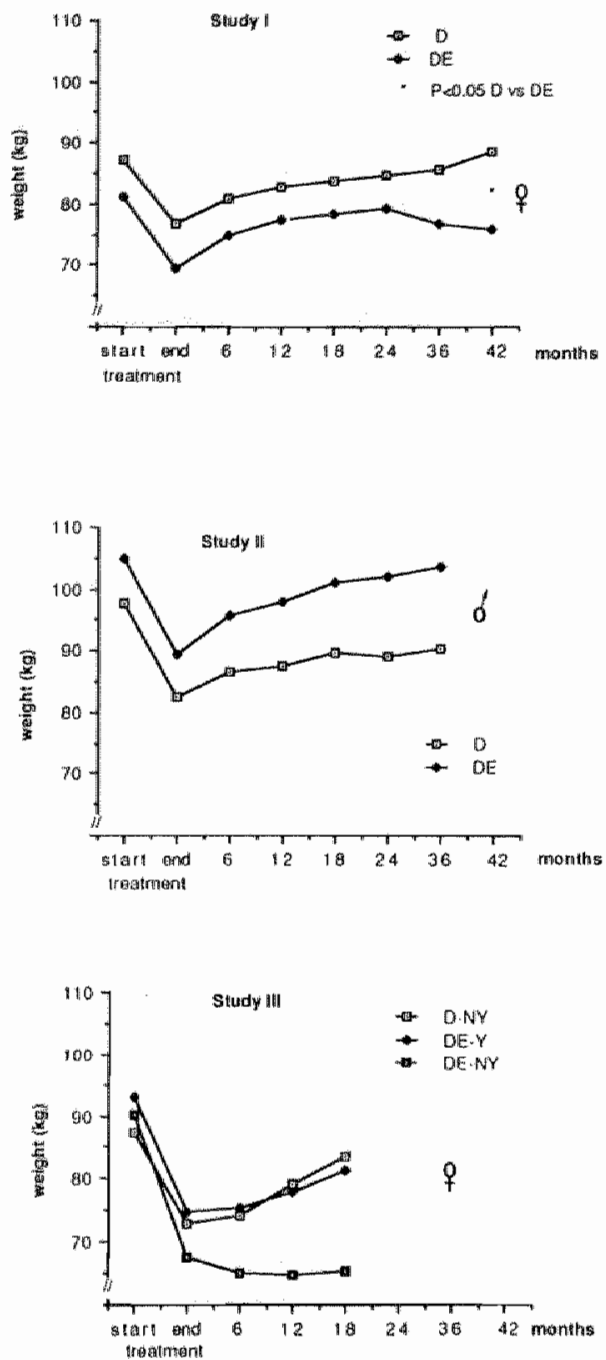

Fig. I Weight changes during a diet (D) or a diet exercise treatment (DE) and during an 18,36 or 42 months follow-up period.

$D=$ diet group; $D E=$ diet-exercise group; $D N Y=$ diel non-yo-yo group;

$D E-Y=$ diel-exercise yo-yo group: $D E-N Y=$ diel-exercise non-yo-ya group (from this group 4 subjects dropped out'). 
comparisons were performed with the Student's t test for paired means.

\section{Results}

Ten subjects did not complete the treatment for reasons such as noncompliance and inability to sustain. the severe energy restriction diet. In the subsequent follow-up phase 8 subjects ( 7 females and 1 male) withdrew from the study. Mean weight, percentage of fat at the start and weight loss of these drop-outs during the treatment was $90.7 \pm 2.8$ $\mathrm{kg}, 40.7 \pm 16 \%$ and $14.3 \pm 1.4 \mathrm{~kg}$ respectively, which was not significantly different from the other participants. Reasons for their refusal to attend all the follow-up measurements are not exactly known. We have the impression that their refusal was associated with the weight gain. In the end, of the or iginal 54 subjects, 17 subjects in the D group and 19 subjects in the diet-exercise group completed the follow-up period.

In Fig. 1 the weight changes during the follow-up phase are presented for all 3 studies. Without exception all groups gained weight after completing the diet period with or without the intensive exercise program and this weight gain increased proportionally with time after treatment.

It was found that most of the subjects of the original DE groups had not continued exercise. Seventy two percent (18 subjects) discontinued the exercise training after completing the treatment. Only $28 \%$ (7 subjects) of the DE group and 2 subjects in the D group continued or started physical training in the fol- low-up period. During the entire follow-up period their mean exercise period was $3 \mathrm{~h}$ per week (range 1.5-6 h).

With respect to successful weight maintenance and body composition changes, subjects who had maintained or started exercise activities during the follow-up phase (EX) were compared with the original diet (D) and diet-exercise groups (DE), who had not engaged in exercise activities during the follow-up. In Table 2 a comparison is made between the D group, the DE group and the EX group with respect to duration of the follow-up and the number of subjects who were successful in their weight maintenance. Successful maintainers were delined as subjects who regained less than $25 \%$ of their weight loss, moderately successful as those who regained 25 to $75 \%$ of their weight loss and regainers as subjects, who regained more than $75 \%$ of their initial weight loss. Those who maintained their exercise activities (EX) were most successful; there were no regainers but only successful and moderately successful maintainers. Of the original D group and DE groups fewer subjects were able to maintain their weight loss. Only $29.4 \%$ (D) and $27.8 \%$ (DE) managed to regain less than $75 \%$ of their original weight. The others regained more of their weight loss. A remarkable finding was the large drop-out rate for the DE group (33.3\%) compared to that of the D group (11.1\%).

Another important fact to note is that for the EX group, the length of the follow-up period was only 26 months compared to 32 months for the D and DE groups (N.S.). In order to take account for this possible time effect, weight and fat mass 
Table 2 Numbers of subjects with less than 25\%, 25-75\% and more than $75 \%$ weight gain during the follow up period.

\begin{tabular}{lccc}
\hline & $D$ & DE & EX \\
\hline less than 25\% weight gain" & 1 & 2 & 5 \\
25\%-75\% weight gain & 4 & 3 & 4 \\
more than 75\% weight gain & 10 & 7 & 0 \\
Drop-out & 2 & 6 & 0 \\
Number of subjects in the follow-up & & & \\
study after 18, 36 or 42 months & 15 & 12 & 9 \\
Mean follow-up period (months) & 32.2 & 31.8 & 26.0 \\
SEM & 2.7 & 2.8 & 4.0
\end{tabular}

$1 \mathrm{D}$ and DE are the subjects of the original diet and diet-exercise groups, who had no exercise activities during the follow-up phase.

2 EX are the subjects, who had regular exercise activities during the rollow-up periad of 18,36 or 42 months.

* Percentage weight gain is defined as body weight after 18,36 or 42 months follow-up minus body weight after $12 / 14$ weeks treatment.

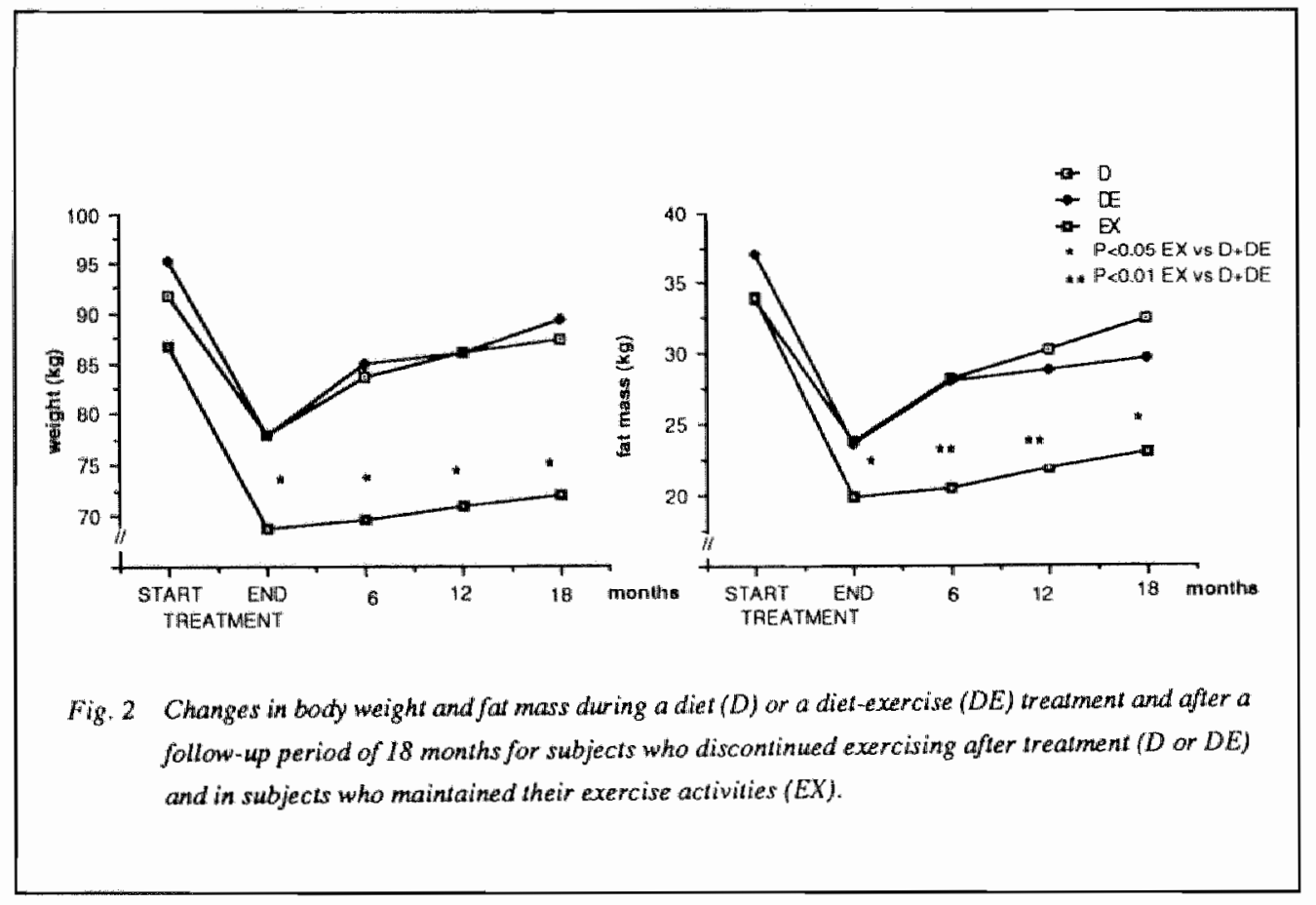


were compared for all 3 studies 18 months after completion of the study (Fig. 2). This comparison at 18 months revealed findings similar to the ones mentioned above, with a smaller weight gain for those subjects who maintained exercise activities (EX). Although the EX group tended to have a lower body weight at the start, the differences with the D and DE group were not statistically significant. However, compared to the D and DE groups body weight and fat mass in the EX group was lower at the start of the follow-up period, and remained lower during the follow-up period. Detailed information about weight and body composition after 18,36 or 42 months of follow-up is given in Table 3. A diet-exercise treatment was found to result in a larger weight

Table 3 Weight lass and changes in body composition after 14 weeks of a dies (D) or a diet-exercise treatment (DE) and a follow-up period in subjects who exercised during follow-up (EX) and those who had no exercise during follow-up (D and DE) (meantSEM).

\begin{tabular}{|c|c|c|c|c|}
\hline & $D(\mathbb{N}=15)$ & $D E(N=12)$ & $\mathrm{EX}(\mathrm{N}=9)$ & $P$ \\
\hline Body weight at start (kg) & $91.4 \pm 2.8$ & $95.2 \pm 3.2$ & $86.5 \pm 3.5$ & N.S. \\
\hline Weight loss during treatment $(\mathrm{kg})$ & $12.0 \pm 0.9$ & $16.5 \pm 1.0$ & $17.9 \pm 1.9$ & "EX, DEvs D \\
\hline $\begin{array}{l}\text { Weight loss at the end of the } \\
\text { follow-up period }{ }^{1}(\mathrm{~kg})\end{array}$ & $2.7 \pm 1.7$ & $7.7 \pm 1.9$ & $14.4 \pm 2.4$ & $\begin{array}{r}\text { DEvs D } \\
\text { "EX us D }\end{array}$ \\
\hline Percentage fat at start & $36.8 \pm 1.3$ & $39.2 \pm 1.4$ & $38.6 \pm 1.6$ & N.S. \\
\hline$\Delta \%$ fat during treatment & $7.0 \pm 0.5$ & $9.4 \pm 0.4$ & $10.8 \pm 0.6$ & $\begin{array}{l}\because \text { EX,DEws D } \\
\text { EXvsDE }\end{array}$ \\
\hline $\begin{array}{l}\Delta \% \text { fat at the end of the } \\
\text { follow-up period }{ }^{1}\end{array}$ & $0.1 \pm 0.9$ & $4.3 \pm 1.8$ & $7.0 \pm 1.3$ & $\begin{array}{l}* \text { EX, DE ws D } \\
\text { DEvs D }\end{array}$ \\
\hline Fat mass at start (kg) & $34.0 \pm 1.9$ & $37.2 \pm 1.7$ & $33.8 \pm 2.6$ & N.S. \\
\hline Fat loss during treatment $(\mathrm{kg})$ & $9.5 \pm 0.8$ & $13.5 \pm 0.8$ & $14.0 \pm 1.2$ & "EX, DEWS D \\
\hline $\begin{array}{l}\text { Fat loss at the end of the } \\
\text { follow-up period }{ }^{1}(\mathrm{~kg})\end{array}$ & $1.7 \pm 1.2$ & $5.5 \pm 2.8$ & $10.3 \pm 1.9$ & "EXvs D \\
\hline Fat free mass at start $(\mathrm{kg})$ & $57.8 \pm 1.9$ & $58.0 \pm 2.5$ & $52.7 \pm 1.3$ & * EX $w$ \\
\hline Loss of FFM during treatment $(\mathrm{kg})$ & $2.5 \pm 0.4$ & $3.0 \pm 0.6$ & $3.9 \pm 0.6$ & N.S. \\
\hline $\begin{array}{l}\text { Loss of FFM at the end } \\
\text { follow-up period } 1(\mathrm{~kg})\end{array}$ & $1.0 \pm 0.7$ & $2.2 \pm 1.0$ & $4.1 \pm 0.7$ & N.S. \\
\hline \multicolumn{5}{|c|}{$\begin{array}{l}\text { "P<0.05," } P<0.01 \text { and "* } P<0.005 \text {. } \\
1 \text { weight, percentage fat, fat mass and fat free mass at the end of the follow-up period compared to } \\
\text { base line values. }\end{array}$} \\
\hline
\end{tabular}


and fat loss during treatment but also in a better maintenance of weight and fat loss compared to a diet treatment only. Moreover, the subjects who had maintained their exercise activities showed the best results on the long term. Subjects who continued exercising regained $22.9 \%$ of their initial weight loss, compared to $89.9 \%$ and $59.9 \%$ of the subjects in the diet and diet-exercise group, who did not continue exercise training $(P<0.05$ for EX vs D and for DE v $D$ ). Similar results were found in the maintenance of fat mass and the percentage of fat.

Seventy seven percent of the initial fat loss was regained in the D group, compared to $54.1 \%$ in the dict-exer- cise group, whereas the lowest increase $(32.4 \%)$ was observed in the subjects who kept exercising $(\mathrm{P}<0.05 \mathrm{D}$ vs EX). Exercise did not result in a gain of fat free mass, since the EX group remained similar in fat free mass compared to the results directly after treatment. The other groups gained fat free mass in proportion to their fat gain.

Since so many people had difficulties maintaining their weight, it may be questioned whether there were differences between successful maintainers and regainers in the adaptation of metabolic rate during and after dieting between successful maintainers and regainers. Fig. 3 presents changes in resting metabolic rate

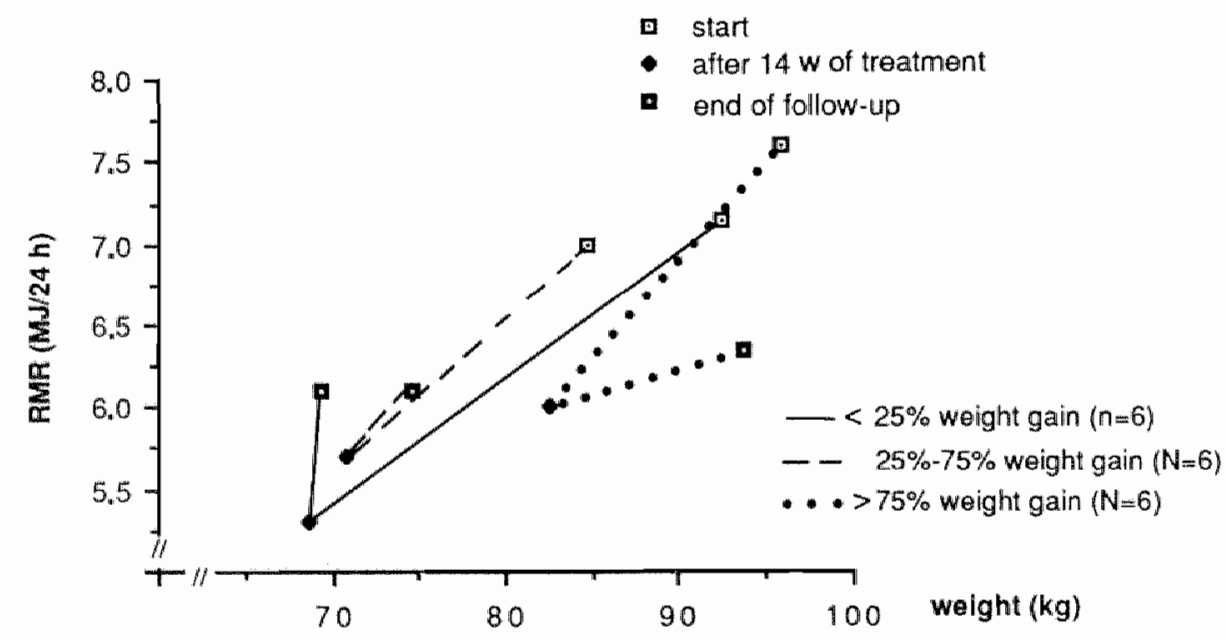

Fig. 3 Changes in resting melabolic rate (RMR) in relation to body weight, at the shart and after 14 weeks of treatment $(D$ or $D E$ ), and a the end of the follow-up period, for subjects who regained less than $25 \%, 25-75 \%$ or more than $75 \%$ of the ir initial weight loss. RMR is calculated as. average RMRih measured from 03.00-06.00 a.m.* $24 \mathrm{~h}$. 
and weight during treatment and follow-up of 6 regainers, 6 moderately successful maintainers and 6 successful subjects.

Expressed in absolute values RMR did not differ significantly at the start of the study (successful maintainers $7.14 \mathrm{MJ} / 24 \mathrm{~h}$, moderately successfull maintainers $6.96 \mathrm{MJ} / 24$ h and regainers $7.59 \mathrm{MJ} / 24 \mathrm{~h}$ ). During treatment the successful maintainers showed a smaller decline in RMR (11\%) compared to the moderately successful maintainers (20\%) and the regainers ( $23 \% ; \mathrm{P}<0.05$ successful ws moderately successful maintainers and regainers). At the end of the follow-up the higher RMR values for the successful subjects had become more pronounced. Regainers did not seem to increase their metabolic rate proportionally to their body weight, in contrast with the successful subjects who showed higher values of RMR compared to post-treatment values, despite a minimal weight gain. Since most of the successful maintainers were still exercising, a similar comparison was made between exercising and non-exercising subjects of the $\mathrm{D}$ and $\mathrm{DE}$ group. From Fig. 4 it can be seen that subjects who maintained their exercise activities during the followup phase increased their RMR more than non-exercising subjects from the D and DE group, despite a larger weight gain for the latter subjects. Expressed per $\mathrm{kg}$ fat free mass. and per $\mathrm{kg}$ body weight, the differences become more clear. The difference in RMR per $\mathrm{kg}$ body weight at the end of the follow-up period reached the level of significance. Although there is a difference in the length of the follow-up period between the non-exercisers and the exercising subjects, it is not likely that with equal follow-up periods the differences between the groups would have been smaller.

\section{Discussion}

\section{Drop-out}

Maintaining weight loss has been demonstrated to be one of the most difficult tasks in obesity treatment. Most studies have reported a considerable regain (Björvell \& Rössner, 1986; Andersen et al., 1988; Hovell et al., 1988; Kirschner et al., 1988) or a large drop- out rate in the long term (Van Gaal, 1986). In the present study $17 \%$ of the partipants did not complete the treatment and from the subjects who successfully completed it, $18 \%$ withdrew during the maintenance phase, which is low compared to other studies without a maintenance program (Hovell et al., 1988; Perri et al., 1988). Most of the drop-outs were found in the $\mathrm{DE}$ groups.

\section{Maintenance of weight and fat loss}

Like other investigators (Björvell \& Rössner, 1986; Andersen et al., 1988; Hovell et al., 1988; Kirschner et al., 1988), we also found that the maintenance of body weight after a treatment to be very difficult. Most of the subjects from the diet $(58 \%)$ or the $\mathrm{DE}$ group (39\%) regained more than $75 \%$ of their initial weight loss. Although the DE group seemed to have better weight maintenance, when the large drop-out rate in the DE group was taken into account, the D and DE group were found to have a similar percentage unsuccessful subjects (D $70 \%$ and DE $72 \%$ ). 

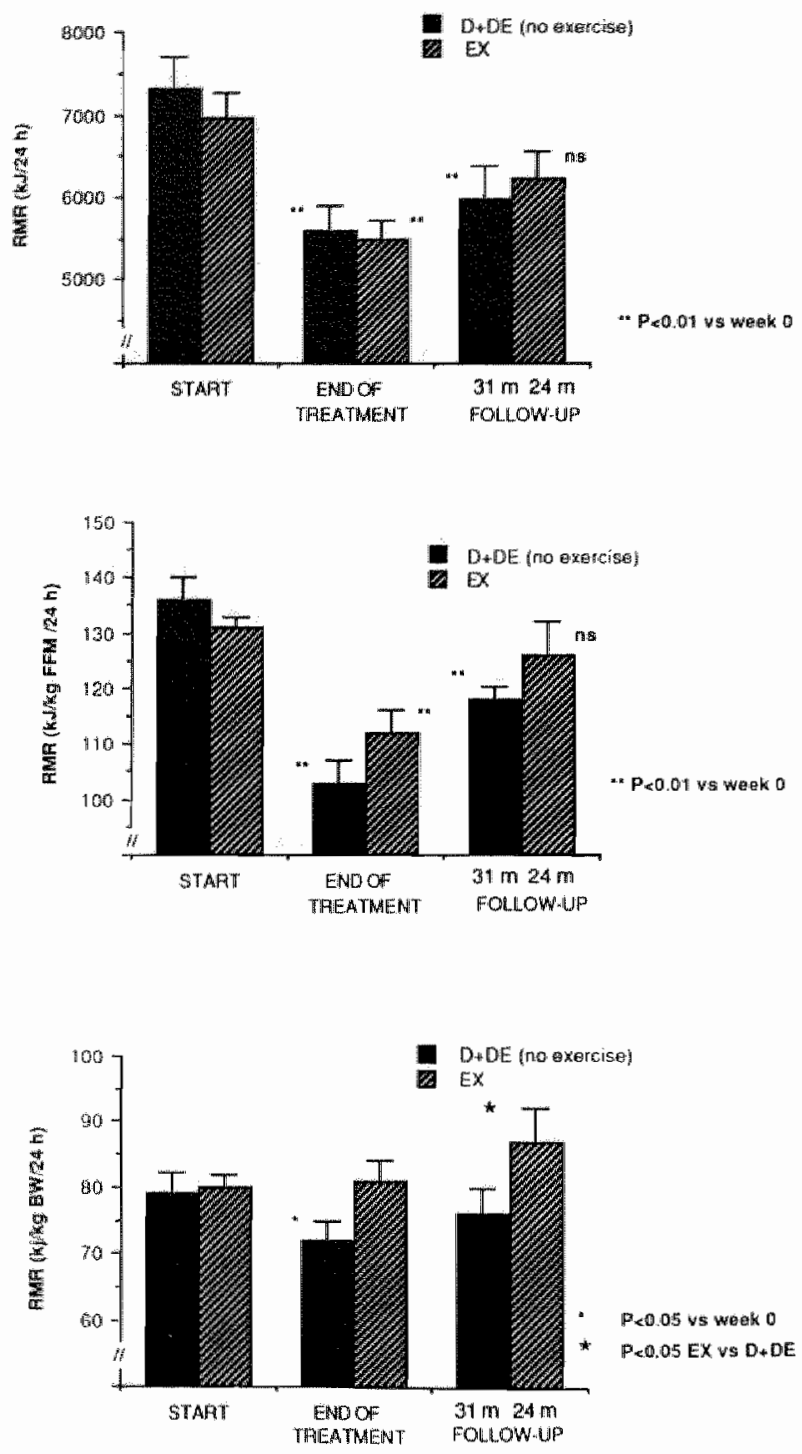

Fig. A RMR, RMR per kg fat free mass and RMR per $\mathrm{kg}$ body weight at the start, after 14 weeks of treatment $(D$ or $D E$ ) and after a follow-up of 31 months for subjects who discontinued exercising $(D+D E ; N=9)$ and at a follow-up of 24 months for subjects who maintained exercise activities during the follow-up period (EX; $N=9)$.

RMR is calculared as: average RMR / h measured from $03.00-06.00 \mathrm{~h} \mathrm{am}$ *24 $\mathrm{h}$. 
In contrast with these disappointing results a better weight maintenance was shown for a small number of subjects from the $\mathrm{DE}$ group $(\mathrm{N}=7)$ and the $D$ group $(\mathbb{N}=2)$, who kept exercising or started to exercise (EX). The subjects who went on exercising maintained most of their weight loss and showed significantly lower body weight, fat percentage and fat mass at the end of the follow-up period. However, the average number of months of follow-up tended to be smaller for the subjects from the EX group (26 months) than for those from the D and DE groups (32 months). Since it was shown (Fig. 1) that weight increases with time, it is possible that these differences between the EX and D/DE groups have to be attributed to a time effect instead of an exercise effect. Therefore we compared the three groups 18 months after treatment (Fïg. 2). Since similar results are shown after 18 months as after 26 months (the mean follow-up of $\mathrm{EX}$ ) and 32 months (the mean follow-up period of $\mathrm{D}$ and $\mathrm{DE}$ ), the better weight maintenance for the exercising subjects could be attributed to an exercise effect. Moreover, the mean uncrease in body weight in studies I and II (Fig. 1) from 18 to 42 or 36 months is only about $2 \mathrm{~kg}$. Assuming a simillar follow-up period for the EX group, with a similar weight increase over this period, the weight loss would still be significantly better compared to the D and DE groups. Another difference, although not significant, between the EX group and the $\mathrm{D}$ and $\mathrm{DE}$ groups is the lower body weight and fat mass for the EX group at the start of the follow-up period. It is possible that because of their lower body weight it was easier for them to stay physically active, since they were less hampered by excess body fat compared to subjects with a higher body weight and more fat.

\section{RMR and maintenance of exercise activities}

In addition to the better maintenance of weight loss and body composition, the EX group also showed significantly better values with respect to the restoration of RMR in the long term. Despite the maintenance of their weight loss, RMR increased to similar or higher values than those for the non-exercising subjects, who showed a considerable regain. In addition, when the $R M R$ of subjects who had less than $25 \%$ weight gain, was compared with that of subjects who had regained more than $75 \%$ of their weight loss, similar higher $R M R$ values were found for the successful maintainers at the end of the follow-up. However, as mentioned above the follow-up period was shorter for the successful maintainers ( 24 months) than for the non-exercising subjects (31 months). The length of the period after a treatment is important with respect to the possibility of depressed values of $R M R$. The most depressed vallues are to be expected soon after treatment. Since the period between treatment and follow-up was shortest for the successfully reduced obese (18 months), correcting for the difference in time might have led to even more significant differences.

Other studies of RMR in successfully reduced obese subjects have reported equivocal results. Normal values were found in severely obese subjects who had lost a considerable amount of weight (Doré et al., 1982; Tang et all, 1988). In contrast with 
these findings were the still depressed values of RMR 32 months after treatment in the present study (D + DE $18.6 \%$ compared to EX $9.8 \%$ lower with respect to baseline values). Similar lower values at the end of the follow-up period were shown in RMR per $\mathrm{kg}$ FFM (D + DE $15.8 \%$ vs EX $3.7 \%$ $\mathrm{P}<0.05)$. On the basis of subjective reports of energy intake, James at al. (1987) demonstrated that post-obese subjects had lower energy requirements. However, the determination of energy requirements in a respiration chamber revealed similar energy requirements in these post-obese subjects compared to normal controls. On the other hand, other studies have shown lower RMR values after successful dieting, implying more difficulties in maintaining body weight (Leibel \& Hirsch, 1984; Jequier, 1986; Geissler et al., 1987; Jequier, 1988). So far, no other studies have reported a higher RMR for successfully reduced obese subjects, as we have found in the present study.

The observation that those who continued exercise showed the best results in the long term management of their weight is in agreement with studies reporting that exercise or daily physical activity is one of the few factors predicting success in the long run (Miller \& Sims, 1981; Brownell, 1984; Hoiberg et al., 1984).

\section{Physiogical advantages of exercise}

Why is exercise so important? First of all it increases energy expenditure during the exercise session as well as for a few thours afterwards. The suggestion that exercise results in a sustained elevation of RMR for more than a few hours, which has been extensively discussed (Thompson \& Blanton, 1987), has not been clearly confirmed in short term studies. However, the results of the present study seem to indicate that exercise prewents a sustained decrease in RMR in the long term. Since these elevated values could not be attributed to the effects of exercise taken on the previous day, it may be concluded that the elevated RMR in the $\mathbb{E X}$ group was due to long term effects of exercise. However, in view of the small number of subjects involved, further studies should be performed to confirm this finding.

\section{Psychological advantages of exercise}

Apart from physiologicall advantages of exercise there are also psychological effects which may enhance weight maintenance. Epstein \& Wing (1980) suggested an advantageous effect of exercise on control of eating. For obese subjects eating and especially the loss of control of eating are often related to their emotional state and changes in emotions (Rodin, 1984). Eating is often used as a stress-coping behaviour and exercise training could serve as a replacement for eating as a consequence of emotional disturbance. Furthermore a weight reduction regimen itself induces stress and exercise has been shown to reduce this stress (Burbach \& Schomer, 1987). Similarly, regular exercise participation has been demonstrated to have favourable effects on happiness, depression and self-acceptance. Such factors can divert the subject's attention away from food intake (Carter, 1977; Heaps, 1978). 


\section{Effects of discontinuing exercise}

Our results and those of others (Harris \& Hallbauer, 1973; Stalonas et al., 1978; Dahlkoetter et al., 1979; Kayman, 1986) have been made it clear that exercise is an important factor, which can contribute to long term success of weight maintenance. On the other hand, if not continued, the effects of exercise do not last very long, and a rebound reaction can occur when subjects discontinue physical training. In contrast with the increased lipid oxidation and mobilization during exercise, detraining has been demonstrated to be associated with an increased adipose lipoprotein lipase activity and lipogenesis in rats (Applegate et al., 1984; Applegate \& Stern, 1987). In man, adaptations obtained during training, e.g. an increased activity of skeletal muscle fat metabolizing enzymes, are lost during a detraining of 8 weeks (Sjogaard, 1984). An increased capacity for lipogenesis has also been clemonstrated in ex-marathon runners, who, after an initial fat loss of $22 \%$ during training, increased their body fat to $95 \%$ of pretraining levels after 8 weeks of detraining (Titchenal et al., 1987). In the present study, weight gain and increase of fat mass after 18,36 or 42 months of follow-up did not differ between the diet and diet-exercise group, despite the removal of subjects who kept up their exercise activities $(\mathrm{N}=7)$. The $\mathrm{D}$ group increased with $6.9 \%(9.3 \mathrm{~kg})$, compared to $5.1 \%(8.3 \mathrm{~kg})$ in the diet-exercise group (N.S.). Similar comparisons were made for 6 months post treatment, but no significant differences were observed.

\section{Diet-Induced Thermogenesis}

With respect to the possible existence of a "post-obesity syndrome", Diet Induced Thermogenesis (DIT) has been suggested as one of the factors leading to a reduced energy expenditure in post-obese subjects compared to their lean counterparts. Jéquier (1988) showed that in reduced obese subjects (DIT) was decreased compared to lean controls. Results of other studies also suggest that a reduction in energy requirements may occur particularly in a reduced DIT (de Boer et al., 1986). Such a reduced DIT might play a role in the difficulty of maintaining weight. However, the difference in DIT between lean and obese subjects is very small. The differences in food intake between lean and obese subjects shown by James et al., (1987) are much larger and it is likely that these differences in food intake form a more important contribution to weight gain than the observed small differences in DIT.

\section{Conclusion}

In summary, exercise promotes diet induced weight reduction and is important for a long term success in weight maintenance. It may be that exercise induces an elevated RMR in the long term, since subjects from the EX group revealed higher values, than non-excrcising subjects from the D and DE groups, who showed still a depressed RMR after 32 months post treatment, despite a large weight gain. Some of the subjects of the D $+D E$ group showed still after 32 months post treatment depressed RMR values despite weight gain. However, since in the present study anly a small number of subjects was involved, further 
Long Term Effects

studies are needed to confirm this

suggestion. 


\section{DISCUSSION}

\section{AND GENERAL CONCLUSIONS}

In the present thesis short and long term results of four different studies about the effects of diet or diet-exercise studies have been presented. It was hypothesized that a combination of an energy restricted diet and exercise program has better effects on weight reduction and on metabolic factors associated with weight loss than diet treatment alone, resulting in alarger and sustained weight and fat loss.

\section{Energy intake}

One of the most difficult objectives in obesity research is to monitor the compliance to the diet. It has been demonstrated that particularly obese people tend to underreport their actual food intake (Hallfrisch et al., 1982). However, recently underreporting has also been demonstrated in lean subjects (Lissner et al., 1988). In any case, it is clear that determination of the actual food intake is very difficult. In the present study a low energy formula diet $(3.0 \mathrm{MJ})$ was provided in the first 4-5 weeks of the treatment period. Except in chapter 4 , the formula diet was reduced to $1.7 \mathrm{MJ}$ during the last 8 weeks of the treatment period and supplemented with normall food $(1.5 \mathrm{MJ})$. The reason for this approach was the assumed better compliance to a formula diet. However, since a formula diet will not change food habits, a supplementation with normal food was given in the second period of the treatment in order to educate subjects about changing their food habits. An estimation of the actual food intake was obtained by means of a diary. Most of the subjects reported fewer difficulties with the formula diet than with the combination of the formula diet and normal food. In addition, it was in the mixed diet period that the highest number of drop-outs due to non-compliance to the diet was recorded. No other data were found to support the assumption that a formula diet results in a better dietary compliance.

Both dieting and exercise have been shown to influence vitamin B requirements (Conzolazio, 1971b; Belko et al., 1984). Therefore in study II (chapter 5) vitamin intake and vitamin concentrations in plasma were determined. In previous studies (Conzolazio, 1971b, Belko et al., 1984) vitamins $B$, and in particular riboflavin status, has been shown to decrease during dieting and exercise, whereas the present study showed no larger decreases in thiamin and riboflavin for the dietexercise group. This may be explained by the fact that in the abovementioned study subjects were marginally deficient with respect to riboflavin at the start of the study, and vitamin intake during the study was also lower than in the present study. A higher intake of riboflavin did not result in major decreases in riboflavin concentration during dieting and exercise (Belko et all, 1984). Exercise studies have shown that exercise acutely affects vitamin B-6 concentration. The large decrease in vitamin B-6 for the diet-exercise 
groups was in agreement with the results of such studies (Belko et al., 1985; Belko, 1987b).

Although vitamin intake was within the normal range, large decreases in the fat soluble vitamins were demonstrated for both groups (chapter 5, Table 4). This decrease was in agreement with other studies and appeared to be independent of the vitamin intake (Zwiauer et $a 1 ., 1986$; Widhalm et al., 1988), since supplementation of especially vitamin A did not result in an increase in plasma concentration during dieting (Widhalm et al., 1988). The decrease in vitamus $A$ and $E$ has been found to be caused by a decrease in plasma proteins (Zwiauer et al, 1986 ; Widhalm etal., 1988). The significant correlation between the decrease in fat free mass and the decrease in vitamins $A$ and $E$ found in the present study points in the same direction.

\section{Energy expenditure}

There are two ways to increase energy expenditure. One is to increase programmed activities, including sports and exercises that occur in scheduled sessions (e.g. jogging, swimming, aerobic dancing), and the other is to increase routine (regular) activities, which can readily be incorporated into daily living (using stairs instead of elevators, walking instead of driving short distances). Although a combination of the two is preferable with respect to weight loss, the present study stressed exercise, because of its suggested positive effects on RMR during the exercise and for several hours afterwards and the possiblity to monitor the compliance to the exercise sessions. Moreover, exercise has been suggested to result in an increase of normal dally life activities, which was confirmed in the present study (Chapter 3).

\section{Short term effects}

\section{Weight loss and its composition}

In accord with the majority of the available literature a diet-exercise treatment did not result in a significantly larger weight loss compared to diet treatment alone in three of the four diet or diet-exercise studies described in this thesis (chapters 2,3,4,5) (Henson et al., 1987; Hill et al., 1987b; Nieman et al., 1988). Only a few studies showed significant differences in weight loss between a diet and a diet-exercise treatment (Hagan et al., 1986) similar to those we found in study III (chapter 6). Differences in study results can be partly attributed to methodological factors, which will be discussed later.

Total weight loss, however, does not give any information about the proportion of fat loss and loss of fat free mass. With respect to health aspects fat loss is more important, while fat free mass has to be maintained. However, a small reduction in fat free mass is inevitable since the accumulation of body fat necessarily involves accumualtion of FFM as well. Excess weight in the obese body consists of about $75 \%$ fat mass and $25 \%$. of fat free mass. Hence, the weight to be lost in the obese subject should have the same $75: 25 \mathrm{com}-$ position (Garrow, 1981). 
Pavlou et al. (1985) found similar weight losses in a diet and a diet-exercise group, but the amount of fat mass lost differed significantly (11.2 $\mathrm{kg}$ in DE vs $5.2 \mathrm{~kg}$ in D). Although other studies did not find such large differences, the proportion of fat loss is consistently reported to be larger in diet-exercise groups (Belko et al., 1987a; Henson et al., 1987; Hill et al., 1987b; Nieman et al., 1988 ;). Our results were in accord with these findings (Chapters 2,4 and 6).

A larger loss of fat mass for the dietexercise groups may explain the lack of significant differences in weight loss between diet and diet-exercise groups. Since the energy equivalent of $1 \mathrm{~kg}$ of fat is much larger ( 38.8 MJ) than that of $1 \mathrm{~kg}$ of fat free mass (4.2), the rate of weight loss is slower when relatively more fat is used up during weight reduction. However, calculating the energy equivalent of $1 \mathrm{~kg}$ of weight lost on the basis of fat loss and loss of fat free mass in our study revealed an energy equivalent of $31.0 \mathrm{MJ}$ per $\mathrm{kg}$ weight lost for the diet groups and $32.2 \mathrm{MJ}$ for the diet-exercise groups. This small difference cannot explain the lack of significant differences in weight loss between the diet and diet exercise groups in the present study. If fat loss is larger for diet-exercise groups, loss of fat free mass is expected to be smaller. However, in most studies loss of fat free mass is not reported to be significantly smaller for diet-exercise groups than for diet groups (Hill et al., 1987b; Nieman et al., 1988). In the present study the fat free mass decreased by $22.9 \%$ in the diet groups and by $19.2 \%$ in the diet-exercise groups, which was not significantly different. It is possible that the type of exercise is important for the prevention of the loss of fat free mass, as resistance weight training has been demonstrated to induce gain in lean body mass, while no such findings are reported for aerobic exercise (Gettman \& Pollock, 1981). Ballor et al. (1988) did find maintenance of fat free mass with weight resistance training during weight reduction. However, energy restriction in the study of Ballor et al. (1988) was less severe than in the present study, and since the percentage of weight lost as lean body weight increased proportional to the severity of the caloric deficit (Durrant et al., 1980), a comparison is not appropriate.

\section{Total energy expenditure}

During an energy restricted period total 24-EE has been shown to be reduced (Webb \& Abrams, 1983; Ravussin et al., 1985c; de Boer et al., 1986; de Groot, 1988), as was also demonstrated in the present study (Chapters 3,4$)$. The reduction in 24EE can be attributed to the reduction in RMR, and DIT and to reduced energy costs during daily physical activities (Ravussin et al., 1985c). The largest contribution to the decrease in $24 . \mathrm{EE}$ is the reduction in RMR, which in the present study was 16 to $29 \%$ for the diet group and 14.8 to $21 \%$ for the dietexercise group, depending on the duration of the study. Other studies have reported decreases of about 15$20 \%$ for both diet and diet-exercise groups (Hill et al., 1987b; Nieman et al., 1988). This reduction in RMR has been shown to be caused for the most part by a decrease in fat free mass, so that, standardized for fat free mass, most of the decrease was expected to disappear. However, in 
contrast to some other studies (Ravussin et al., 1985c), RMR per $\mathrm{kg}$ lat free mass remained decreased compared to baseline levels. Hill et al. (1987a) who also a reduced RMR per $\mathrm{kg}$ fat free mass, suggest that this reduction is caused by reduced levels of triiodothyronine and other studies suggest a reduced sympathetic activity during dieting (Jung et all., 1980).

Compared to the other groups the diet group in study I (chapter 2,3) showed a large reduction in RMR $(29 \%)$. This large reduction could not be attributed to a lower energy intake, since the energy intake was comparable to that in other studies. Another possibility might be that baseline measurements of RMR were elevated, due to the stress of staying in the respiration chamber for the first time. However, the results shown in Chapter 4 contradict this possibility. Only a small coefficient of variation of about $13 \%$ was found for values obtained during the first and the second night in the respiration chamber, although the subjects of study IV (chapter 4) were not familiar with the procedure of spending a night in the chamber either. No explanation can thus be given for this large decrease in RMR in the diet group.

One of the most heavily disputed topics at this moment is the possible elevation of RMR during exercise and for severall hours after exercise. If there is an elevation of RMR, this might be the explanation for any suppression of the diet-induced fall of RMR by exercise. So far consistent evidence for the existence of such a phenomenon is lacking (Thompson \& Blanton, 1987). Since some studies found a preventive effect of exercise on the drop in RMR
(Donahoe et al., 1984; Lennon et al., 1985; Nieman et al., 1988) during dieting, a number of factors have been proposed as important. One of these is the intensity of exercise (Lennon et al., 1985). However, studies with affirmative findings regarding preventive effects of exercise on the drop in RMR during dieting have used a low and a high exercise intensity, indicating that other factors are also important. In the present study (chapter 4) frequent and intensive exercise of $6 \mathrm{~h}$ per week did not result in a significant restoration of the diet-induced drop in RMR, although a there was tendency to increase compared to the decline after 4 weeks of dieting. The level of energy restriction seems to be an important factor (Nieman et al., 1988). Most studies in which exercise was combined with moderate energy restriction (4.2-6.3 MJ) showed prevention or restoration of the diet-induced decline of RMR (Donahoe et al., 1984; Lennon et al., 1985; Nieman et al., 1988), in contrast to studies using severe energy restriction (0.5 MJ) (Hill et al., 1987b; Donnelly \& Jacobsen, 1988), in which no preventive effects were observed. The present studies also combined severe energy restriction and exercise, and in none of the studies there was a prevention of the dietary-induced fall in RMR. However, at the end of the study period RMR tended to increase in the diet-exercise groups. In study IV (Chapter 4) this was accompanied by a smaller decrease of triiodothyronine, which is involved in the regulation of RMR. However, it may also be argued that at the end of the treatment compliance to diet was less, leading to a decrease in RMR. 
Since rat studies have shown frequent successive periods of weight loss and regain to result in an increased 'energy efficiency' (Brownell et al., 1986b), it was questioned whether subjects who showed a history of weight loss and regain had a lower RMR than subjects who had had no such loss and regain periods (Chapter 7). This question was also of interest since it has been found that after a period of energy restriction RMR remained depressed despite normal feeding (de Boer et all, 1986; Barrows \& Snook, 1987). We found no differences in RMR between groups at the start of the experiment or during dieting, suggesting that frequent dieting has no long term effects on RMR. Recently, our findings have been supported by Albu et al. (1988) who found higher RMR values per kg FFM for obese subjects with frequent weight loss and regain periods compared to subjects with fewer weight loss and regain periods. However, as subjects in both that and our own study were selected on the basis of a dietary history of the subjects themselves, results may be biased by inadequate reports about weight loss efforts. In developing countries long term undernourishment has been shown to result in a slower growth and decreased spontaneous activity (Shetty, 1984). Similar adaptations have not been found during short term underfeeding (Bessard et al., 1983; Ravussin et al., 1985c).

However, since the energy deficit in the diet-exercise group was much larger than in the diet group it was hypothesized that an adaptation in daily activities could occur in the diet-exercise group during the nonexercise periods. Although the methods used in our study to deter- mine daily physical activity may be critized with respect to reliability (chapter 3), a combination of heart rate monitoring and actometer measurements provides a reasonable estimation of daily physical activity (Avons et al., 1988; Spurr et al., 1988). Using these methods, no compensation in activities was found. In the diet-exercise group the physical activities even tended to increase, most probably due to the weight loss and increased fitness as a result of the exercise.

\section{Long term effects}

The success of the treatment of obesity is judged by its long term effects. In accordance with other studies (Wing \& Jeffery, 1979; Hovell et al., 1988) the success rate of weight maintenance in the present study was poor. The cause of relapse (weight loss that is subsequently regained; Sternberg, 1985) can be attributed to a combination of physiological and psychological factors. Physiological factors may hamper weight maintenance and promote an initial slip (unplanned overeating) and this may set into play a series of psychological reactions which may increase the likelihood of relapse.

A low RMR is considered as a physiological factor promoting weight gain. Several studies have found a low metabolic rate in postobese subjects (Leibel \& Hirsch, 1984; Geissler et al., 1987). In the present study we also found a lower RMR post than prior to the dietary intervention, despite a considerable weight gain. Other studies found a lower DIT in successful reduced 
obese subjects (Jéquier, 1988).

Similarly, Weigle et al. (1988)

demonstrated that 24-EE in success-

fully reduced obese subjects was

$25 \%$ lower than predicted on the

basis of FFM and it was found that

most of this reduction occurred

during the day.

These physiological consequences of dieting form the initial difficulty in maintaining weight loss. An interaction of individual, environmental and psychological factors determines further the extent of the relapse. Social factors such as parties, birthdays, etc. have been shown to cause small slips, whereas individual factors such as negative emotional states and stress events causes more serious relapses. The likelihood of a slip will depend upon the ability to engage in some adequeate coping behaviors. Coping effectively with respect to control of eating will increase feelings of self-control and self-efficacy and decreases the risk for a future slip. Coping ineffectively will have the reverse effect (Sternberg, 1985).

\section{How to prevent re- lapse?}

In the present study it has become clear that exercise plays an impor" tant role with respect to physiological predictor of weight gain such as RMR. The nine subjects who continued their exercise activities showed a marginal weight gain and a higher RMR after $1.5-3$ years than subjects who had no exercise activities. Increasing activities by exercise seems to be a way to overcome the energy saving mechanisms of weight reduction and weight maintenance. So far, there are no other results available confirming our findings on the long term restoration effects of exercise.

With respect to psychological factors leading to relapse exercise can also play an important role in the prevention of relapse and maintenance of weight loss (Dahlkoetter, 1979; Brownell et al.,1986a). As afore mentioned negative affective states and social events such as parties are likely to induce a relapse. To prevent relapse in these high risk situations it is important to prepare the obese subjects and to teach them to cope with these difficult situations. In a successful relapse prevention model Brownell et al. (1986a) proposed cognitive strategies such as decision making, cognitive monitoring and coping skills to change negative eating habits. Exercise can serve as one of these coping skills by using it as a substitute activity for the previous negative habit of eating as a coping behavior. Exercise may help offset the feelings of deprivation during dieting (Burbach \& Schomer, 1987) and when the subjects have handled a high risk situation effectively, this may influence subjects' self-concept and self-efficacy. Self-efficacy has been shown to be an important dimension in weight loss and weight maintenance (Sternberg, 1985).

With respect to weight maintenance, social support and booster sessions has been shown to be successful tools (Brownell \& Stunkard, 1980), in addition to exercise. Exercise may provide a general life style activity that brings gratification, and possibly a positive addiction (Appenzeller, 1981), which serves as a substitute for eating. Exercise has been reported to reduce stress and to im- 
prove sense of well-being (Folkins \& Sime, 1981), hereby reducing the prevalence of situations in which eating is used as maladaptive coping behavior.

However, some important notes have to be made. For changing eating and exercise behavior permanently subjects have to be motivated and to remain motivated. In preventing relapse it is important that before the start of the treatment and during treatment motivation is enhanced. In the present study most of the subjects regained their weight loss. This might be explained by the fact that most of the subjects may have started in a burst of enthusiasm with the aim to lose weight without changing previous eating habits. When the rate of weight loss is stopped at the end of the study, the positive feedback of the weight loss has disappeared. Motivation has to be focused on changing eating behavior rather than weight loss.

Similar remarks can be made for exercise. After the treatment period was completed most of the subjects $(72 \%)$ who started in the diet-exercise group discontinued exercise. This may be attributed to the fact that during treatment exercise was intensive and time consuming, which may have discouraged the subjects from going on. Probably because of their overweight it is more difficult for obese subjects to enjoy exercise activities. In the present study only 7 subjects kept exercising, whereas 2 subjects in the diet group started exercising after their treatment period had finished. As the mean body weight of these exercising subjects was lower at the start but also at the end of the treatment than that of the subjects who discontinued during follow-up, the degree of overweight may have a predictive value with respect to the continuing of exercise during a follow-up period. However, poor adherence to exercise activities is not unique for obese individuals and it was suggested by Brownell et al. (1980) that changing routine activities should result in a better adherence and a better long-term fitness and weight change. Epstein et al. (1982 and 1985) confirmed this hypothesis in children.

\section{Final remarks}

The lack of significant differences between the effects of diet and dietexercise programs on weight loss have been attributed to differences in methodology (Belko et al., 1987a; Hill et al., 1987b). Some of the suggested methodological weaknesses are also found in our study. Many diet and diet-exercise studies have been performed with only a small number of subjects, as was also the case in this study (Belko et al., 1987a; Hill et al., 1987b). This small number of subjects makes it very difficult to reach a level of significance. With such a small number of subjects the differences in weight loss between the D and DE group have to be very large before a level of significance is reached. However, pooling the data of the first five weeks of all the four studies revealed significant differences in weight loss between the $\mathrm{D}$ group $(\mathrm{N}=34)$ and the DE group $(\mathrm{N}=28)$, whereas the $\mathrm{DE}$ group had lost only $0.6 \mathrm{~kg}$ more weight (Saris \& van Dale, 1989). Another reason for the lack of significant differences is caused by the fact that obese subjects vary considerably with respect to a number 
of physiological characteristics. In recent years, it has become clear that there is not one type of obese people. Obese subjects vary in onset of obesity (adult or childhood onset of obesity), number and size of fat cells, fat distribution and insulin sensitivity. These factors may cause different responses to weight reduction regimens with different metabolic consequences as has been shown for instance, with respect to fat cell size and fat cell number (Björntorp et al., 1975). Just as in other studies with a larger number of volunteers (Pavlou et al., 1985; Hagan et al., 1986), significant differences were found when the studies were pooled (chapter 7). If it is not possible to involve a large number of volunteers, careful selection of subjects may contribute to consistency in results.

Although only in one of the four studies significant differences were shown in weight and fat loss between the $\mathrm{D}$ and $\mathrm{DE}$ group, it can be concluded that the addition of exercise to a diet induces more weight and fat loss than diet alone. In every study a trend towards more weight and fat loss can be observed for the DE group as compared to the D group. From this continually returning trend, together with the significantly larger weight and fat loss of the pooled data it can be concluded that exercise gives an additional effect in weight reduction regimens.

Another interesting observation was that differences in response between a diet and a diet-exercise group were beginning to increase towards the end of the treatment. This means that continuing the studies might have resulted in a significantly better weight loss for the diet-exercise group. In agreenent with this finding most studies with a longer study period have shown significantly better results, in terms of weight or fat loss or prevention of RMR in a dietexercise group than in a diet group (Hagan et al., 1986; Nieman et all, 1988). However, a longer period would increase the risk of non-compliance to the diet. 


\section{Conclusions}

- In view of the continually returning trend for a larger weight loss in the diet-exercise group compared to the diet group, it can be concluded that exercise gives an aditional effect with respect to weight loss. The lack of significant differences can nainly be attributed to the small number of subjects. Pooling the results of four studies resulted in significant differences in weight loss between the $D$ and $D E$ group.

- In all studies fat loss tended to be more for the diet-exercise group than the diet group. This tendency becomes significantly larger when the study period is extended (14 weeks). During severe energy restriction ( $3.5 \mathrm{MJ}$ ) exercise cannot prevent the decline in fat free mass.

- Total energy expenditure is found to decrease during diet and diet-exercise treatments, from which the largest contribution to this decline can be attributed to the diet-induced fall in RMR. Using severe energy restriction and moderate to intensive physical training, exercise does not prevent the diet-induced drop in $R M R$. However, in all diel-exercise groups a tendency to restore RMR after an intial decline was shown, which was not shown in the diet groups. This indicates that the restoration of the diet-induced drop in RMR occturs after longer periods than 12-14 weeks.

- Diet-induced themogenesis decreased due to lower energy costs of the reduced energy intake, but expressed in percentage of RMR a decline was also observed in both groups. The diet-exercise group showed a larger decline than the dietgroup, which may be explained by a glycogen sawing capacity due to the intensive exercise program.

- Daily physical activity tended to increase especially in the diet-exercise group, although the diet group showed a slight increase as well. The decreased body weight may increase the tendency to be more active. Since a larger increase in daily physical activities was found in the diet-exercise group, it is concluded that exercise increases daily physical activity.

- The addition of exercise to energy restriction appears to bring about better long tern results. Almost all subjects who kept on exercising showed significantly less regain of weight and a significantly lower body weight and fat mass at the end of the follow-up period. Part of their success can be attributed to the fact that the diet-induced drop in RMR was partly but significantly restored in those individuals who continted exercising with respect to that of individuals who discontinued exercise. In those subjects even after 2.5 years $R M R$ was still depressed compared to pre-diet values. Therefore it seems that the so-called "post-obese syndrome" is based on physiological findings. However, this important observation has been based on a relatively small number of subjects and needs confirmation in future reswarch. 



\section{REFERENCES}

- Acheson KJ, Campbell IT, Edholm OG, Miller DS, Stock MO. The measurement of daily energy expenditure-an ewaluation of some techniques. Am J Clin Nutr 1987; 33:1155-64.

- Albu $J_{4}$ Heska $S$, Heymsfield $S$. Correlates of self-reported large weight cycles in obese women. (abstr) The Sth Anmual Meeting of the North American Association for the Study of Obesity 1988:23.

- Andersen "T, Stoktholm H, Backer OG, Ouade F. Long term (5-year) results after either horizontal gastropllasty or very-low-calorie diet for morbid obesity. Int J Obes 1988;12:277. 84.

- Anonymous. Slimming foods face new curbs. Marketing 1980;4:20-21.

- Apfelbaum $\mathrm{M}_{*}$ Bostzarron J, Lacatis D. Effects of caloric restriction and excessive caloric intake on energy expenditure. Am J Clin Nutr 1971;24:1405-9.

- Appenzeller O. What makes us to run? New Eng J Med 1981;305:578-80.

- Applegate EA, Upton DE, Stern JS. Exercise and detraining: effect on food intake, adiposity and in vivo lipogenesis in Osborne-Mendel rats made obese by a high fat diet. I Nutr $1984 ; 114: 447-59$.

- Applegate EA, Stern JS. Exercise termination effects on food intake, plasma insulin, and adipose lipoprotein lipase activity in the Osborne-Mendel rat. Metrabolism 1987;36:709-714.

- Arner P, Engleldi P, Ostman J. The relationship between lipollysis, cAMP and fat cell size in human adipose tissue during lasting and in diabetes mellitus. Metabolism 1979:28:198-209.

- Arner $\mathbf{P}_{4}$ Bolinder $J_{4}$ Engfeldt $P_{n}$ Lithell $H$. The relationship between basal lipolytic and lipoprotein lipase activities in human adipose tissue. Int J Obes 1983;7:162-72.

- Ashwell $\mathbf{M}_{4}$ Chinn $\mathbf{S}$, Stalley $\mathbf{S}_{4}$ Garrow JS. Female fat distribution: a simple classification based on two circunference measurements Int J Obes $1981 ; 6: 143 \% 52$.

- Astrand I. Astrand PO, Stunkard A., Orggen intake of obese individual duning wonk on a bicycle wrgomeler. Acta Physiol Scand 1960;50:294-9.

- Astrand PO, Rodahl K. Textbook of work physiolagy. New York: McGraw-Hill Book Comp., 2nd ed., 1977.

- Astrup A. Thermogenesis in human brown adipose tissue and skelelal musclle induced by sympathomimetic stimulation. Acta Endocrinol 1986 (suppl);278:1-32.

- Astrup A, Andersen T, Henriksen O, Christensen NJ, Buliöw J, Madsen J, Quaade $\mathbb{F}$. Impaired glucose induced thermogenesis in skeletal nouscle in obesity. The role of the sympatoadrenal system. Int J Obes 1987;11:27-42.

- Avons P, Garthwaite P, Davies H L, Murgatroyd PR, James WPTI. Approarches to estimaling physical activity in the community. callorimetric vallidation of actometer and heart rate momioring. Eur I Chin Nutr 1988;42:185-96.

- Ballor DL, Katch VL, Becque MD, Marks CR. Resistance weight training during caloric restriction enhances lean body weight maintenance. Am J Clin Nutr 1988;47:19-25.

- Barrows $\mathrm{K}$, Snook JT. Effect of a high-protein, very-low-calorie diet on resting metallolism, thyroid hormones, and energy expendilure of obese middle-aged women. Am I Clin Nutr $1987 ; 45 ; 391-8$.

- Belko AZ, Obarzanek E, Roach R, Rotter M, Urban G, Weinberg S, Roe DA Effect of aerobic exercise and weight loss on riboflawin requi rements of moderately obese martinally deficient young women. Am J Clin Nutr 1984;40:553 61.

- Belko AZ, Meredith MP, Kalkwarf HJ, Obarzanek E, Weinberg S, Roach R, McKeon G, Roe DA. Effects of exercise on riboflawin requie rements: biological validation in we ght reducing women. Am J Clin Nutr 1985,41:270-7.

- Belko AZ, Van Loan, Batbieri, Mayclim P. Diet, exercise, weight loss and eneryy expenditure in moderateby obest women. Int J Obes 1987;11:93-104.(a)

- Belko AZ, Vitamins and exercise-an update. Med Soi Sports Exerc 1987;19:\$191-6.(b) 


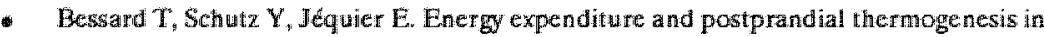
obese women be fore and after weight loss. Am J Clin Nutr 1983;38:680-3.

- Besten den $C$, Vansant $G$, Westrate JA, Deurenberg $P$. Resting metabolic rate and diet-induced thermogenesis in abdominal and gluteal-femoral obese women before and after weight reduction. Am J Clin Nutr 1988; $47840-7$.

- Bidinski $\mathbb{R}$ Schutz $\mathbf{Y}$, Jequier $\mathbb{E}$. Energy metabolism during the postexercise recovery in man. Am J Clin Nutr 1985;42:69-82.

- Bjorntorp P. Classification of obese patients and complications related to the distribution of surplus fat. Am J Clin Nwir 1987;45;1120-5.

- Björntorp P, Carlgren C, Isaksson B, Krotkiewski M, Lanson B, Sjöström L. Effect of an energy-induced diefary regimen in relation to ad ipose tissue cellularity in obese women. Am IT Clin Nutr $1975 ; 28: 445-52$.

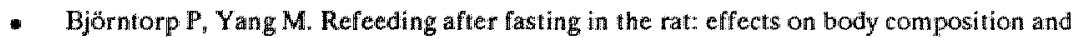
rood efficiency. Am J Clin Nutr 1982;36:444-49.

- Bjorwell H, Rossner $\$$. Long term-effects of commonly avallable weight reducing programmes in Sweden. Int J Obes 1986;11:67-71.

- Blackburn G, Kanders B, Brownell K, Wilson T, Adler J, Stein L, Greenberg 1.: The effects of weight cycling (wc) on the rate of weight loss in man. (absitr) Int $J$ Obes $1987 ; 11: 84$.

- Blondheim SH, Hashkes PJ, Levitsky-Duitch L. Effect on dietary thermogenesis of nonnutritional factors: palability, speed of eating and order of meals, and sham feeding, in the obese and nom-obese. (abstr) First European Congress on Obesity, Stockholm 1988;219.

- Blondheim SH. Dietary thermogenesis: why conflicting results? In: Recent advances of obesity research V. Proceedings of the Fifth International Congress on Obesity, Jerusalem 1986. ed: Berry EM, Blondheim SH, Eliahou HE, Shafrir E, p. 151-4.

- Boer de JO, Es van AJH, Roovers LA, van Raay JMA, Hautvast JGAJ. Adaptation to lowenergy intake, studied with whole body-body calorimeters. Am I Clin Nitr 1986;44:585-95.

- Boer de JO, Es van AJH, van Raaij JMA, Lautvast JGAJ. Energy requirements and energy expenditure of lean and overweight women, measured by indirect calorimetry. An I Clin Nutr 1987;46:13-21.

- Bogardus $\mathrm{C}$, Ravussin $\mathrm{E}$, Robbins D, Wolfe $\mathrm{R}$, Horton $\mathbb{E S}_{3}$ Sins EN. Effect of physical training and diet therapy on carbohyd rate metabolism in patients with glucose intolerance and non-insulindependemt diabetes mellitus. Diabetes 1984;33:311-8.

- Bogardus C, Lillioja S, Ravussin E, Abbott W, Zawadki JK, Young A, Knowler WC, Molt PP. Familial depence on the resting metabolic rate. New Engl J Med 1986;315;96-100.

- Boyle PC, Storlien LJH, Keesey RE. Increased efficiency of food utilization following weight loss. Physiol Be hav 1978;21:261-4.

- Boyle PC, Storlien LH, Harpet AE, Keesey RE. Oxygen consumption and locomotor activily duting resiricted feeding and reglimentation. Am J Physiol 1981;241:R392-7.

- Bray GA, Whipp BJ, Koyal SN. The acute effects of food intake in energy expenditure during cycle etgometry. Am J Clin Nutr 1974;27:254-9.

- Bray G. Relation of thyroid homones to body weight. 1 ancet 1976;1:1206-8.

- Bray G. The energetics of obesity. Med Seil Sports Exerc 1983;15:32-40.

- Bray $G$. Effect of diet and trillodothyronine on the activity of glycerol-3-phosphate dehydrogenase and on the metabolism of glucose pyruvate by adipose tissue of obese patients. J Clin Inv 1969;48:1413-22.

- Bray GA, Zachary WT, Dathms WT, Atkinson RL, Oddie TH. Eating patterns of the massively obese individuals. I: Am Diet Assoc 1978;72:24:7.

- Btay GA Effect of caloric restriction on emergy expenditure in obese patients. Lancet $1969 ; 2: 397-8$

- Brownell KD, Stunkard AA, Albaum JM. Evaluation and modification of exercise patterns in the natural environment. Am J Psychiat 1980;137:1540-5.(a)

- Brownell KD, Stunkard AJ. Physical activity in the development and treatment of obesity. In Stunkard AI (ed), Obesity, Philadelphia: WB Saunders, 1980, p 300-24.(b) 
- Bnownell KD. Behavioral, psychological, and environmental predictors of obesity and success at weight reduction. Int $J$ Obes 1984,8:543-50.

- Brownell KD, Marlatt GA, Lichtenstein E, Willson GT. Understanding and preventing relapse. Am Psychol 1986:38:765 82.(a)

- Brownell KD; Greenwood MRC, Stellar E Shrager EE The effects of repeated gycles of weight loss and regain in rats. Physiol Behav 1986;38.459-64.(b)

- Brouwer E. Report of Sub-Committee on Constants and Factors. In: Energy Metabolism. ed: Blaxter KL Proceedings of 3 rd symposium on energy metabolism. EAAP Publ: 11. Academic Press, London, $1965,440-3$.

- Burbach FR, Schomer HH. The relationship between stress and weight loss in a dief-exercise programme for obese women. South Afr Med J1987,71:937.7.

- Burton BT, Foster WR, Hirsch J, Van Itallie TB. Health implications of obesity: an NIH consensus development conference. Int J Obes 1985;9:155-69.

- Buskirk ER, Thompson RH, Lutwak L, Whedon GD. Energy balance of obese patients during weight reduction: influence of diet restriction and exercise. Ann N Y Acad Sei $1963 ; 110: 918-40$.

- Carter R. Exercise and happiness. I Sports Med 1977;17:307-13.

- Chirico A, Stunkard AJ. Physical activity and human obesity. N Engl J Med 1970;263:935-40.

- Christensen CC, Frey HMM, Foenstelien E, Aadland E, Refsum HE A critical evaluation of energy expenditure estimates based on individual $\mathrm{O}_{2}$ consumption/heart rate curves and average daily heart rate. Am J Clin Nutr 1983;37:468-72.

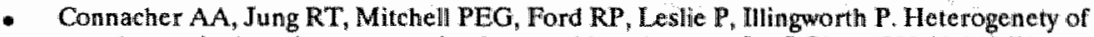
noradrenergic thermic responses in obese and lean humans. Int I Obes 1988; 12:267:76.

- Consolazio CF. Energy expenditure studies in military populations using Kofranyi-Michaclis respirometers. Am J Clin Nutr 1971;24:1431-7.(a)

- Consolazio CF. Thiamin, riboflawin and pyridoxine excretion during acute starvation and caloric restriction. Am J Clin Nutr 1971;24:1060-7,(b)

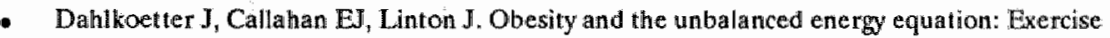
versus eating habit change J Cons Clin Psychol 1979;47:898-905.

- Dale van. D, Saris WHM, Ten Hoor F. Does exercise have an additional effect in weight reduction regimens? Int J Obes 1987; 11:369-75.

- Dale van $\mathcal{D}_{4}$ Saris WHM. Repetitive weight lioss and weight regain: effects of exercise on weight loss, resting metabolic rate and lipolytic activity. Am J Clin Nutr 1989;49:409-16.

- Dauncy M.J, James WPT. Assess ment of the heart-rate method for determining energy expenditure in mat, using a whole body calorimeter. Br IN Nutr 1979;42:1-13.

- Despres JP, Bouchard C. Effects of aerobic trairing and heredity on body fatness and adipocyte lipolysis in humans. $J$ Obes Weight Regui 1984;3:220 34 .

- Donahoe CP Ir, Lin DH, Kirschenbaum DS, Keesey RE. Metabolic consequences of dieting and exercise in the treatment of obesity. J Cons Clin Psychol 1984:5:827-36.

- Donnelly JE Jacobsen DJ. Effects of very low calorie diet (VLCD) and VLCD and exercise on body composition and metabolic rate. (abstr) The Sth Annual Meeting of the North American Association for the Study of Obesity. 1988:27.

- Doré C, Hesp R, Wilkins D, Garrow IS. Predictions of energy requirements of obese patients after massiwe weight loss. Hum Nutt Clin Nutr 1982;36C $41-8$.

- Drenick. EJ, Dennin HF. Energy expenditure in fasting men. J Lab Clin Med 1973;81;421-30.

- Durrant ML, Garrow JS, Royston P, Stalley SP, Sunkin S, Wanwick PM. Factors influencing the composition of the weight lost by obese patients on a reducing diet. Br J Nutr $1980 ; 44 ; 275 ; 85$.

- Epstein LH, Wing RR. Aerobic exercise and weight. Addict Behav 1980;5:371-88.

- Epstein LH, Wing RR, Koeske R, Ossip D, Beck S. A comparison of lifestyle change and programmed aerobiic exercise on weight change and fitness changes in obese childrem. Behav Therap 1982;13:651-65. 
- Epstein $\mathrm{LH}_{4}$ Wing $\mathrm{RR}$ Koeske $\mathrm{R}$, Valoski $\mathrm{D}$. A comparison of lifestyle exercise, ae robic exercise and callishenics in obese child ren. Behav Therap 1985;15:345-56.

- Evantw WI, Pinney $\$$ O, Young VL. Suction applied to a muscle biopsy maximizes sample size, Med Sci Sports Exerc 1982; $14: 101.2$.

- Pagher $B_{\sharp}$ Liebhold H, Montri $M_{4}$ Morritz $U$. Thermogenesis in human skeletal muscle as measured by micro calorimetry and muscle contractile performance during -adrenoceptor blockade. Cin Sei 198670:435-41.

- Fisher MC, Lachance PA. Nutrition evaluation of published weight-redweing diets. Am Diet Assoc 1985,85:450-54.

- Hisler J5, Drenich EJ. Calcium, magnesium, and phosphate balances during a very-lowcalorie diet of soy or collagen protein in obese men: comparison to total fasting. Am J Chin Nutr 1924:40:14, 25 .

- Folkins CH, Sime WE. Physical fitness training and mental health. An Psychol 1981,36:37389

- Freedman-Akabas $S_{*}$ Colt E, Kissilef HR, Pi-Sunyer FX. Lack of sustained increase in $\mathrm{VO}_{2}$ following exercise in fit and unfit subjects. Am J Clin Nutr 1985;41:545-9.

- Fried SK, Hill JO, Digirolamo M. Prolonged affects of fasting-refeeding on rat adipose tissue lipoprotein lipase activily: influence of caloric restriction during refeeding. I Nutr $1983 ; 113: 1861.9$.

- Gaesser GA, Brooks GA. Muscular efficiency during steady-rate exercise: effects of speed and work rate. I Appl Physiol 1975;38:1132-9.

- Garrow JS. Energy balance and obesity in man. Amsterdarm: North-Holland Publishing Company, 1974

- Garrow JS, Durrant ML, Man S, Stalley SF, Warwick P. Factors determining weight loss in obese patients in a metabollic ward. Int J Obes $1978 ; 2 * 441-7$.

- Garrow JS. Treat obesity seriously. A clinical manual. Edinburgh: Churchill Livingstone, 1981.

- Garrow JS. Energy balance in man-an overwiew. Am II Clin Nuir 1987;45:1114-9.(a)

- Garrow JS. Effect of exercise on obesity. Acta Med Scand Suppl 1987;771:67-73.(b)

- Geisster CA, Dzumbira TMO, Ismail NM. Validation of a field technique for the measurement of energy expenditure: factorial method versus continuous respirometry. Am J Clin Nutr 1986;44:596-602.

- Geissler CA, Miller DS, Shah M. The daily metabolic rate of the post -obese and the lean. Am J Clin Nutr 1987;45:914-20.

- Getn nan LR, Pollock ML. Circuit weight training a critical review of its be nefits. Phys Sportsmed 1981,9:44-60.

- Golay A, Schutz Y, Meyer HU, Thicbaud D, Curchod B, Maeder E, Felber JP, Jequier E Cincose-inducex thermogenesis in nondiabetic and diabetic obese subjects. Diabetes $1982,31 \div 1023-8$.

- Golay A, Felber JP, Dusmet M, Gomez F, Curchod B, Jéquier E. Efrect of weight loss on glucose dispostl in obese and obese diabetic patients. Int J Obes 1985 (suppl 2),9:181-90.

- Goldberg GR, Prentice AM, Davies. ML, Murgatroyd PR, Overnight and basal metabolic rates in men and women. Eur JI Clin Nutr 1988;42:137-44.(a)

- Goldberg GR, Murgatroyd PR, Davies HL, Prentice AM. Interactions between the intensity of exercise and the residual effect on metabolic rate. Proe Nutr Soc 1988a:7.(b)

- Gray DS, Fisler JS, Bray GA Effects of repeated weight loss and regain on body composition in obese rats. An J Clin Nutt 1988;47:393-9.

- Groot, L.PIM. Eneryy metabolism of overweight women before, during and after weight reduction; assessed by indirect calorimetry. Dissertation, Wageningen, The Netherlands, 1988.

- Gwinup G. Weight loss without dietary restriction: Efficacy of different forms of ae robic exercise. Am J Sports Med 1987;15:275-79. 
- Hagan RD, Upton SJ, Wong L, Whittam I, The effects of aerobic conditioningand/or caloric restriction in overweight men and women. Med Sci Sports 1986, 18,87-94.

- Hallfisch J, Steele P, Cohen L. Comparison of a seven-day diet record with measured foot intake of twenty-four subjects. Nutr Res $1982,2: 263-73$.

- Harris MB, Hallbawer ES. Self-directed weight control through eating and exercise. Behaw Res Ther 1973;11:523-9.

- Heaps RA. Relating physical and psychological fitness: a psychological point of view. J Sports Med 1978; 18;399-408.

- Hegsted DM. Problems in the use and interpretation of the reconmended dietary allowances. Ecol Food Nutr 1972;1:255.

- Henry FR, Wiest-Kent TA, Schaeffer OG, Olefsky JM. Metabolic consequences of a very. low-calorie diet therapy in obese non-insulim-dependent diabetic and nondiabetic subjects. Diaberes 1986;35:155-64.

- Henson LC, Poole DC, Donahoe CP, Heber D. Effects of exefrise training on resting ener. gy expenditure during caloric restriction. Am J Clin Nutr 1987;46:893-9,

- Hermansen L, Grandmontagne M, S Maehlum, Ingnes J. Postexercise elevation of resting. axygen uptake: Possible mechanism and physiological significance. Med Sports Sci $1984 ; 17: 119-29$.

- Hill JO, Heymsfield SB, McMannus I, Digirolamo M. Meal size and thermic response to food in male subjects as a function of maximum aerobic capacity. Metabolism 1984;33:743-9.

- Hill JO, Thacker $S$, Newby D, Nickel M, and Digirolamo M. A comparison of constant leed. ing with bouts of fasting-refeeding at three levels of nutrition in the rat. Int $\mathfrak{J}$ Obes 1987;11:251-62.(a)

- Hill JO, Sparling PB, Shields TW, Heller PA. Effects of exercise and food restriction on body composition and metabolic rate in obese women. Am J Clin NUtr 1987;46:622-30.(b)

- Hoiberg A, Berard $S$, Watten RH, Caine C. Correlates of weight loss in treatment and at fol. low:up. Int J Obes 1984;8:457-65.

- Holden J, Darga LL, Olson SM, Lucas CP. Long term follow-up of weight loss in formerly obese patients. The Sth Annual Meeting of the North American Association for lline Study of Obesity. 1988:31.

- Horton ES. Introduction: an overview of the assessment and regulation of energy balance in humans. Am J Clin Nutr 1983; (suppl) 38:972-7.

- Horton ES. Metabolic aspects of exercise and weight reduction. Med Sci Sports Exerc $1986 ; 18: 10-7$.

- Howell MF, Koch A, Hofstetter CR, Cipan C, Faucher P, Dellinger A, Borik $G_{1}$ Forsylhe A, Feliti VJ. Long term weight losis maintenance: assessment of bethavioural and a supple. mented fasting regimen. Am 3 Pub1 Health 1988:78:663-6.

- James WPT, Lean MEJ, McNeill G. Dietary recommendations after weight lloss: how to avoid relapse of obesily. Am J Clin Nutr 1987;45:113541.

- Jeffery RW. Behavioral treatment of obesily. Ann Behav Med 1987,9:20-4.

- JEquier E. Themogenesis and obesity. Medicographia 1986;8:7-9.

- Jáquier $\mathrm{E}$. Energy metabolism in obese patients before and after weight loss, and in pattents who have relapsed.(abstr) The Sth Annual Meeting of the North American Association for the Study of Obesity. 1988:19.

- Jung RT, Shetty PS, James WP. The effect of refeeding after energy restriction on catecholamine and thyroid metabolism. Int J Obes 1980;4:95ino0.

- Kather H. Adrenergic regulation of Mpolysis in abdominal adipocytes of obese subjects during caloric restriction: reversal of catccholamine action caused by relief of endogenteous inhibition. Eur J Clin Inv 1985;15:30-7.

- Kayman S. Relapse and maintenance after weight loss in women. Doctoral disarertation, University of California Berkely Campus. In: Stem IS, Titchenal A, Johnson PR Obesily: Does exercise make a difference? Recent advances in obesity research: $V$, ed Blondheim $B$ and Shafrir E. 1986, p. 352-64. 
- Kenrick MM, Ball FM, Canary JJ. Exercise and wejght reduction in obesity. Arch Phys Med Rehabil $1972,3: 323-7$.

- Keys A, Brozek J, Hensel A, Mickelsen O, Taylor TH. "The biology of human stanation. Minmeapolis: The University of Minnesota Press, 1950.

- Kirschner MA, Schneider $G$, Ertel NH, Gorman J. An eight-year experience with a very-lowcalorie formula diet for control major obesity. Int $\mathbf{J}$ Obes $1988 ; 12.69 .80$.

- KJuthe R, Schubert A. Obesity in Europe Ann Intern Med 1985;103:1037 42 .

- Koppenschaar HPF, Meinders AE, Schwarz F. Metabolic responses during modified fasting and refeeding. Hum Nutr Clin Nut $1985,39 \mathrm{C}: 17-28$.

- Krotkiewski M, Toss L, Bjorntorp P, Holm G. The effects of a very low calorie diet with and without chronic exercise on thyroid and sex homones, plasma proteins, oxygen uptake, insulin and ci-peptide concentrations in obese women. Int J Obes 1981;5:287-93.

- Krotkiewski M, Björntorp P, Sjöstrôm $\mathbb{1}$, Simth U. Impact of obesity and metabolism in men and women. Importance of regional adipose tissue distribution. J Clin In 1983; 72:1150-62.

- Krotkiewski M, Björntorp P. Muscle tissue in obesily whth different distribution of adipose

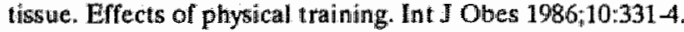

- Kurzer MS. Effect of activity on the energy cost of sitting in men and women: implications for calorimeter studies. Hum Nutr Clin Nutr 1987;41 C:403-7.

- Lafontan M, Dang.Tran, Berlan M. Alphamadrenergic receptors and the regulation of lipolysis in adipose tissue. Trends Pharm Sci 1979;9:261-6.

- Luber K. Bestimnung von serumeisen und eisenbindungskapazita ohne entweissung: Zeits Klin Chent $1965 ; 3: 96$.

- Leblanc J, Blondel L. Role of palatability on meal-induced thermogenesis in human subjects. Am J Physiol 1984;248:1333-6.

- Ieblanc J. Thermogenesis in relation to feeding and exercise training Int J Obes 1985 (suppl 2);9:75-9.

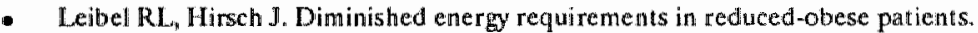
Metabolism 1984;33:164-70.

- Leibel RI, Hirsch J, Berry EM, Gruen RK. Alterations in adipocyte free fatty acid reesterification associated with obesity and weight reduction in man. Am J Clin Nutr $1985 ; 42: 198-206$.

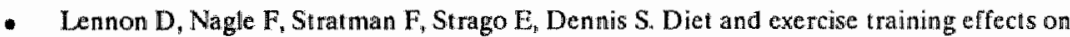
Jest ing metabolic rate. Int J Obes $\$, 985 ; 9: 3947$.

- Lillioja S, Foley J , Bogardus C. Mott D, Howard B. Free fatty acid netabolism and obesity in mian: In vivo in vit ro comparisons. Metabolism 1986;35:505-14.

- Lissner 1 , Habicht JP, Strupp BJ, Levitsky DA, Roe DA. Body composition and energy intake in women: do the ovenweight overeat and underreport? (abstr) The Sth Annual Meet. ing of the North Ame rican Association for the study of Obesity. "the Joule, the adipocyte and obesity", Canada, 1988333 .

- Machlum S, Grandmontagne M, Newsholme EA, Sejersted OM. Magnitude and duration of excess postexercise oxygen consumption in healthy young subjects. Metabolisn 1986;35:4259.

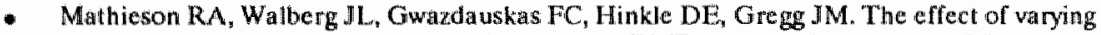
carbohydrate content of a wery-low-caloric diet on RMR and thyroid hormones. Metabolism $1986 ; 35: 394-98$.

- McMurtay RG, Ben-Ezra W, Forsyth WA Responses of endurance trained athletes: diet vs exercise. Med Sci Sports Exerc 1985; 17:574-9.

- Merritt RJ, Blackburn GL, Bistrian BR, Palombo J, Susking $\mathbb{R M}$, Conseqwences of modified fasting in obese pediat ric and adolescent patients: effect of a carbohydrate-frec diet on serum proteins. Am I Clin Nutr 1981;34:2752-5.

- Miller DS, Parsonage S. Resistance to slimming. Adaption or illusion? Lancet 1975;2:773-5.

- Miller PM, Sims KL. Evaluation and conponent analysis of a conprehensive wreight cont rol program. Int J Obes 1981;5:57-65. 
- Miller WH, Faust M, Goldberger AC, Hirsch J. Effects of sever long term food depurwation and refeeding on ad ipose tissue cells in the rat. Am J Physio 1983,245:E74-E80.

- National Research Council: Committee on Dietary Allowances, National Acadeny of Sciences, Wasihington, 1980 .

- Nederlandse Voedings middelen Tabel. Uitgawe van het Voorlichtingsbureaw woor de Voeding, "s-Gravenhage, 34c druk, 1983 .

- Nevo tabel: Nederlands woedingsmiddelen bank 1986-1987, Nevo stichting. Voorlichtingsburo voor voeding, 1987.

- Newmark S. Survey of wery-low-calorie weight reduction diets. Novelty diets. Arch Intern Med 1984;143:1195-8.

- Newsholme EA. Substrate cycles: their metabolic, energetic and thermic consequences in man. Biochem Soc Symp 1978;43:183-205.

- Newsholme EA. A possible metabolic basis for the control of body weight. N Engl J Med $1980 ; 302: 400-5$.

- Nieman DC, Haig JL, Guia de ED, Dizon GP, Register UD. Reducing diet and exercise training effects on resting metabolic rates in mildly obese women. I Sports Med Phys Fitness 1988;28:79-88.

- Pacey D, Barton $N_{4}$ Webster J Garrow JS. The energy costs of aerobic exercise in fed and fasted normal subjects. Am J Clin Nutr 1985;42:764-8.

- Pasquali $R_{2}$ Cesare MP, Melchionda N, Boschi S, Munarini A, Barbara L. Erythrocyte Na-K. ATPase membrane activity in obese patients fed over a long-tern period with a very-lowcalorie diet. Metabolism 1988;37:86-90.

- Passmore $R$, Thomson JG, Wamock GM. A balance sheet of the estimation of ene rgy intake and energy expenditure as measuxed by indirect calorimetry using the Kofranyi-Michaelis respirometer. Br J Nutr 1952;6:253-64.

- Passmore R. Eastwood MA. Human Nutrition and dietitics. Edinburgh: Chruchill Livingstone, 8 th edition, 1986.

- Pawlou KN, Steffee WP, Lerman $\mathbb{R}$, Leman LH, Burrows BA. Erfects of dieting and exercise on lean body mass, oxygen uptake, and strengh. Med Sci Sports Exenc 1985;17;466-71.

- Perri MG, McAllister DA, Gange JJ, Jordan RC, McAdoo WG, Nezu AM., Erfects of four maintenance programs on the long term management of obesity. J Cons Clin Psychol 1988;4:529-34.

- Phinney SD, Horton ES, Sims EAH, Henson JS, LaGrange BM. Capacity for moderate exercise in obese subjects after adaptation to a hypocaloric ketogen ic diet. Clin Res 1980;66:1151. 61.

- Poehiman ET, Melby CL, Badylak SE. Resting metabolic rate and postprandial thermogenesis in highly trained and untrained males. Am J Clin Nutr 1988;47:793-8.

- Poole DC, Henson LC. Effect of acule caloric restriction on wrork efficiency. Am J Clin Nutr;47:15-8.

- Prentice AM, Black AE, Cowand WA, Davies HL, Goldberg GR, Murgat royd PR, Ashford $\mathrm{J}$, Saywer M, Whitehead RG. High levels of energy expenditure in obese women. Br Med I $1986 ; 292: 983-8$

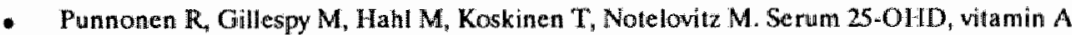
and vitamin $\mathbf{E}$ concentrations in healthy Finn ish and Foridian women. Int $J$ Will Nutr Res $1988 ; 58: 37-9$.

- Ravussin E, Burnand $B$, Schutz $X$, Jéquier $E$. Twenty-four hour energy expenditure and resting metabolic rate in obese, moderately obese, and control subjects. Am J Clin Nutir $1982 ; 35 ; 566-73$.

- Rawussin E, Bogardus C, Schwartz RS, Robbins DC, Wolfe RR, Horton S, Danforth E Ji, Sims EAH. Glucose-induced thermogenesis and insulin resistance in man. Int 1 Obes $1985 a$ (suppl 2):9:103-9.(a)

- Rawussin E, Acheson $\mathrm{KJ}$, Vernet $\mathrm{O}$, Danforth $\mathrm{E}$, Jequier E. Evidence that insulin resistance is responsible for the decreased the rmic effect of glucose in human obesity. I Clin Invest $1985 ; 76: 1268-73 .(\mathrm{b})$ 
- Ravussin $\mathrm{E}$, Burnand $\mathbb{B}_{3}$, Schutz $\mathrm{Y}$, Jequier F. Energy expenditure before and during energy restriction in obese patients. Am J Clin Nutr 1985c:41:753-9.(c)

- Ravussin E, Lillioja S, Anderson TE, Christin L, Bogandus C. Determinants of 24-hour Energy expenditure in man. Methods and reswls using a respiratory chamber. J Clin Im $1986 ; 78: 1568-78$.

- Ravussin $\mathrm{E}_{\mathrm{f}}$ Lillioja $\mathrm{S}, \mathrm{Knowler}$ WC, et al. Reduced rate of energy expenditure as a risk factor for body-weight gain. New Eng J Med 1988;318;467-72.

- Rebuffe-Serive $M_{4}$ Enl L, Crona N, Lonnroth, Abrahansson L, Smith U, Björntorp P. Fat cell metabolism in different regions in women-effects of menstrual cycle, pregrancy and lacllation. J Clin Inv 1985; 75:1973-6.

- Rebufre-Serive M, Eldh J, Hafstrom L, Björntorp P. Metabolism of mammary, abdominal. and femoral adipocytes in women before and after menopause. Metabolism 1986:35:792-7.

- Reeves RS, Foreyt IP, Darnell LS, Goodrick GK, Jackson AS, Hartung GH. Effects of exereise and dietary resiriction on body weight of overweight adults. Med Sci Sports Exere $1985,18: 44$.

- Reger WE, Alison TG, Kuruce RL Exercise. postexercise metabolic rate and appetite. 1984 Olympic Scientific Congress proceedings. In: Sport, health and nutrition, ed. Katch FI, PP 115-23. Champaign, Illinois: Hunan Kimetics Publishers Inc., 1986.

- Rodin J. Psychological factors in obesity. In: Recent advances of obesity research.IV. 1984. ed. Mirsch J and Van Itallie TB, John Libbey London.

- Rogers EL, Douglass W, Russell RM, Bushman $\mathrm{L}$, Hubbard TB, lber F.L. Deficiency of fat soluble vitamins after jejunoileal bypass surgery for morbid obesuty . Am J Clin Nutr 1980;33:1208-14.

- Romieu I, Willet WC, Stampfer MJ, Colditz GA, Sampson L, Rösner B, Hennekens. CH,Speizer FE. Energy intake and other determinants of relative weight. Am J Clin Nutr $1988 ; 47: 406-11$.

- Rothwell $\mathrm{NJ}_{\mathrm{f}}$ Stock MJ. A role for brown adipose tissue in dict-induced thermogenesis. Nature $1979 ; 281: 31-5$.

- Round Table on comparison of Dictary Recommendations in different European Countries. Nutr Metab 1977:209.

- Royal College of Physicians. Obesity. A report of the royal college of physicians. reprinted from J Royal Coll Phys 1983;17.

- Saris WHM, Binkhorst RA. The use of pedometer and actometer in siudying daily physical activity in man. Part I. Reliability of pedometer and actometer. Eur J Appl Physiol 1977,$37 ; 219-228$.

- Saris WHM, Binkhorst RA. The use of pedonneter and actometer in studying diaily physical activity in man. Part II. Validity of pedometer and actometer neasuring the daily physical at:tivity. Eur J Appl Physiol 1977b;37:229-35.

- Saris WHM. Aerobic power and daily physical activity in children. Meppel: the Netherlands: Kripps Repro. Dissertation, 1982.

- Saris WHM. Long term results of the treatment of obesity. J Drugs Res 1983;8:2075-80.

- Saris WHM, Dale D van. Effects of exercise during a VCD diet on metabolic rate, body composition and aerobic power: pooled data of four studies. (abstr) Second European Congress on Obesity, Oxford, 1989 ; submitted.

- Scheen AJ, Pirnay F, Luyckx AS, Lefebvre PJ. Metabolic adaptions to prolonged exercise in sewercly obese subjects. Int J Obes 1983;7:221-29.

- Schneider F. Die Ernährung des Spontlers. Med u Sport 1979;11:321.9.

- Schoffelen P, Saris WHM, Westerterp KR, Hoor ten F. Evaluation of an automatic indirect calorinter for measurement of energy balance in man. In: Human energy metabolism: Physical activily and energy expenditure measurement in epidemiological research based upon direct and indirect calorimetry. Ed: AJH van Es. Euro Nut report 5, 1985: p 51-4, Wagenimgen. 
- Schrijwer J, Weelen BWC van, Schreurs WIHP. Bioce mical evaluation of the vitamin and iron status of an apparently healthy duteh free living elderly population. Internat $J$ Vit Nutr Res $1985 ; 55: 337-49$.

- Schultz CK, Bernater PA, Mole PA, Superko MR, Stem IS Effects of severe caloric restriction and moderate exercise on basal metabolic rate and hormonal status in adult humans. (abstr) Fed Proc 1980;39:783.

- Schutz Y, Ravussin E, Diethe $\|$ m, Jequier E, Spontaneous physical activity measured by radar in obese and control subjects studied in a respiration chamber. In J Obes 1982;6:23-8.

- Schutz X, Bessard T, Jequier E. Decreased glucose-induced themogenesis affer weight loss in obese subjects a predisposing factor for relapse of obesity? Am I Clin Nutr 1984;39:380:7.

- Schwartz KS, Jaeger LF, Silberstein S, Veith RC. Sympathetic nervous system activily and the thermic effect of feeding in man. Int $J$ Obes $1987 ; 11: 1414-9$.

- Seidell JC, Bakx JC, de Boer E, Deurenberg P, Haurvast JGAJ. Fat distribution of overweight persons in relation to morbidity and subjective health. Int J Obes 1985;9:363-74.

- Seidell JC, de G noot CPGM, van Sonsbeek ILA, Deurenberg P, Hautvast JCA. Associations of moderate and severe owerweight with self-reported illness and medical care in Dutch adults. Am J Pub॥ Health 1986;76:264-9.

- Shah M, Geissller CA, Miller DS. Metabolic rate during and after acrobic exercise in post obese and lean women. Eur J Clin Nutr 1988;42:455-64.

- Shetty PS. Adapative changes in basal metabolic and lean body mass in chronic undernutrition. Hum Nutr Clin Nutr 1984;38C:443-51.

- Sikand G, Kondo A, Foreyt JP, Jones PH, Gotto AM. Two-year follow-up of patients treated with a very-low-calorie diet and exercise training. J Am Diet Assoc 1988;88:487-8.

- Simmons DA, Kern EEFO, Winegrad WI. Basall Phosphatidyl-inositol turnower controls aortic NA + -K + ATPase activity. Eur J Appl Physiol 1986:503-13.

- Sims EA, Danforth E Jr. Expenditure and storage of energy in man. J Clin Inw 1987,79:101925.

- Siri WE. The gross composition of the body. Adv Biol Med Physiol 1956;4:239-80.

- Sjogaard G. Changes in skeletal muscle capillarity and enzyme activity with training and detraining. Med Sports Sci 1984; 17:202-14.

- Spurr GB, Prentice AM, Murgatroyd PR, Goldberg GR, Reina JC, Christman NT. Energy expenditure from minute-by-minute heart rate recording: comparison with indirect calorimetry. Am J Clin Nutr 1988;48:553-9.

- Sitallings VA, Archibald EH, Penchar PB. Potassium, magnesium, and calcium balance in obese adolescents on a protein-sparing modified fast. Am J Clin Nutr 1988;47:2204.

- Statonas PM, Johnson Jr WG, Christ M. Behaviont modification for obesify: The evaluation of exercise, contigency management and program adherence. J Cons Clin Psych 1978:46:46369.

- Steen SN, Oppliger RA, Brownell KD. Metabolic effects of repeated wight loss and regain in adolescent wrestlers. JAMA $1988 ; 260 ; 47-50$.

- Sternberg B. Relapse in weight control: defintions, processes, and preventions strategies. In: Relapse prevention. Maintenance strategies in the trealtment of addictive behaviors. ed: Marlatt GA, Gordon JR New York.: The Guillford Press, 1985, p 521 -45.

- Stevenson PW, Darg LL, Spafford TR, Ahmad N, Lucas CP. Variable effects of weight loss on serum lipids and lipoproteins in obese patients. Int J Obes 1988; 12:495-502.

- Stunkard AJ, Kaplan D. Eating in public places: a review of reports of the direct observation of eating behavior. Int J Obes 1977;1:89-101.

- Stunkard AJ. Obesity. Philadelphia, WB Saunders, 1980.

- Tagliaferro AR, Kertzer R, Davis JR, Janson $C_{,}$, Keung Tse S. Effects of exercise-lraining on the thermic effect of food and Body fatness of adult women. Physiol Behav 1986;38: 703.10.

- Tang $S$, Yang MU, Wang J, Pierson RN, Kral Jr JG. Ene rgy expenditure after massive weight loss. The 5th Annual Meeting of the North American Association for the St wdy of Obesity. 1988:41. 
- Thompson IK, Jarvie GJ, Lahey BB, Cureton KJ. Exercise and obuesity: etiology, physiology, and interention. Psychot Bull 1982;91:55-79.

- Thompson IK. Blanton F. Energy conservation and exercise dependence: a sympathetic arousal hypothesis. Med Sci Sports Exerc 1987;19:91-9.

- Titchenal CA, Stem JS, Mole PA, Grivetti LE. The effects of marathon training and detraining on diet and body composition of previously untrained middel-aged man. Abstr, Fifth In wernational Congress on Obesity, Jerusalem, Israel, September 14-19. Int J Obes 1987;11 (suppll 2)

- Tremblay $\mathrm{A}_{\mathrm{B}}$ Cote $\mathrm{J}$, leBlanc J. Diminished dietary thermogenesis in exercise-trained human subjects: Eur J Appl Physiol 1983,52:1-S

- Tremblay A, Després J, Leblanc C, Bouchard C. Sex dimorphism in fat loss in response to

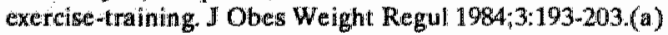

- Tremblay $A$, Despres $J$, Bouchard C. Adipose tissue characteristics of ex-obese long-dislance runners. Int J Obes 1984;8:641-8.(b)

- Tremblay $A_{\text {, Fontaine }}$, Poehiman $\mathrm{ET}_{3}$ Mitchell D, Perron $\mathrm{L}$, Bouchard $\mathrm{C}$. The effect of exercise-training on resting metabollic rate in lean and moderately obese individuals. Int J Obes 1986;10:511-7.

- Tremblay A, Nadeau A, Foumier G, Bouchard C. Effect of a three-day interruption of exercise training on resting metabolic rate and glucose-induced thermogenesis in trained individuals Int J Obes 1986;12:163-8.

- Uwnäs-Mobery K. Neuroendocrine regulation of hunger and satiety. Abstr First Eur Congress on Obesity Stockholn 1988, 1.

- Van Es AJH , Vogt JE, Niessen C, Vet J, Rodenburg $L_{\text {, Teeuws }}$, Dhwywetter J, Deurenberg P, Hativast JGAJ, Beek van der E. Human energy metabolism below, near and above equilibrium. Bi J Nutr 1984;52:429-42.

- Van Gaal LF, De Leeww IH. Short-and long-term effects of protein-sparing very-lowcalorie diets. In: Recent advances in obesity research: V. ed; Blondheim $\mathrm{B}$ and Shafrir $\mathrm{E}$. 1986:347.51

- Vandewoude MG, Van Gaal L, Leeuw de I. Changes in vitamin E status during obesity treatment. Ann Nutr Metab 1987;31:185-90.

- Van Itallie TB. Health implications of overweight and obesity in the United States. Ann Intern Med 1985;103:983-8

- Wadden TA, Stunkard AJ. Social and psychological consequences of obesily. Ann Int Med 1985; 103:1062-7.

- Wadden TA, Foster GD, Letizia KA, Stunkard AJ, Mullen JL. Eiffect of calioric restriction on resting ene rgy expenditure (RIE). The Sth Annwal Meeting of the North Ane rican Association for the Study of Obesity, Canada, 1988,42 .

- Walberg JC, Reed CE, Hinkle DE. The effects of light vs mode rate exercise added to diet cont trol in a weight reduction program for overweight college women.(abstr) Med Sci Sports Exerc 1984; 16:135.

- Warnold 1, Carlgren G, Krotkiewski M. Energy expendijture and body composition during weight reduction in hyperplastic obese women. Am J Clin Nutr 1978;31:750-63.

- Warwick $P$, Garrow JS. The effect of addition of exercise to a regime of dietary rest riction on weight loss, nitrogen balance, RMR and spontaneous activity of 3 obese women in a metabolic ward. Int J Obes 1981;5:25-32.

- Waxman M, Sturikard AJ. Caloric intake and expenditure of obese boys. J Pediatr $1980 ; 97: 187-93$.

- Webb P. Energy expenditure and fat-tiree mass in men and women. An J Clin Nurr $1981 ; 34: 1816-26$.

- Webb P, Abrams T. Loss of fat stores and reduction in sedentary energy expenditure from undereating. Hum Nutr Clin Nutr 1983;37C:271 $\approx 82$.

- Webb P. Amnis JF. Adaptation to overeating in lean and ovierweight men and women. Hum Nutr Clin Nutr 1983;37C:117-31. 
- Webb P. The exchange of matter and energy in lean and overweight men and women: $a$ callorimetric study of overeating, balanced intake and undereating. Int J Obes 1985,9 (suppl 2):139-45.

- Weigle DS, Sande KJ, Iverius PH, Monsen ER, Brunzell JD. Weight loss leads to a marked decrease in monresting energy expenditure in ambulatory human subjects. Metabolism $1988 ; 37 ; 930-6$

- Widdowson EM. A study of english diets by the indiwdual method. Part I Men. J Hyg 1936 $36,269-92$.

- Widhallm K, Zwiauer $\mathrm{K}$, Bubacher $\mathrm{G}$. Vitamin $\mathrm{A}$ and Esupplementation in grossly obese children and adolescents during weight reduction. (abstr) Fitst European Congress on Obesity, Stockholm, 1988, 271.

- Wing RR Jeffery RW. Outpatient treatments of obesity: a comparison of methodology and clinical results. Int J Obes 1979;3:261-79.

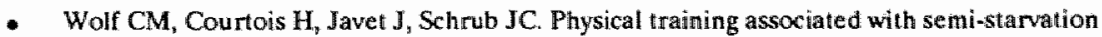
in the treatment of obesity. In: Recent adwances in obesity research. Ist ed. A Howard, pp $281-83$, London: Newman, 1975.

- Woo R, Garrow JS, Pi-Sunyer FX. Effect of exercise on spontancous calorie intake in obesity. Am I Clin Nutr 1982;32;470-7.

- Zuti WB, Golding LA. Comparing diet and exercise as weight reduction tools. Phys Sportsmed 1976:4:49-53.

- Zwiauer $K_{,}$Widhalm $K$, Brubacher $G$, Fulmek $R$. Markanter abfall von vitamin A und $\mathbb{E}$ im plasma übergewichtiger kinder wahrend einer reduktionsdiat. Akt Ernähr 1986;11:248-52. 



\section{SUMMARY}

Obesity is caused by a longlasting higher energy intake than energy expenditure, resulting in an excess of body fat. Dependent upon the degree and distribution of fat over the body, obesity has been found to be associated with health risks such as high blood pressure and a high fat content in blood. Reducing this excess weight to normal proportions results in a decreased prevalance of these health risks.

Weight loss can be achieved by reducing energy intake or increasing energy expenditure. Both methods, however, have their advantages and disadvantages, which are extensively described in chapter 1. Combining energy restriction and increasing energy expenditure might remove the disadvantages of both methods and result in more weight and fat loss than energy restriction or the increase in energy expenditure alone.

From 1985 to 1988 four diet or dietexercise studies were performed to find out whether the combination of diet and exercise had better results that diet alone. All studies had the same study design, but varied with respect to study period and aim of the study. Subjects were randomly assigned into a diet or a diet-exercise group by matching of their body mass index. The study period varied from 8 to 14 weeks. The first 4-6 weeks diet consisted of a low energy formula $\operatorname{diet}(3.0 \mathrm{MJ} / \mathrm{d})$, which in the last 8 weeks of the study was combined with normal food $(1.7 \mathrm{MJ} / \mathrm{d}$ formula diet and $1.8 \mathrm{MJ} / \mathrm{d}$ normal food). To increase the physical activities aerobic exercise activities such as aerobic dancing, fitness, swimming and jogging were used. There were 4 to 6 trainings per week and each training lasted 1 hour. Measurements to evaluate the effect of the diet and exercise treatment were performed before the start of the study, after a period with the low energy formula diet (4-6 wk) and at the end of the study (8-14 wk). In all studies weight, body composition, resting metabolic rate (RMR) and maximal aerobic power $\left(\mathrm{VO}_{2} \mathrm{max}\right)$ were measured. Percentage of body' fat was determined hydrostatic weighing. RMR was measured in the respiration chamber from 03.00 $06.00 \mathrm{a} . \mathrm{m}$. and incremental bicycle ergometry test was used to determine the change in maximal aerobic power $\left(\mathrm{VO}_{2} \max \right)$. Other methods, which were used in only one study, are described in the summaries of the chapters mentioned below.

In chapter 2 the effect of a diet and a diet-exercise treatment of 12 weeks on body composition and RMR of 12 females is described. The addition of two hours aerobic dancing and two hours weight resistance training per week for the dietexercise group (DE group) could not prevent the diet-induced fall in RMR and the loss of fat free mass. There were no significant differences between the diet (D group; $\mathrm{N}=6)$ and the $\mathrm{DE}$ group $(\mathbb{N}=6)$ with respect to weight and fat loss and loss of fat free mass. Both groups showed a significant decrease in RMR and in RMR per $\mathrm{kg}$ fat free mass. However, particularly in the second period of the study there was a tendency to a larger fat loss and a smaller 
duced fall of RMR in the DE group compared to the D group.

In chapter 3 the same female subjects as in chapter 2 were used and in this chapter it was questioned whether the subjects in the $\mathrm{DE}$ group decreased their daily physical activities such as walking, cycling, etc. in order to compensate for the extrat energy expenditure of the training. To measure this possible compensation two methods were used: on the daly without training 24-hour energy expenditure (24-EE) was determined by heart rate monitoring and the actometer (movement counter) was used to delermine physical activity during and directly after exercise. The actometer was worn on the ankle for five consecutive days, including weekend and exercise days.

Twenty-four hour energy expenditure decreased for both groups as a consequence of the decreatse in RMR and there were no significant differences between the $D$ and $D E$ group. Daily physical activity measured with the actometer showed a significant increase for the $\mathrm{DE}$ group $(27 \%$ : $\mathrm{P}<0.05)$, whereas the $\mathrm{D}$ group had only a small and insignificant increase (10\%). With respect to these results it was concluded that there is no compensation for the training in daily physical activity for the DE group.

In chapter 4 the elfect of an eightweek period with a diet and dietexercise intervention on RMR and glucose-induced thermogenesis (GIT) is described. In the literature it has been suggested that exercise induces an elevated RMR in the night subsequent to the training. It has also been suggested that in the second night after the training $R M R$ should have returned to normal levels. The equivocal results with respect to the preventing effects of exercise on the diet-induced RMR up to now might be attributed to differences in the moment of determination of RMR.

For 24-h EE, RMR and GIT measurements subjects stayed for $36 \mathrm{~h}$ in the respiration chamber. During the first four weeks only the formula diet was provided for all 12 females subjects and no other intervention was included. After four weeks six h training per week was included for six (DE) of the 12 subjects. After four weeks of dieting both groups exhibited a decreased RMR, 24-EE and GIT similarly. The addition of six $h$ training per week caused a slight increase in $R M R$ in the diet-exercise group, which was in agreement with the lower decrease of the hormone triiodothyronine (T3) in the $\mathbb{D E}$ group compared to the D group. No differences were observed in RMR measured in the night following the training and RMR determined in the second night after training. GIT decreased for both groups, but the DE group tended to a larger decrease. This larger decrease might be explaïned by a glycogen sparing mechanism due to the intensive training.

In chapter 5 the change in micronutrient status of 12 obese male subjects before and after a 14-week period of a low energy diet with or without the addition of exercise is described. After 14 weeks a tendency to a better weight and fat loss was observed for the DE group but there were no sïgnificant differences. With respect to changes in the micronutrients in plasma only the decrease in ferritin was significantly different 
between the D and DE group, with a larger decrease for the DE group. In both groups significant decreases of about $20 \%$ in fat soluble vitamins were observed. The decrease in plasma proteins during dieting is the most important cause of the decrease in the fat soluble vitamins.

With respect to the B-vitamins no significant differences were observed between the $D$ and $D E$ group. The decrease in vitamin B-6, however, showed a trend to a larger decrease for the DE group compared to the D group. This larger decrease can be explained by the addition of exercise because of an increased protein turnover during exercise.

In chapter 6 it is questioned whether repetitive weight loss and weight regain results in a permanently decreased energy metabolism. Frequent dieters (yo-yo'ers) were compared with subjects who had a stable overweight (non-yo-yo'ers). Subjects were defined as yo-yo'ers if they had lost at least two times $10 \mathrm{~kg}$ or more of weight and had regained all of their weight loss. Subjects who had never lost $3 \mathrm{~kg}$ of weight in the five years preceding the study were defined as non-yo-yo. Three groups were formed: a diet-exercise yo-yo group, a diet-exercise non-yo-yo group and a diet-non-yo-yo group. After 14 weeks significant differences were observed between the D and DE groups but not between the yo-yo and non-yo-yo dieters. Despite frequent dieting RMR did not differ at the start of the study between the yo-yo and non-yo-yo dieters. After 14 weeks the DE groups showed a smaller decline in the diet-induced RMR than the D group. In this study lipolytic activity was also measured. Lipolytic activity was determined by in vitro release of glycerol of abdominal adipose tissue without the addition of the $\beta$-blocking agent isoprotenerol (basal lipolysis) or with isoprotenerol (stimulated lipolysis). No effects of frequent dieting or exercise on basal or stimulated lipolytic activity were observed.

It is concluded that there is no increased efficiency in energy expenditure in yo-yo dieters compared to non-yo-yo dieters during weight reduction...

In chapter 7 the long term results of 44 subjects ( 32 females and 12 males) who had received a diet or dietexercise treatment are described. The follow-up phase varied from 18 to 42 mont hs. Mean weight loss after treatment (12-14 wk) was 12.0 and $16.5 \mathrm{~kg}$ for $\mathrm{D}$ and $\mathrm{DE}$ respectively $(\mathrm{P}<0.05)$.

Nine subjects dropped out during the follow-up phase. After 18, 36 or 42 months follow-up the $D$ group regained $90 \%$ of their initial weight loss compared to $60 \%$ of the DE group ( $P<0.05)$. Seven subjects out of the original DE group kept up their exercise activilies, while 2 from the D group started exercising. These subjects (EX) regained only $30 \%$ of their weight loss.

During the last follow-up measurement RMR of 18 subjects was determined ( 9 subjects who continued their exercise activities and 9 subjects from the D and DE groups who had no exercise activities in the follow-up period). RMR for the 9 nonexercising subjects was $19 \%$ lower than before the diet intervention. For the EX group RMR was $10 \%$ lower than baseline values. However, per $\mathrm{kg}$ fat free mass RMR of the EX group was found to be almost restored to baseline values, whereas 
RMR of the non-exercising subjects was still depressed (16\% lower than baseline RMR), despite weight gain. It is concluded that exercise is an important factor in the restoration of RMR and long-term maintenance of weight loss.

In chapter 8 the results of the prececling chapters are discussed and summarized in the following conclusions:

- In view of the continually returning trend for a larger weight and fat loss for the diet-exercise group compared to the $\mathrm{D}$ group, it can be concluded that exercise increases weight and fat loss. The lack of significant differences can mainly be attributed to the small number of subjects. Pooling the results of four studies resulted in significant differences in weight and fat loss between the D and DE group.

With respect to the long-term results it can be concluded that continuing exercise activities after treatment is promotive for weight maintenance.

- The combination of a low energy diet and moderate to intensive training cannot prevent the dietinduced fall in RMR. The observation that RMR tended to increase after an initial decrease indicates that restoration of the diet-induced RMR in a diet-exercise group will appear after a period of 12-14 weeks. The restoration of the RMR per $\mathrm{kg}$ fat free mass in the exercising subjects after 18 to 42 months confirmed this hypothesis. The decrease in glucose-induced thermogenesis cannot be prevented by the addition of exercise. On the contrary, exercise induced a lower thermogenic effect after the ingestion of glucose. This decreased thermogenic effect in the DE group might be explained by a glycogen sparing mechanism due to intensive exercise

- There is no decrease in daily physical activity outside the exercise hours as compensation for the extra energy expenditure of the training for the DE group. The DE group increased their daily physical activity as measured by the actometer. 


\section{SAMENVATTING}

Obesitas of vetzucht wordt veroorzaakt door een energie opname die gedurende een langere periode hoger is dan het energieverbruik. Het gevolg is een overmatige hoeveelheid aan vetreserves. Afhankelijk van de hoeveelheid en verdeling van dit vet over het lichaam, blijkt obesitas in verband te staan met een aantal risicofactoren voor de gezondheid zoals hoge bloeddruk en een hoog vetgehalte in het bloed. Het terugbrengen van het overgewicht tot een normaal gewicht leidt tot een vermindering van deze risicofactoren.

Verlaging van de energieopname en verhoging van het energieverbruik zijn methodes om het overgewicht terug te brengen tot een normaal gewicht. Beide methodes hebben vooren nadelen, welke uitgebreid in hoofdstuk 1 zijn beschreven. Een combinatie van verlaging van energieopname en verhoging van het energieverbruik zou mogelijk de verschillende nadelen van beide methodes opheffen. De combinatie zou uiteindelijk tot betere resultaten kunnen leiden ten aanzien van gewichtsverlies en behoud van het verkregen lagere gewicht dan de toepassing van slechts één van beide methodes.

Om deze veronderstelling te toetsen zijn er binnen het kader van dit onderzoek vanaf 1985 tot 1988 vier verschillende studies verricht. Alle studies hadden dezelfde onderzoeksopzet, maar varieerde in vraagstelling. Proefpersonen werden op basis van hun quetelet index gematched in een dicet (D groep) of een dieet-sport groep (DS groep). De sport en/of di- eet interventieperiode varieerde van 8 tot 14 weken. Het dieet bestond in de eerste 4-6 weken uit een laag energetisch formule dieet $(3.0$ $\mathrm{MJ} / \mathrm{dag}$ ), wat in de laatste 8 weken gecombineerd werd met normale voeding ( $1.7 \mathrm{MJ} / \mathrm{dag}$ formule dieet en $1.8 \mathrm{MJ} / \mathrm{dag}$ normale voeding). Ter verhoging wan de lichamelijke activiteiten, werd gebruikt gemaakt van aerobische sporten zoals aerobic dancing, zwemmen en hardlopen naast fitness. Trainingen van elk ến wur vonden 4 tot 6 maal per week plaats.

Vór de start van de studies, na 4 tot 6 weken met uitsluitend het formule dicet en aan het eind van de interventieperiode (8-14 weken) werden cen aantal metingen verricht. Deze metingen hadden betrekking op de volgende variabelen: gewicht, lichaamssamenstelling, ruststofwisseling en het maximale aerobe vermogen $\left(\mathrm{VO}_{2} \mathrm{max}\right)$. Het vetpercentage werd met behulp wan onderwaterwegen bepaald. De ruststofwisseling werd in de respiratiekamer gemeten gedurende de nachtperiode van 3.00 tot 6.00 uur en veranderingen in het prestatievermogen werden met de Fietsergometer vastgesteld. Andere methodes, dio slechts in Eén studic werden gebruikt, zullen in de onderstaande samenvatingen van de hoofdstukken beschreven worden.

In hoofdstuk 2 wordt het effect van een dieet $(\mathrm{D} ; \mathrm{N}=6)$ en een dieetsporttherapie (DS; $N=6$ ) van 12 weken op de lichaamssamenstelling en ruststofwisseling van 12 vrouwen beschreven. In deze studie bleek dat 2 uur acrobic en twee uur fitness traiming per week niet voldoende was 
om de daling van de ruststofwisseling en de afbrak van de vetwrije massa in de dicet-sportgroep te yoorkomen. In beide groepen dalde de ruststofwisseling (D $29 \%$ en DS $20 \%$, ook wanneer deze per kilogram vetvrije massa werd berekend. Gewichts - en vetverlies was eveneens niet significant verschillend tussen de D en DS groep. Aan het einde van de 12 weken was er echter wel een tendens waar te nemen naar meer vetwerlies en een minder sterke. daling in de rusistofwisseling woor de DS groep.

In hoofdstuk 3 wordt nader ingegaan op de vraag of personen in de dieetsportgroep minder aktief worden in hun dagelijkse lichamelijke activiteiten zoals lopen, fietsen, etc. om het extra energieverbruik van de training te compenseren. Daarbij werd gebruik gemaakt van dezellde proefpersonen en gegevens als in hoofdstuk 2.

De dagelijkse lichamelijke activiteiten werden op 2 manieren gemeten:

- Op de dag dat er geen training was, word het 24-uurs energieverbruik gemeten met behulp van de hartfrequentiemethode.

- Op trainingsdagen werd de actometer (een bewegingsteller) gebruikt om de verandering in licha. melijke activiteiten tijdens en na het sporten te meten. Deze actometer werd om de enkel gedragen gedurende 5 dagen.

Het 24-uurs energieverbruik daalde voor beide groepen als gevolg van de daling in de ruststofwisseling en or werden geen significante verschillen tussen de D en DS groep gevonden. Lit de resultaten van de actometer bleek de DS groep een aanzienlijke stijging in dagelijkse lichamelijke activiteiten te vertonen $(27 \%, \mathrm{P}<0.05)$ en de $D$ groep slechts een stijging van $10 \%$ (N.S.). Op grond van deze resultaten wordt geconcludeerd dat er geen compensatie voor de training is in de dagelijkse lichamelijke activiteiten van de DS groep.

In hoofdstuk 4 wordt beschreven welke veranderingen de ruststofwisseling en het thermogenetisch effect van glucose (stijging van het energieverbruik als gevolg van de inname van $100 \mathrm{~g}$ glucose) ondergaan tijdens en na een sport en/of dieetinterventie van 8 weken.

In de literatuur bestaat er nogal tegenstrijdigheid over de effecten van sport op de ruststofwisseling. Eén van de oorzaken van deze tegenstrijdigheid zou het verschil in het momenl wan meten kunnen zijn. De ruststofwisseling gemeten in de nacht volgend op de training kan mogelijk nog wel verhoogd zijn, terwijl dit in de tweede nacht niet meer het geval is.

Het 24-uurs energieverbruik, de ruststofwisseling en het thermogenetisch effect van glucose werden gedurende 36 uur in de respiratickamers gemeten. Het onderzoeksprotocol was in de eerste 4 weken voor alle 12 vrouwelijke proefpersonen gelijk. Na 4 weken gingen 6 (DS) van de 12 personen 6 maal per weck sporten.

$\mathrm{Na}$ de dieetperiode van 4 weken was het 24-uurs energieverbruik en de rustst ofwisseling in beide groepen verlaagd. Na 8 weken bleck deze daling voortgezet te zijn in de D groep. In de DS groep herstelde de ruststofwisseling zich door de intensieve training in de laatste 4 weken: Van week 4 tot en met week 8 werd een trend naar een kleine stijging in de ruststofwisseling van de DS groep waargenomen. Deze stijging was in overeenstemming met de kleinere daling 
van het hormoon trijodothyronine in de DS groep vergeleken met de D groep.

Sporten bleek geen preventilef effect te hebben op het thermogenetisch effect van glucose. Voor beide groepen was dit lager dan vóór het dieet, maar de daling was voor de DS groep het sterkst. Er werden echter geen significante verschillen gevonden, vanwege een grote variatie tussen de personen. De sterke daling in het thermogenetische effect na de inname van glucose in de DS groep kan wellicht verklaard worden door een glycogeen sparend mechanisme tijdens intensieve training.

In hoofdstuk 5 wordt aandacht besteed aan de weranderingen in micronutriënten in het bloedplasma gedurende een dieet of een dieet-sporttherapie van 14 weken. Het onderzoek werd uitgewoerd bij 12 mannen. Ook deze mannen vertoonden slechts een trend naar meer gewichts-en vetverlies voor de DS groep vergeleken met de D groep. Het verschil was echter niet significant. De veranderingen in de micronutriënten in het plasma waren eveneens niet significant verschillend tussen de D en DS groep. Alleen de daling van het ferritine was significant groter voor de DS groep vergeleken met de D groep. Well werd er in beide groepen een aanzienlijke daling (20\%) in de vet oplosbare vitamines waargenomen. De belangrijkste oorzaak voor deze sterke daling in de vetoplosbare vitamines is waarschijnlijk de daling in de transporteiwitten van de vitamines.

De B-vitamines daarentegen lieten een minder sterke daling in beide groepen zien. De DS groep vertoonde wel een trend nareen grotere daling in vitamine B- 6 dan de D groep. Deze grotere daling in de DS groep kan mogelijk verklaard worden door een verhoogde activiteit wan het eiwitmetabolisme en een toegenomen gluconeogenese door de training.

In hoofdstuk 6 wordt nader ingegaan op de vraag of frequent afvallen en weer aankomen (jojo effect) tot een permanent verlatagd energiemetabolisme leidt. Frequente lijners (jojo'ers) werden vergeleken met personen die cen stabiel overgewicht hadden (niet-jojo'ers). lemand werd als jojo gedefinieerd als ze minimaal 2 keer $10 \mathrm{~kg}$ of meer gewicht verloren had en daarna weer volledig op het oude gewicht teruggekomen was. lemand die in de 5 jaar voorafgaand aan de studie niet meer dan $3 \mathrm{~kg}$ gewicht verloren had, werd als nietjojo gedefinieerd. Er werden 3 groepen gevormd: een dieet-sport-jojo groep $(N=6)$, een dieet-sport-nietjojo groep $(\mathrm{N}=7)$ en een dieet-nietjojo groep $(\mathrm{N}=7)$. Na 14 weken werden alleen significante verschillen in gewicht-en vetverlies gevonden tussen de dieet en dieet-sport behandeling, maar geen verschillen tussen jojo en niet-jojo groepen. Aan het begin van de studie verschilden de jojo"ers niet ten opzichte van de nictjojo'ers in hun ruststofwisseling ondanks vele gewichtsveranderingen in het verleden van de jojo'ers. Ook na de dieet/sportinterventie werden alleen significante verschillen gevonden tussen de dieet en sport-dieet groepen.

In deze studie werd ook de lipolytische activiteit van het abdominale vetweefsel gemeten. De glycerol release werd in vitro bepaald zonder toewoeging van een $\beta$-blokker isoprotenerol (basale lipolyse) en met de toevoeging van isoprotenerol (gesti- 
mulerde lipolyse). De basale en gestimuleerde lipolyse waren niet verschillend tussen de jojo en nietjojo groepen:

Op grond van deze resultaten wordt geconcludeerd dat er tijdens een vermageringsperiode geen sprake is van een toegenomen efficiëntie in de ruststofwisseling van jojo'ers vergeleken met niet-jojo'ers.

In hoofdstuk 7 zijn de lange termijn resultaten beschreven van 44 personen ( 32 vrouwen en 12 mannen), die een dieet of een dieet-sporttherapie hadden gevolgd. De follow-up periode varieerde van 18,36 tot 42 maanden. Gemiddeld gewichtsverlies tijdens de studie was $12.0 \mathrm{~kg}$ voor de dicet groep $(\mathrm{N}=25)$ en $16.5 \mathrm{~kg}$ voor de dieet-sportgroep $(\mathrm{N}=19 ; \mathrm{D}$ t.o.v. DS $\mathrm{P}<0.05$ ).

Er waren 9 uitvallers tijdens de follow-up periode. De toename van het gewicht van de overige personen in de D groep en de DS groep bedroeg respecticvelijk $90 \%$ en $60 \%$ van hun eerder gewichtsverlies. Zeven personen van de groep bleven doorgaan met sporten na het beëindigen van de studie, terwijl 2 personen van de D groep begonnen met sporten. Deze personen hadden de beste resultaten wat betreft gewichtsbehoud; de toename van hun gewicht bedroeg slechts $23 \%$ van hun eerder gewichtsverlies.

Aan het einde van de follow-up periode werd de ruststof wisseling van 18 personen gemeten $(9$ sporters en 9 niet-sporters $(D+D S)$. Het bleek dat de ruststofwisseling voor de 9 niet-sporters $19 \%$ lager was dan vór de dieet of dicet-sport interventie. Voor de sporters was dit $10 \%$.

Per kg vetvrije massa was de ruststofwisseling van de sporters bijna hersteld ten opzichte van de start- waarden (3.7\% lager; N.S.), maar voor de niet-sporters was de ruststofwisseling per $\mathrm{kg}$ vetvrije massa nog steeds $16 \%$ lager dan de beginwaarden van de ruststofwisseling vóór de interventie ( $\mathrm{P}<0.05$ sporters t.o.v. niet-sporters). Hieruit blijkt dat sporten een belangrijke factor is voor het herstel van de ruststofwisseling na een vermageringsperiode en daarmee samenhangend ook een belangrijke factor voor het behoud van het verkregen lagere gewicht op de lange termijn.

In hoofdstuk 8 worden de resultaten van alle voorgaande hoofdstukken bediscussieerd en samengevat in de volgende conclusies.

" Gezien de steeds terugkerende trend van meer gewichts- en vetverlies voor de DS groepen vergeleken met de $\mathrm{D}$ groepen, is de conclusie van dit onderzoek dat spor ten tot meer gewichts- en vetverlies leidt. Het ontbreken van de significante verschillen wordt veroorzaakt door de kleine groepen in dit onderzoek. Wanneer de resultaten van alle studies samengevoegd worden, blijken kleine verschillen in gewichtsverlies al significant.

Ten aanzien van de lange termijn resultaten blijkt sporten een belangrijke rol te spelen bij het behoud van het verkregen lagere gewicht.

De combinatie van een laag energetisch dieet en matige tot intensieve training kan de daling in de rustst ofwisseling niet voorkomen. Dat de ruststofwisseling wel een tendens tot stijgen heeft in de DS groepen na een daling na 5 weken wijst er op dat herstel van de door het dieet veroorzaakte daling in de ruststofwisseling pas na 12-14 
weken zal plaatsvinden. Deze veronderstelling wordt ondersteund door de resultaten van de lange. termün metingen. De ruststofwisseling per kilogram vetwrije massa is bijna volledig hersteld bij degenen die zijn blijven sporten, terwijl de ruststofwisseling van de niet-sporters op een lager niveau blijft dan vóór de studie. Daarnaast blijkt uit andere studies dat bij een minder streng energiebeperkt dieet (5.0-6.3 MJ/dag) de daling van de ruststofwisseling wel kan worden voorkomen door verhoging van lichamelijke activiteiten.

- Het thermogenetisch effect van glucose daalt tijdens een energiebeperkt dieet en intensieve sportbeoefening kan deze daling niet voorkomen. Het intensieve sporten bleck een sterkere daling in het thermogenetisch effect van glucose te veroorzaken, hetgeen verklaard wordt door een glycogeen sparend mechanisme tijdens intensieve sportbeoefening.

- De dagelijkse lichamelijke activiteiten buiten de trainingen om, gemeten met de hartfrequentiemethode en actometer, vertonen een stijging vooral in de sport-dieetgroep. 



\section{LIST OF ABBREVIATIONS}

\begin{tabular}{|c|c|}
\hline a.m. & -morning (ante meridium) \\
\hline $\mathrm{AT}$ & -adaptive thermogenesis \\
\hline ATP & -adenosine triphosate \\
\hline BMI & -body mass index \\
\hline BMR & - basal metabolic rate \\
\hline $\mathrm{CHO}$ & -carbohydrate \\
\hline BW & -body weight \\
\hline $\mathrm{D}$ & -diet group \\
\hline $\mathrm{DE}$ & -diet-exercise group \\
\hline $\mathrm{DE}-\mathrm{Y}$ & -diet-exercise yo-yo group \\
\hline DE-NY & -diet-exercise non-yo-yo group \\
\hline $\mathrm{D}-\mathrm{NY}$ & -diet non-yo-yo group \\
\hline$D-Y$ & -diet yo-yo group \\
\hline DIT & -diet-induced thermogenesis \\
\hline $\mathrm{EE}$ & -energy expenditure \\
\hline 24-EE & -24-hour energy expenditure \\
\hline 24-EE $\mathrm{hr}$ & $\begin{array}{l}\text { - 24-hour energy expenditure measured by } \\
\text {-heartrate monitoring }\end{array}$ \\
\hline $12-\mathrm{EE}_{\mathrm{resp}}$ & $\begin{array}{l}\text {-12-hour energy expenditure measured } \\
\text {-in the respiration chamber }\end{array}$ \\
\hline $\mathrm{EX}$ & -exercise group \\
\hline$\Delta$ & -delta \\
\hline FFA & -free fatty acids \\
\hline FFM & -fat free mass \\
\hline $\mathrm{FM}$ & -fat mass \\
\hline $\mathrm{g}$ & -gram \\
\hline $\mathrm{mg}$ & -milligram $\left(10^{-3}\right.$ gram $)$ \\
\hline$\mu g$ & -microgram $\left(10^{-5}\right.$ gram $)$ \\
\hline ng & -nanogram $\left(10^{-9}\right.$ gram $)$ \\
\hline GIT & -glucose-induced thermogenesis \\
\hline $\mathrm{h}$ & -hour \\
\hline $\mathrm{Hr}$ & -heart rate \\
\hline $\mathrm{kcal}$ & -kilocalorie \\
\hline $\mathrm{kg}$ & -kilogram \\
\hline $\mathrm{kgBW}$ & - per kilogram body weight \\
\hline $\mathrm{kgFFM}$ & -per kilogram fat free mass \\
\hline $\mathrm{kJ}$ & kilojoule \\
\hline 1 & -liter \\
\hline LDL & -low density lipoprotein \\
\hline LPL & -lipoprotein lipase \\
\hline $\max$ & -maximal \\
\hline $\mathrm{meq}$ & -milli-equivalent \\
\hline $\min$ & -minute \\
\hline $\mathrm{ml}$ & -milliliter ( $10^{-3}$ liter $)$ \\
\hline $\mathrm{M}$ & -mole \\
\hline
\end{tabular}




\begin{tabular}{|c|c|}
\hline $\begin{array}{l}\mathrm{Na}^{+}-\mathrm{K}^{+} \text {ATPase } \\
\text { nmol }\end{array}$ & $\begin{array}{l}\text {-sodium-potassium adenosine triphosphatase } \\
\text {-nanomole }\left(10^{-3} \mathrm{~mol}\right)\end{array}$ \\
\hline$\mu \mathrm{mol}$ & -micromole $\left(10^{-6} \mathrm{~mol}\right)$ \\
\hline pmol & - picomole $\left(10^{-9} \mathrm{~mol}\right)$ \\
\hline MI & -megajoule \\
\hline N & - number \\
\hline N.S. & -not significant \\
\hline$\%$ & -percentage \\
\hline PL. & -pyridoxal \\
\hline PLP & -pyridoxal phosphate \\
\hline $\mathbf{R}$ & -respiratory quotient \\
\hline $\mathrm{RDA}$ & -recommended daily allowences \\
\hline RMR & -resting metabolic rate \\
\hline SEM & -slandard error of mean \\
\hline SMR & -slecping metabolic rate \\
\hline TEE & -thermic effect of exercise \\
\hline TEF & -thermic effect of feeding \\
\hline $\mathbb{T} 3$ & -trilodothyronine \\
\hline $\mathrm{VO}_{2}$ & -oxygen uptake (volume/time) \\
\hline $\mathrm{VCO}_{2}$ & - carbondioxide production (volume/time) \\
\hline $\mathrm{VO}_{2} \max$ & -maximal oxygen uptake \\
\hline W & -watt \\
\hline wk & -week \\
\hline
\end{tabular}




\section{NAWOORD}

Het was misschien een wat ongebruikelijke stap om na een gedragswetenschappelijke studie als Gezondheidsvoorlichting-en opvoeding verder te gaan in het obesitasonderzoek bij de vakgroep humane biologie. Het was niet allijd makkelijk om als nieuweling in een ander wetenschapsgebied te stappen, naar er zijn altijd mensen om me heen geweest die me weer op weg hielpen. Ik heb dan ook met veel plezier aan mijn onderzoek gewerkt.

Iemand die daarvoor met name verantwoordelijk is geweest, is Wim Saris. Hij heeft me enthousiast gemaakt voor het onderzoek in de energiewisseling en van hem heb ik veel geleerd. Ik heb met veel genoegen en succes met hem samengewerkt.

Mijn tweede promotor, Foppe ten Hoor, was altijd vol belangstelling naar het onderzoek, ondlanks drukke werkzaamheden. Alleen in de laatste fase van mijn proefschrift hebben we intensief samengewerkt. De periode was kort, maar het was voor mij een hele nuttige periode, waarin ik veel heb geleerd.

Mijn proefpersonen zijn uiteraard de hoofdpersonen van het onderzoek en het proefschrift. Veel bewondering heb ik gehad voor hun doorzettingsvermogen tijdens het onderzoek. Ondanks het strenge dieet-en sportregime bleven ze volhouden. Verder heb ik erg veel plezier met hun gehad on ben ze in mijn schrijfperiode gaan missen.

Paul Schoffelen en Loek Wouters waren onmisbaar tijdens mijn onderzoek. Wanneer er weer een printer, computer of analyser vastliep, stonden zij altijd klaar om het te verhelpen. Paul heeft daarbij heel wat programmatuur ontwikkeld waardoor de gegevens sneller en beter verwerkt konden worden.

Ook Ed Beckers zal ik niet vergeten. Bij nacht en ontij stond hij mot een goed humeur klaar om bloed te prikken en de analyses daarvan te verzorgen. Met hetzelfde goeie humeur zorgde hij ook uitstekend voor de vrijdagmiddagborrel.

Jan de Vries, Karin van de Kooy en Boy Houben zorgden gezamelijk voor de analyse van het vetweefsel. Geen van allen hebben ze een helle proef mee kunnen maken, maar met allen heb ik kort maar prettig samengewerkt.

Engels is geenszins mijn moedertaal en ik ben Nancy Rehrer maar vooral ook Jan Klerkx zeer erkentelijk voor de correcties die zij in korte tijd hebben uitgevoerd in mijn proefschrift.

En dan zijn er mensen die niet direct hun medewerking verleenden aan mijn onderzoek, maar wel zorgden voor goeie secundaire arbeidsvoorwaarden: mijn huidige en mijn ex-huisgenotes Geertje Knols en Renata Klop. Het valt niet altijd mee een promoverende huisgenoot te hebben, die nooit ergens tijd 
voor theeft.

Mijn vader en moeder, die ten allen tijde in me blijven geloven en altijd klaar staun. Het is zeer prettig zo"n thuisbasis te hebben.

Lest best Hein; het waren niet alleen zijn uitstekende lay-out kwaliteiten die hebben bijgedragen tot de totstandkoming van dit proefschrift. 


\section{CURRICULUM VITAE}

Djoeke van Dale werd op 12 mei 1961 in Amsterdam geboren. In 1980 behaalde zij het VWO diploma op het Hermann Wesselink College te Amstelveen. Vanaf 1980 tot 1984 studeerde zij Gezondheidswetenschappen met als afstudeerrichting Gezondheidswoorlichting en -opvoeding aan de Rijksuniversiteit Limburg te Maastricht.

Bij de vakgroep Humane Biologie van deze zelfde universiteit volgde zij een 1jarige onderzoekersopleiding. Tijdens deze opleiding startte zij met het in dit proefschrift beschreven onderzoek. Vanaf mei 1985 werkte zij als assistent in opleiding (A.I.O.) bij de vakgroep Humane Biologie verder aan dit onderzoek. 